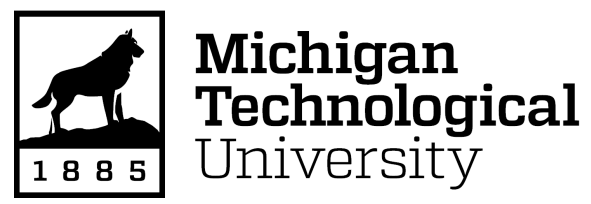

Michigan Technological University Digital Commons @ Michigan Tech

\title{
A QUANTITATIVE INVESTIGATION OF THE WATER CONDENSATION INSIDE TUBES OF COMPACT CHARGE AIR COOLER
}

Robin Cash

Michigan Technological University, ryjohnso@mtu.edu

Copyright 2015 Robin Cash

Recommended Citation

Cash, Robin, "A QUANTITATIVE INVESTIGATION OF THE WATER CONDENSATION INSIDE TUBES OF COMPACT CHARGE AIR COOLER", Open Access Dissertation, Michigan Technological University, 2015.

https://doi.org/10.37099/mtu.dc.etdr/10

Follow this and additional works at: https://digitalcommons.mtu.edu/etdr

Part of the Automotive Engineering Commons, and the Computational Engineering Commons 


\title{
A QUANTITATIVE INVESTIGATION OF THE WATER CONDENSATION INSIDE TUBES OF COMPACT CHARGE AIR COOLER
}

\author{
By \\ Robin Y. Johnson-Cash
}

\begin{abstract}
A DISSERTATION
Submitted in partial fulfillment of the requirements for the degree of DOCTOR OF PHILOSOPHY

In Mechanical Engineering — Engineering Mechanics
\end{abstract}

MICHIGAN TECHNOLOGICAL UNIVERSITY

2015

(C) 2015 Robin Y. Johnson-Cash 
This dissertation has been approved in partial fulfillment of the requirements for the Degree of DOCTOR OF PHILOSOPHY in Mechanical Engineering - Engineering Mechanics.

Department of Mechanical Engineering — Engineering Mechanics

Dissertation Advisor: Edward Lumsdaine

Committee Member: Jeffrey S. Allen

Committee Member: Song-Lin Yang

Committee Member: Bashar AbdulNour

Department Chair: William W. Predebon 
In loving memory of my father, Mr. David Johnson, Sr. and to my mother, Beatrice Holt Johnson for a lifetime worth of unwavering love and support. 


\section{Table of Contents}

List of Figures.................................................................................................. vi

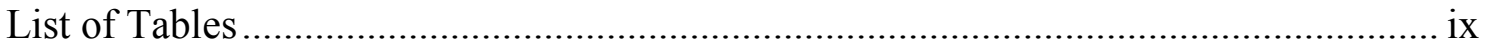

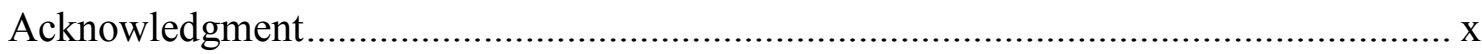

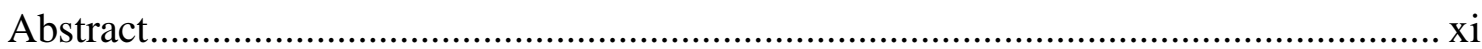

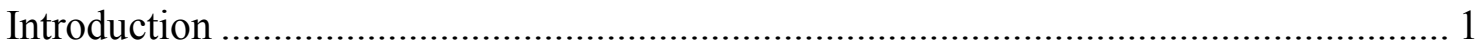

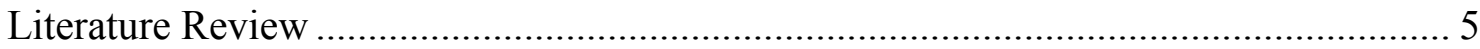

Enhancements of heat transfer coefficient ……………….................................. 7

Reductions in heat transfer rate ..................................................................... 7

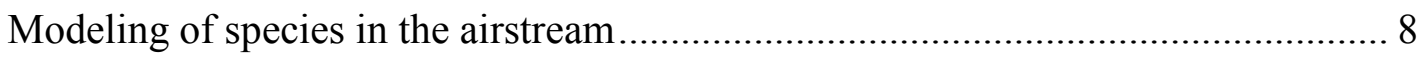

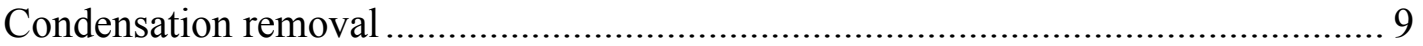

Prediction of onset of condensation in tubes using Computational Fluid Dynamics. 9 Flow pattern prediction during condensation ....................................................... 10

Description of Problem............................................................................................. 12

Mathematical Formulation ......................................................................... 13

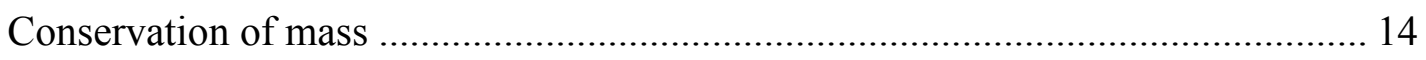

Conservation of momentum (Navier-Stokes Equations)......................................... 14

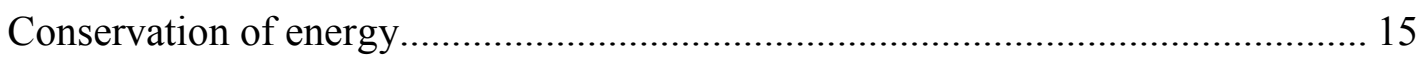

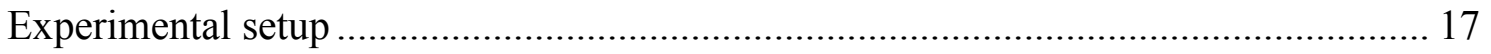

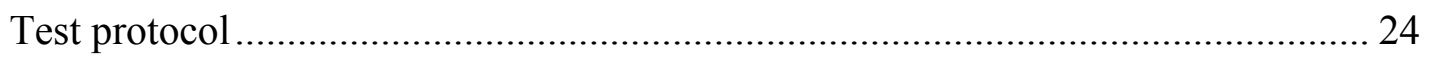

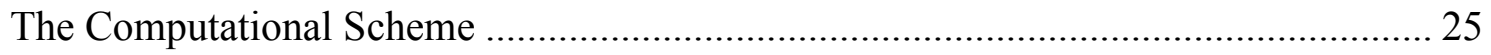

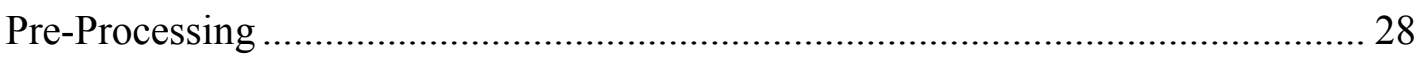

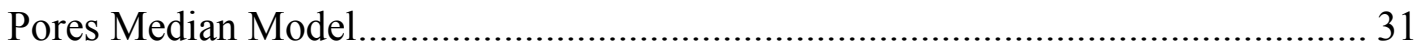

Turbulence Model (k-epsilon $\varepsilon$ Re-Normalization Group RNG) ……..................... 34

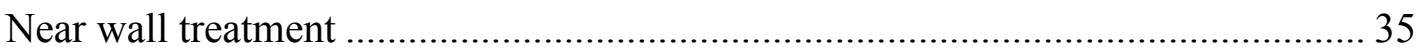

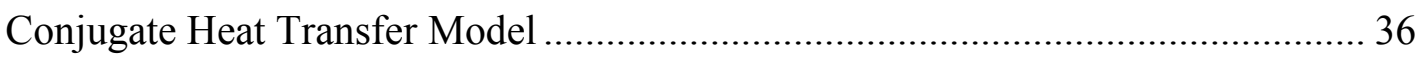

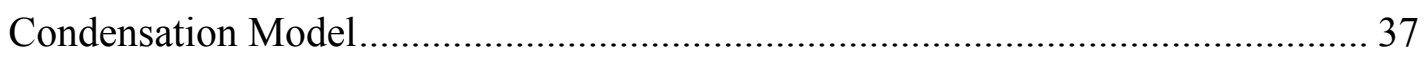

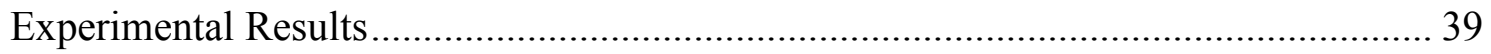

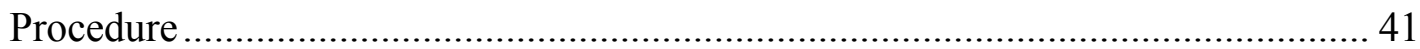




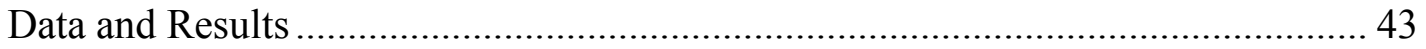

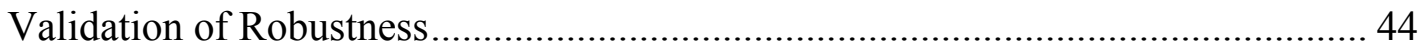

Conclusion/Opportunities ............................................................................ 50

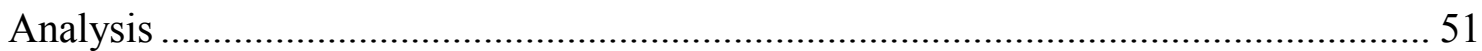

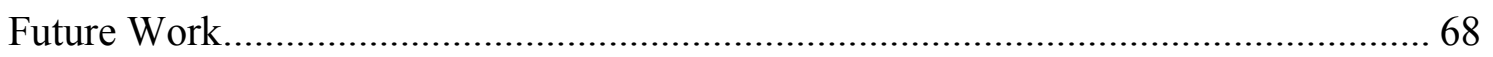

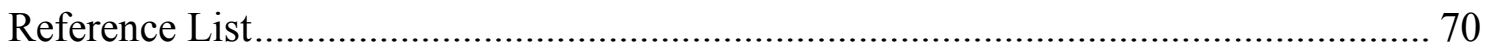

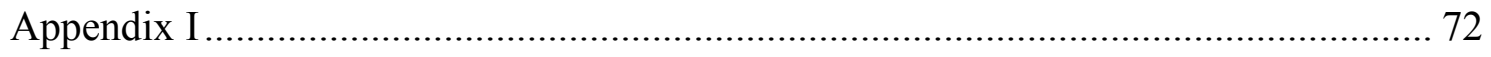

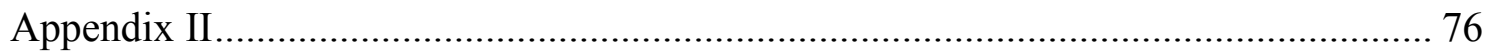

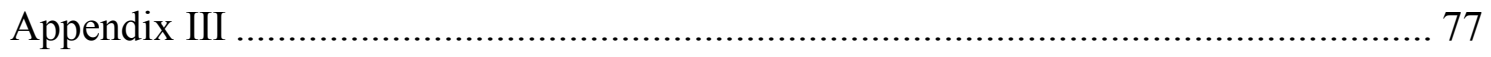

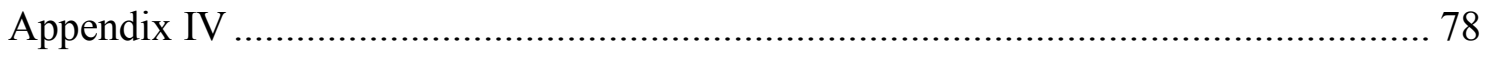

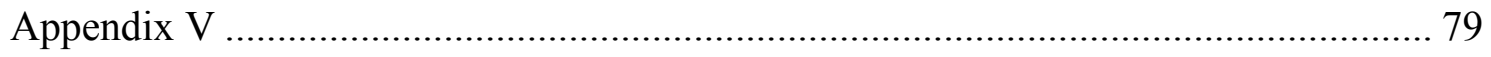

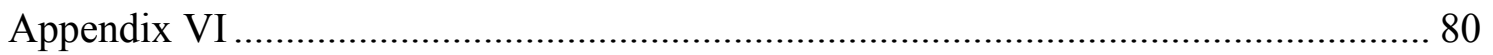




\section{List of Figures}

Figure 1.1 Schematic of Turbocharged Engine equipped with CAC.....................1

Figure 1.2 Air flow direction from air induction to engine intake manifold..........2

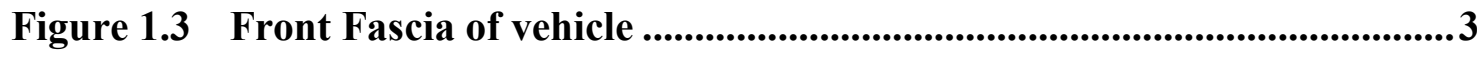

Figure 1.4 Fascia cut away exposing CAC location in vehicle position ...................3

Figure 2.1 The criteria for an exampled charge air system, including turbocompressor-CAC at 20 degrees ambient ...................................................5

Figure 3.1 A schematic representation of the flow problem ................................12

Figure 4.1 Cooling test rig experimental set up ....................................................... 17

Figure 4.2 Block diagram of experimental hardware .......................................... 18

Figure 4.3 Vehicle Block Diagram of cooling module in vehicle position............. 20

Figure 4.4 CAC Thermocouple Instrumentation...................................................... 21

Figure 4.5 CAC thermocouples location ............................................................21

Figure 4.6 CAC mounted to allow flow through one tube .................................22

Figure 4.7 CAC mounted to air duct......................................................................... 22

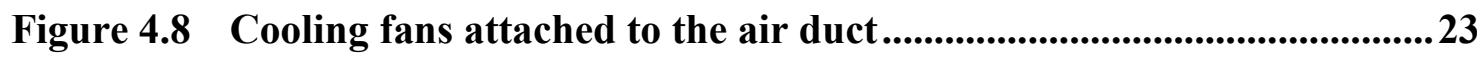

Figure 4.9 Pressure and velocity instrumentation in air box at charge air let.....23

Figure 5.1 Overview of Computational approach .....................................................26

Figure 5.2 Geometry of 3-D tube with surrounding cooling air region ................ 28

Figure 5.3 The aluminum tube meshed with the two air flow bodies are connected ....................................................................................29 
Figure 5.4 CAC Fin Cross-Area at opening Geometry used for Porosity Calculation 33

Figure 6.1 Cooling test rig experimental setup ...............................................40

Figure 6.2 Charge air inlet Temperature form start to end of test cycle............. 43

Figure 6.3 Measure-to-actual temperature in non-dimensional time $t / \tau \ldots . . . . . . . . .44$

Figure $6.4 \quad 95 \%$ confidence interval for TC2 ............................................... 46

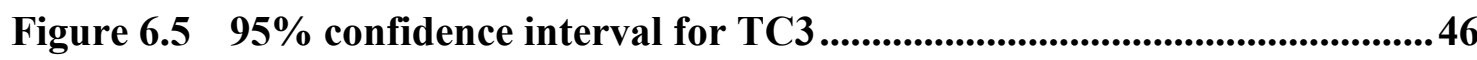

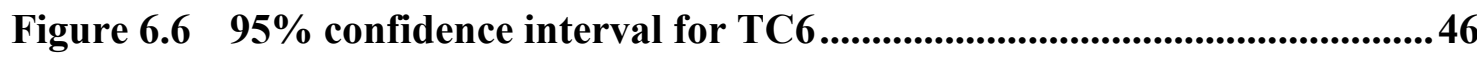

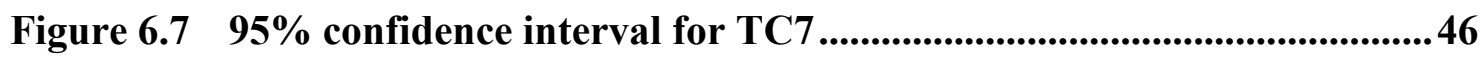

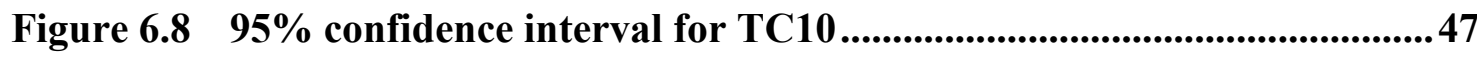

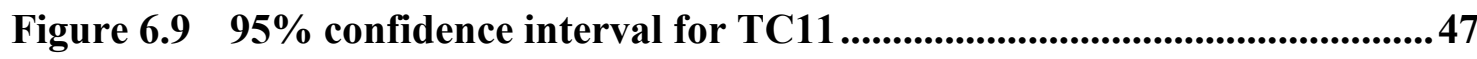

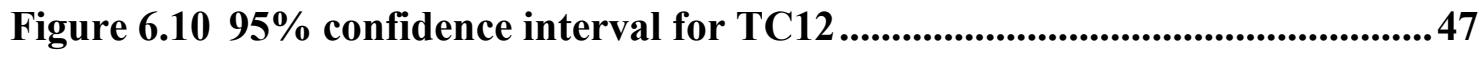

Figure $6.1195 \%$ confidence interval for TC13 ............................................... 47

Figure 6.12 Temperature Profile of even thermocouples.......................................48

Figure 6.13 Temperature Profile of odd thermocouples ............................................ 49

Figure 6.14 Temperature vs Length of the tube for all the cases from experiment

Figure 7.1 Correlation of experimental to simulation data for coarse mesh $10 \mathrm{~m} / \mathrm{s}$,

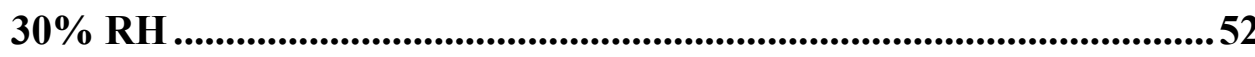

Figure 7.2 Fine Mesh Geometry ...........................................................................53

Figure 7.3 Correlation of Experimental to simulation dad for Fine mesh $10 \mathrm{~m} / \mathrm{s}$, 40\% RH 
Figure 7.4 Correlation of Experimental to simulation dad for Fine mesh $10 \mathrm{~m} / \mathrm{s}$, $30 \%$ RH .55

Figure 7.5 Contour plot of film thickness on inner wall of CAC...............................56

Figure 7.6 Contour Plot of Film Temperature on inner wall of CAC ...................57

Figure 7.7 Contour plot of Film Thickness of the CAC tube Inner Wall the (m) for $12 \mathrm{~m} / \mathrm{s}$ and $50 \%$ RH..............................................................................57

Figure 7.8 Contour plot of film thickness 100 second inner wall film development

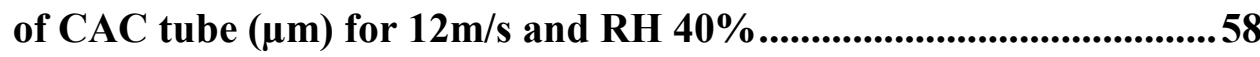

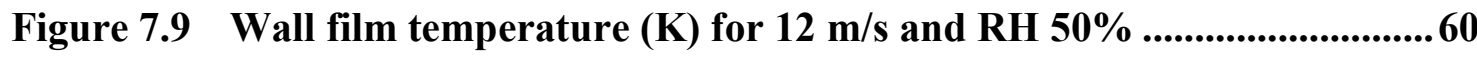

Figure 7.10 Inner-wall temperature for $12 \mathrm{~m} / \mathrm{s}$ and $50 \mathrm{RH}$.....................................60

Figure 7.11 Surface Heat Transfer Coefficient (W/m2-K) for $12 \mathrm{~m} / \mathrm{s}$ and

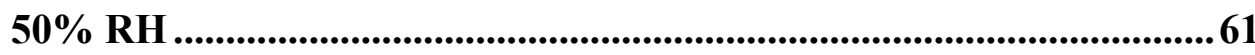

Figure 7.12 Contours of Heat Transfer Coefficient $\left(W / \mathrm{m}^{2}-\mathrm{K}\right)$ for $12 \mathrm{~m} / \mathrm{s}$ and

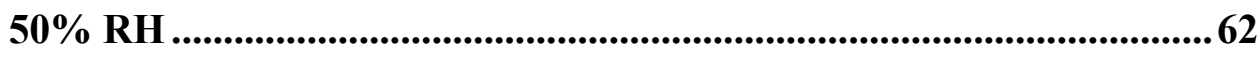

Figure 7.13 Total Heat Flux $\left(\mathrm{W} / \mathrm{m}^{2}\right)$ for $12 \mathrm{~m} / \mathrm{s}$ and $50 \%$ RH ..................................62

Figure 7.14 Validated simulation methodology …..........................................................64

Figure AII.1 Contours of Surface Heat Transfer Coefficient ........................................76 
List of Tables

Table 4.1 Test Rig Build of Material.......................................................................... 19

Table 4.2 Test Rig Operation Limits..............................................................20

Table 5.1 CAC Mesh Statistics ..........................................................................29

Table 5.2 CAC Computational Boundary Conditions .......................................31

Table 6.1 Test Boundary Conditions .............................................................. 41

Table 6.2 Experimental Test Conditions ........................................................... 41

Table 6.3 Mean temperature thermal couples: Temperature of specified thermocouples during steady-state region (40-80 mins).....................45

Table 7.1 Condensate Values from CFD Simulation...........................................51

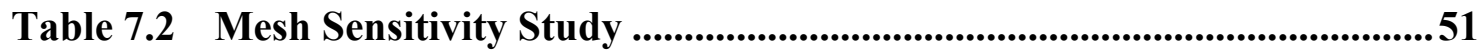

Table 7.3 Condensation creation for 50\% RH ................................................59 


\section{Acknowledgment}

I would like to acknowledge my advisor, Dr. Edward Lumsdaine, who encouraged me to pursue my $\mathrm{PhD}$ at Michigan Technological University. You have supported and motivated me throughout this process. Your enthusiasm and passion for science is truly contagious and your desire to see your students succeed has kept me going throughout my $\mathrm{PhD}$ journey. I owe you deep and sincere appreciation.

To the remainder of my committee: Dr. Jeffrey S. Allen, Dr. Song-Lin Yang, and Dr. Bashar AbdulNour, words cannot express how invaluable you are to me. Your advice, your mentorship, and your guidance have helped me through this journey. Thank you for giving me the opportunity to work and learn from you. Also, thank you so much Apoorv Talekar, for your dedication to my project; I wish you the very best.

To the Ford Motor Company team, Julie McCoy, Tom McCarthy, and the outstanding engineering team of the Research and Innovation Center: thank you for allowing me the opportunity to contribute to important research at Ford and for your support and assistance through this research project.

I want to express my gratitude to Dr. Mary Brake and Dr. McArthur Stewart for your counsel, advice, coaching, and motivation as I traveled through this $\mathrm{PhD}$ program.

To the many readers of my manuscript, thank you for your time, your patience, your eyes, your encouragement, and all that you've contributed to this work.

I am grateful to my loving husband, John, and wonderful children, Rachel, Leah, and John Evan, for your unconditional love and support. I could have never done it without you! And thank you to Kim, Tim, David, Karen, David III, and Jacob, your love and support provided me strength and determination.

Above all, I give honor and praise and sincere thanks to my Lord and Savior Jesus Christ - it is He who provides me enduring strength. 


\begin{abstract}
To address the need of increasing fuel economy requirements, automotive Original Equipment Manufacturers (OEMs) are increasing the number of turbocharged engines in their powertrain line-ups. The turbine-driven technology uses a forced induction device, which increases engine performance by increasing the density of the air charge being drawn into the cylinder. Denser air allows more fuel to be introduced into the combustion chamber, thus increasing engine performance. During the compression process, the air is heated to temperatures that can cause pre-ignition, resulting in reduced engine functionality. The introduction of the charge air cooler (CAC) is therefore, necessary to extract heat from the compresses air. The present research describes the physics and develops the theoretical equations that define the process. It also develops a 3-D computational model of the CAC internal flow with condensate using ANSYS ${ }^{\circledR}$ Fluent and validates the predictions of the 3-D model using measurements from Ford experimental data. Finally, the research presents a correlation that provides an approach for designing heat exchangers for practical applications that encounter moisture in the powertrain air intake air stream. The overall benefit identified is an experimentally validated simulation methodology to evaluate and design CACs that function outside the condensate formation zone during vehicle operation modes.
\end{abstract}




\section{Introduction}

A charge air cooler (CAC) heat exchanger is used in conjunction with gasoline turbo direct injection (GTDI) internal combustion (IC) engines, as illustrated in Figure 1.1, and diesel engines to increase combustion output. Engines make use of exhaust gas recovery (EGR) from the exhaust gas (deisel engine application) or fresh air from the atmosphere (IC application) to increase air intake density (also refered to as compressed or charge air) by compressing and cooling air or EGR prior to its entrance into the combustion chamber. Original Equipment Manufacturers (OEMs) have reported up to a $20 \%$ fuel economy improvement and up to a $15 \% \mathrm{CO}_{2}$ reduction. OEMs recognize that an I-4 GTDI provides performance equivalent to that of a V-6 and a V-6 GDTI performs equivalent to that of a V-8, per the NHTSA ${ }^{1}$ estimates.

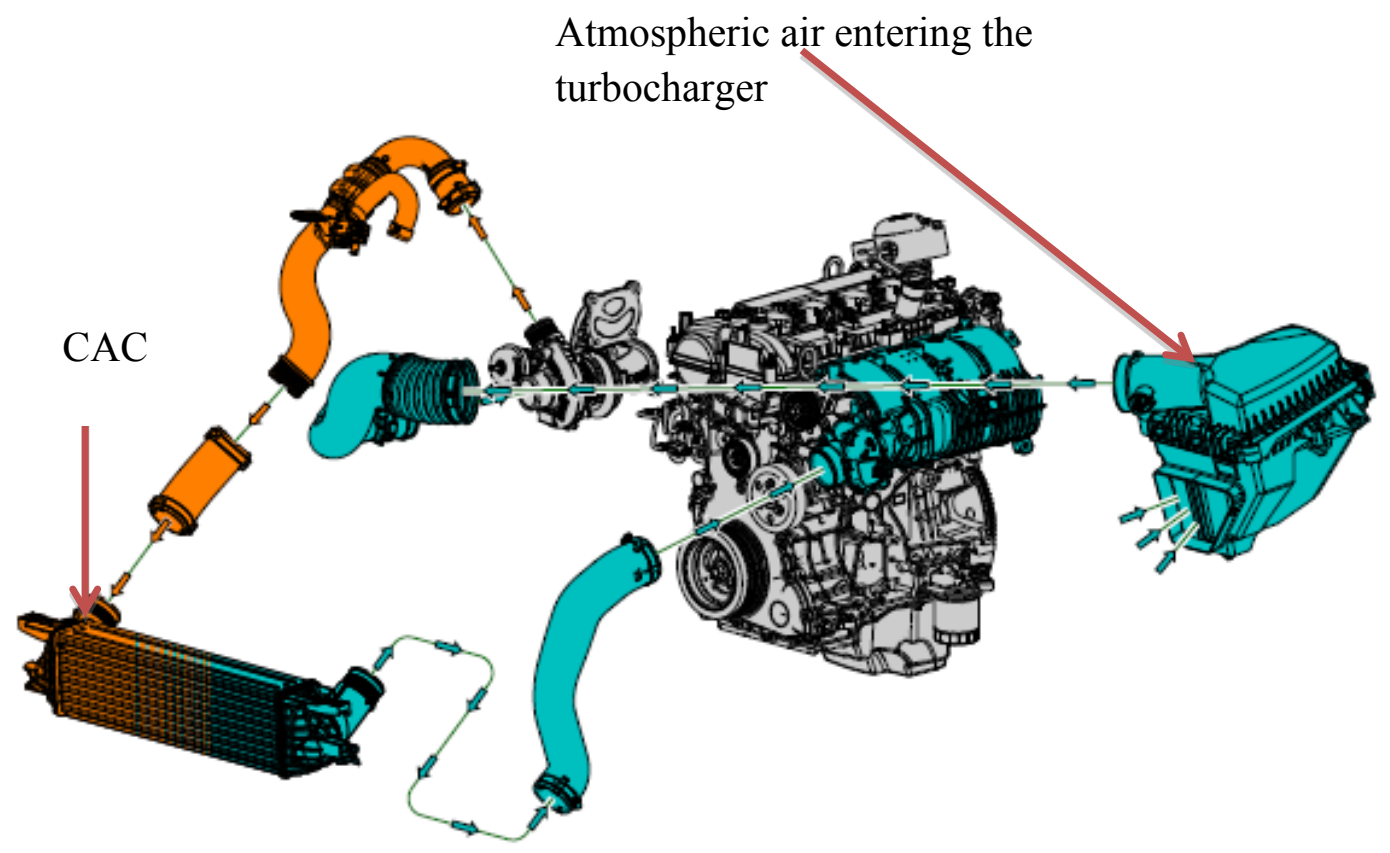

Figure 1.1 - Schematic of turbocharged engine equipped with a CAC

Reprinted with permission from Ford Motor Company; Internal Report

\footnotetext{
${ }^{1}$ National Highway Traffic Safety Administration "2017-2025 Model Year Light Duty Vehicle GHG Emission and CAFÉ Standards: Supplemental"
} 
Atmospheric air enters the air-induction tube and is sent through the turbocharger for compression, as shown in Figure 1.2. The turbocharger and CAC are introduced in the powertrain system to compress (IC application) or EGR (diesel application) and cool the air, respectively. The result is denser air, which increases horsepower, improves fuel economy output, and reduces emissions.

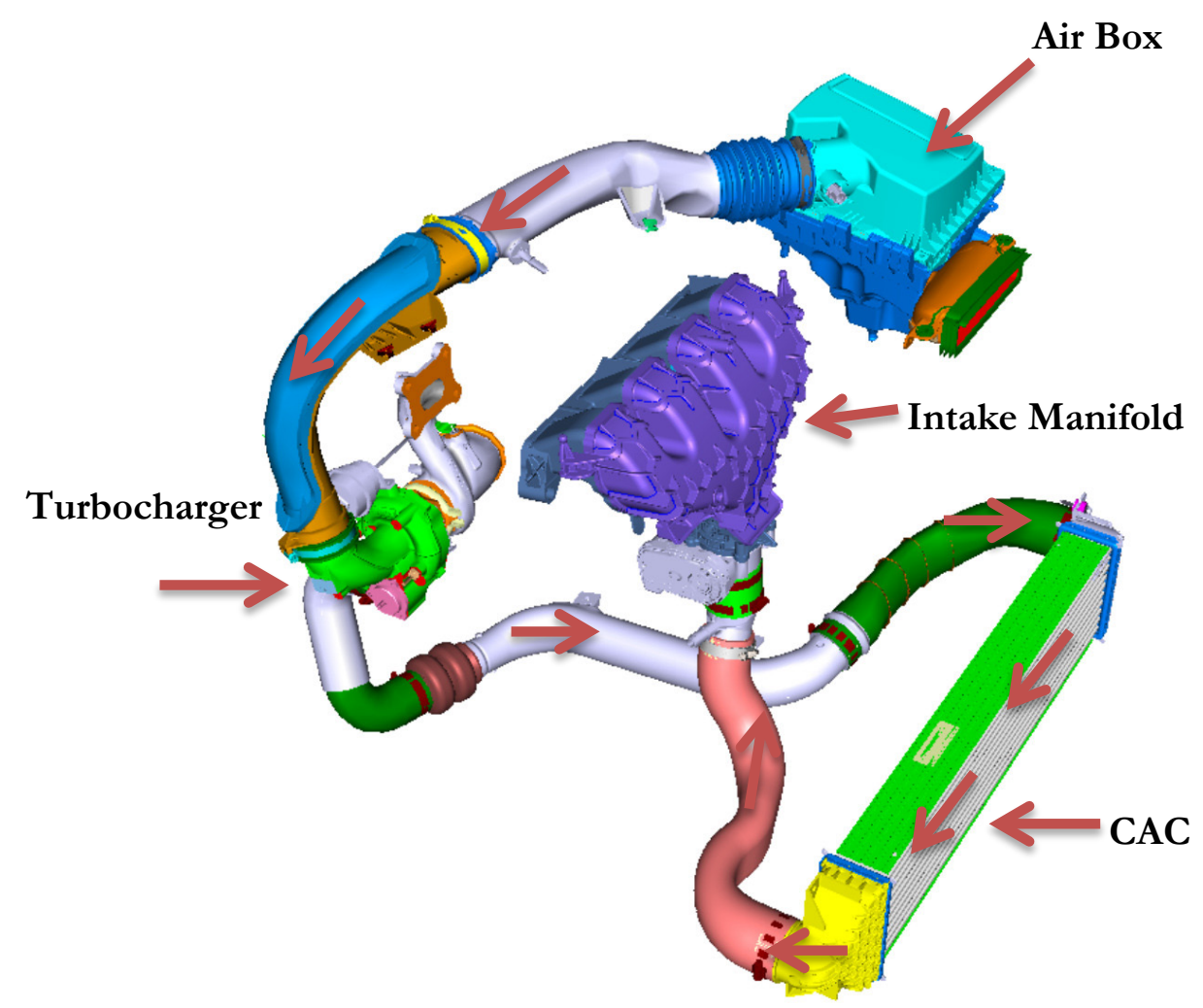

Figure 1.2 - Air flow direction from air induction to engine intake manifold Reprinted with permission from Ford Motor Company; Internal Report

Eco-boost ${ }^{2}$ GTDI engines deliver compressed, cool, dry air into the combustion chamber. In gasoline applications, atmospheric air enters through the turbocharger for compression. Moisture is always present in atmospheric air in the form of water vapor. If the water vapor is condensed, it can lead to boosted engine operational failures such as misfire due to ingestion of water into the combustion chamber.

\footnotetext{
${ }^{2}$ Called Ecoboost by Ford Motor Company.
} 
During the compression process, the air is heated to temperatures that can result in reduced engine functionality, such as pre-ignition engine knock. The introduction of the $\mathrm{CAC}$ is necessary to remove heat after the turbocharging process to cool the compressed air to the appropriate temperature, thus preventing engine misfire.

The CAC is positioned directly behind the front fascia and in front of the condenser and radiator, as depicted in Figures 1.3 and 1.4. The air is heated when it is compressed in the turbocharger before it enters the rectangular cross-section of the horizontal intake tube of the CAC. While the heat is being removed from the air to achieve the desired exit temperature, formation of undesirable condensate can occur.

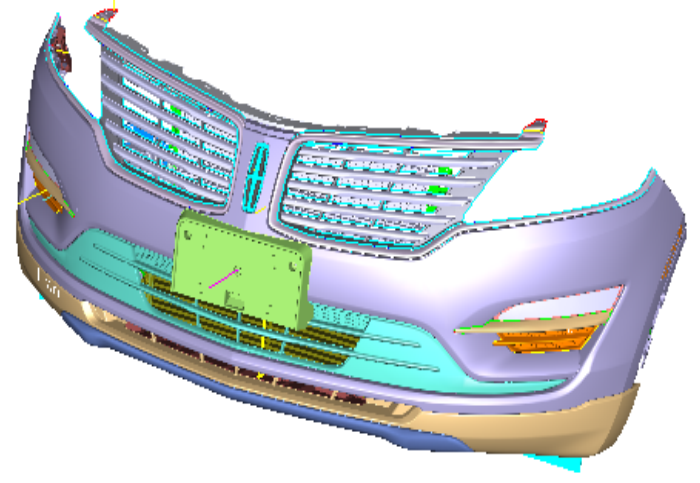

Figure 1.3

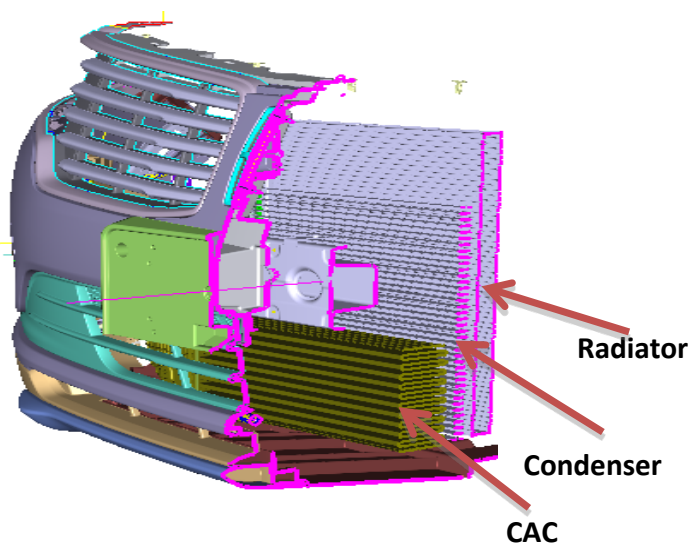

Figure 1.4

Front fascia and fascia cut away exposing CAC location in vehicle position

Reprinted with permission from Ford Motor Company; Internal Report

The current solution, as discussed in the literature review section, is insufficient for predicting the amount of condensate that forms and collects in the $\mathrm{CAC}$ and air induction system (AIS) ducts during engine operation. The CAC inlet conditions, temperature, pressure, relative humidity, and air velocity are well defined and are based on ambient weather conditions during operation. The CAC exit conditions are defined by specific vehicle programs and are based on the required engine performance, as dictated by vehicle driving duty cycles. The CAC is introduced to cool the charged air compressed by the turbo charger prior to its entrance into the combustion chamber. 
Depending on the required exit temperature and pressure, the CAC is sized to reject a prescribed amount of heat that is generated during the compression process. As the charged air moves through the $\mathrm{CAC}$, it is cooled down, often resulting in an undesirable condensate due to the temperature reduction.

Under the condition in which too much condensate is generated and accumulation occurs, there is a risk of the condensate being pushed into the combustion chamber during demanding engine loads or maximum velocity with vehicle grade, referred to as a wideopen throttle (WOT) condition. The ingestion of a critical mass of water into the combustion chambers can lead to misfire and other adverse effects. Currently, there is no way to accurately predict the amount of condensate formation during engine operation or the conditions under which it is formed.

The objective of this research is to study the physics of condensate accumulation in a horizontal aluminum tube and accurately predict the incident of insipid condensation across the entire line of the tube. The understanding of this phenomenon will aid in the proper design of systems that use dry compressed air. During the heat removal process, unwanted condensate can be formed and may lead to operational error states that can affect the quality of the end product. The case in which a heat exchanger is used to remove heat and, thereby, lower the temperature of the compressed air is studied. This research will result in an experimentally validated simulation methodology to evaluate and design $\mathrm{CAC}$ heat exchangers for practical applications that encounter moisture in the air stream in cooling systems; heat, ventilation, and air condition (HVAC) systems; and power process industries. 


\section{Literature Review}

A detailed review of research on condensate formation of compressed air inside horizontal tubes was conducted. Dry compressed air is used in many applications, including engines, paint spraying, driving pneumatic tools, mixing sterile pharmaceuticals, food processing, and heating and refrigeration systems. Condensate in these systems can lead to operational error states that can affect the quality of the end product. The issue of compressed atmospheric air from the immediate environment and the creation of condensate - because air will always contain moisture in the form of water vapor - was also reviewed.

There is very little information available on the subject of the creation of condensate in charge air coolers. Published research on the physical accumulation of condensate in heat exchanger tubes and its effects on the downstream processes are limited.

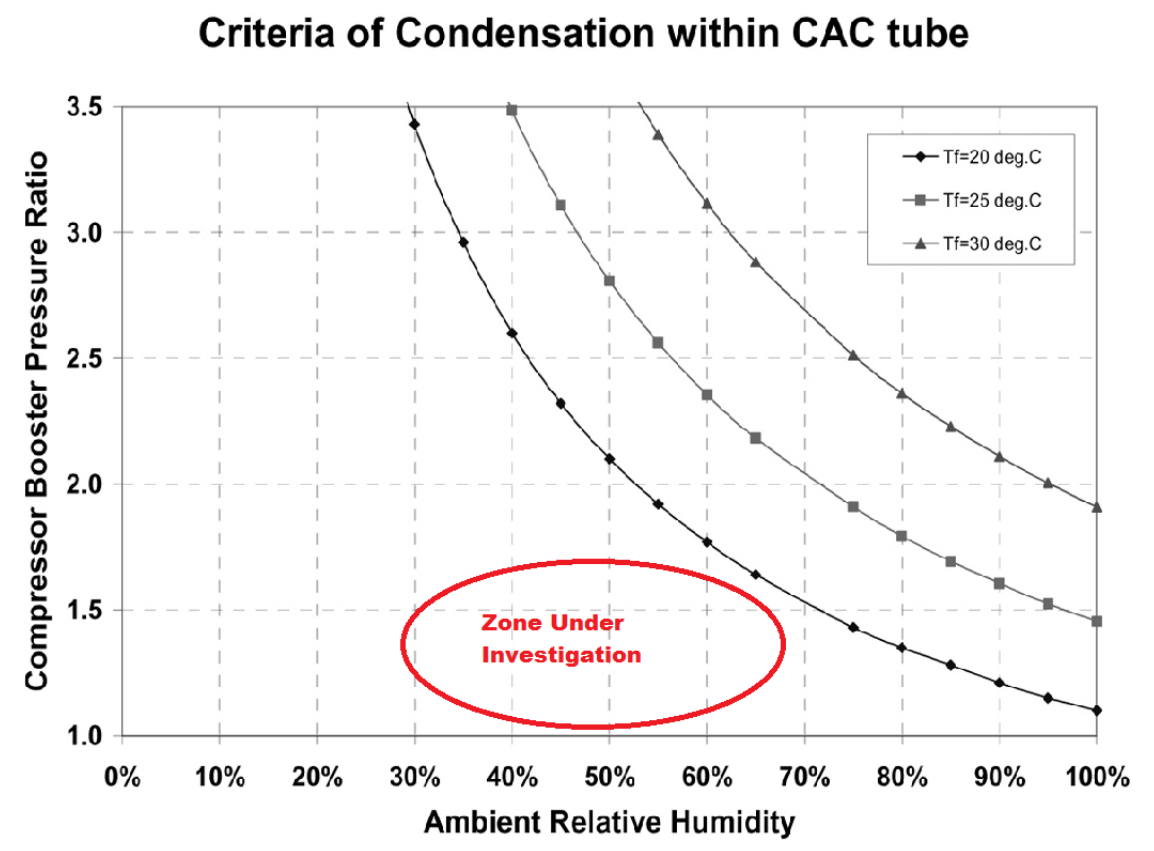

Figure 2.1 - The criteria for an exampled charge air system, including turbo-compressor-CAC at 20 degrees ambient

Reprinted with permission from SAE International Report No. 0148-7191 
According to Tang (Tang 2011), a criterion is defined for condensation based on the typical CAC opening condition of 10,000 Pascal and $20^{\circ} \mathrm{C}$, as shown in Figure 2.1.

Saturation temperatures increase as pressure ratios increase. Tang asserted that when the defined operational conditions are met, condensation will occur above the temperature curves. The highlighted red zone represents the condition currently under investigation. The subject zone does yield condensation; therefore, additional study is needed. Further, Tang's study does not include CFD simulation or experimental correlation of the condensation mechanism creating a need for added work.

Much of the work that is available is not related to the adverse effects as a result of the presence of water condensate in the flow stream, addressing instead the use of condensation as a method of enhancing heat transfer, the removal of water from compressed air to a level where no condensate can be formed, and any other containments that are present.

Dalkilic (A. S. Dalkilic and Wongwises 2009) presented a comprehensive body of research pertaining to condensation creation during internal tube flow. Their research summarizes condensation studies inside horizontal tubes and the review of different approaches in determining the heat transfer coefficients. The authors categorize their research into tube orientation and tube geometry, considering flow patterns and pressure drop. A summary of their work lists all reviewed correlations.

The authors believe that the study of condensation heat transfer mechanism is unlimited. The automotive industry would benefit from a better condensation map that more accurately predicts the flow patterns in the horizontal tubes of the heat exchangers and how the heat transfer coefficient is affected.

This current research uses the literature review completed by Dalkilic, focusing specifically on smooth horizontal tubes, and develops a correlation specific to CAC flow patterns that is impactful to automotive industry applications. 
The available research was divided into several categories, as outlined in subsequent subsections.

\section{Enhancements of heat transfer coefficient}

Dalkilic (Amet Selim Dalkilic et al. 2013) investigated heat transfer enhancement techniques for internal tube flow used by refrigeration, automotive, and process industries. The study focuses on discovering methods to increase heat flux of flow in horizontal tubes through improvements in heat transfer coefficients. The flow pattern and phase of refrigerant have critical effects on the convective heat transfer coefficient and associated heat flux.

Their study emphasizes the relationship between tube geometry and phase of fluids with the size of heat transfer coefficient. The research concludes that heat transfer coefficients increase with the mass flux average vapor quality of the refrigerant. As a result of this study, a correlation for the condensation heat transfer coefficients was proposed.

\section{Reductions in heat transfer rate}

Conversely, Murase (Murase et al. 2006) described the reduction in heat transfer performance of a given row of a bank of horizontal tubes due to the inundation of condensate falling from higher tubes to lower tubes in the bank. It was noted that this is due in part to the larger film thickness around the lower tubes. It was determined that inundation affected the heat transfer coefficient and, therefore, the heat flux. Correlations were also drawn between the surface of the tube (smooth, wired wrapped or finned) and the effect of inundation on the heat transfer coefficient. Ultimately, the authors confirm the relationship between the condensation on the tube and the rate of heat flux.

Vyskocil (L. Vyskocil et al. 2014a) modeled two vessels filled with several species connected by a tube. The article contends that non-condensable gas layers degrade the heat transfer rate when temperatures are lowered to saturation conditions during containment. In this case, a non-condensation barrier created near the wall reduced the heat transfer coefficient. The goal of the authors' work was to develop a condensation 
model when non-condensable gases are present. The model predicted the rate of condensation and the reduction in heat flux.

\section{Modeling of species in the airstream}

Articles on the physical accumulation of condensate in tubes and its effect on downstream processes have not been found. The majority of the work related to this topic is found in internal studies currently underway at Ford Motor Company. The Ford research team is working to determine the effect of condensate and soot in charged diesel applications that consider exhaust gas recovery. Ford created a CAC condensation model based on a study by Mehdi Abarham (Ford Confidential) to understand the challenges associated with lowpressure EGR, including engine misfiring, freezing damage, and charge air cooler corrosion. The intent was to understand water condensation, evacuation, and entrainment, as well as to estimate the water ingestion rate. Several items were considered, including the soot particulate chemistry of EGR and the effects on the performance and life cycle of the charge air cooler.

Garcia (Garcia 2012) studied the corrosive nature of EGC condensate in CACs that develops as a result of lower operating pressures due to introduction of EGR in diesel engines. The acidic natural of the condensation on exhaust gases can lead to corrosion of the $\mathrm{CAC}$ and other components, thereby introducing additional contaminates in the system. Bench tests were developed and run to determine the amount of condensate and level of acidity present during the vehicle driving cycle. While a corrosion bench test was developed, predictions models were not developed. There is an opportunity to expand this work to include a simulation that predicts condensation and its species that correlates to the corrosion bench test. This would be useful in predicting heat flux and estimating the useful life of components and systems.

Unlike the 2-stroke diesel engine, the 4-stroke naturally aspirated engine needs only to consider atmospheric intake air. Therefore, the study by Kanefsky et al. (Ford Confidential) was modified to consider only atmospheric air. In parallel, the research laboratory constructed a full test rig and gathered experimental data using actual hardware 
to measure the amount of condensate accumulation in various tube geometries of compact charge air coolers and compare that to real-life data. The referenced test rig and resulting data will be used to correlate the 3-D model that will be developed as a result of this research. Additional work is still underway to document research in the area of charge air cooler condensate accumulation. Recommended methodologies for accurately predicting when condensate is accruing will be referenced and used as a tool while conducting this research.

\section{Condensation removal}

Industrial plants use compressed air for many purposes. The compressed air contains condensate which causes corrosion and a resulting deterioration and ultimate breakdown in the equipment of the operating systems, according to Mikhushkin (Mikhushkin and Bogachenko 1992). The author proposes the use of a three-stage heat exchanger for drying the compressed air prior to its use. While it is understood that the condensate will form and needs to be removed, the drying equipment proposed is arbitrary. There is an opportunity to improve the prediction of condensate to be removed and develop a model to optimize the drying equipment. In passenger car applications where there in a shortage of component real estate, it is difficult to find package space to accommodate such a dryer.

\section{Prediction of onset of condensation in tubes using Computational Fluid Dynamics}

Vyskocil (Ladislav Vyskocil et al. 2014b) created a Computational Fluid Dynamics (CFD) simulation of air-steam flow with condensation over a flat plate, making use of ANSYS ${ }^{\circledR}$ Fluent code. The study concluded that non-condensable gases form a layer and then degrade heat transfer to the wall. The model was also able to correctly predict the point at which condensation begins. In addition, the calculation on vapor concentration and temperature were in agreement with their experimental data. As the heat exchanger tube can be modeled as flow between parallel flats plate, the study will be relevant and will be used to expand the scope of flow through tubes.

AbdulNour (Bashar S. AbdulNour and Foss 1997) describes a CFD methodology that will be used. In this study, a 3-D steady flow was considered. A methodology to solve 
similar non-isothermal flow problems was described in detail by AbdulNour (Bashar AbdulNour 1998; 1999). He used CFD to solve the 3-D flow and energy equations associated with phase change due to the defrosting of the ice layer on automobile windshields. The methodology starts with generating surfaces from the solid model. These surfaces, wetted by the fluid, constitute the flow and heat transfer boundaries of the flow domain. Surface mesh is then spread on the surfaces and volume mesh is generated by projecting the surface mesh on the interior of the domain. The density, distribution, and uniformity of the mesh are critical to the quality of the results and speed of convergence of the computational solution.

The flow parameters dictating the equations to be solved, flow and thermal boundary conditions, mathematical models such as turbulence, and the numerical control parameters are included in the computational model during the pre-processing step. The CFD solver is then run to yield the results. The residuals of the solution variables are monitored at each iteration until they converge when all residuals diminish to the preselected error criteria. The results include the velocity, pressure, temperature, and other flow parameters of interest at every single cell in the computational domain. These results are examined in the post-processing step and presented in a format suitable to evaluate the relevance of the results and quality of the solution. The cited authors compared CFD results to test measurements and concluded that the CFD predictions are adequate to model complex flow problems.

\section{Flow pattern prediction during condensation}

Tanhan (Tandon et al. 1982) discussed the problem of flow pattern prediction during condensation inside horizontal tubes. It is necessary to select the best correlation for predicting condensation heat transfer coefficients. There are numerous correlations that exist in literature. However, Tanhan asserts that no single correlation is best for heat exchanger design purposes and takes an experimental approach to predicting various flow maps. Several flow pattern maps were discussed and compared in the article. The authors have proposed a correlated flow regime map that takes into consideration the full body of work cited in their study. These flow patterns were considered in this research to develop 
a useful profile that can be used to predict the flow patterns during charge air cooling in the horizontal-tube heat exchanger considered in the research. 


\section{Description of Problem}

Charge air flows through aluminum tubes of a CAC to remove enough heat to achieve the required temperature for efficient engine operation. A singular rectangular tube is analyzed in the study. The tube is depicted in Figure 3.1 by a three-dimensional, turbulent flow of a Newtonian, isotropic, homogenous fluid with constant density and kinematic viscosity. The computational results are obtained by making use of the Cartesian coordinate system three-dimensional solver strategy. The governing transport equations are defined and the various boundary conditions are described for the problem.

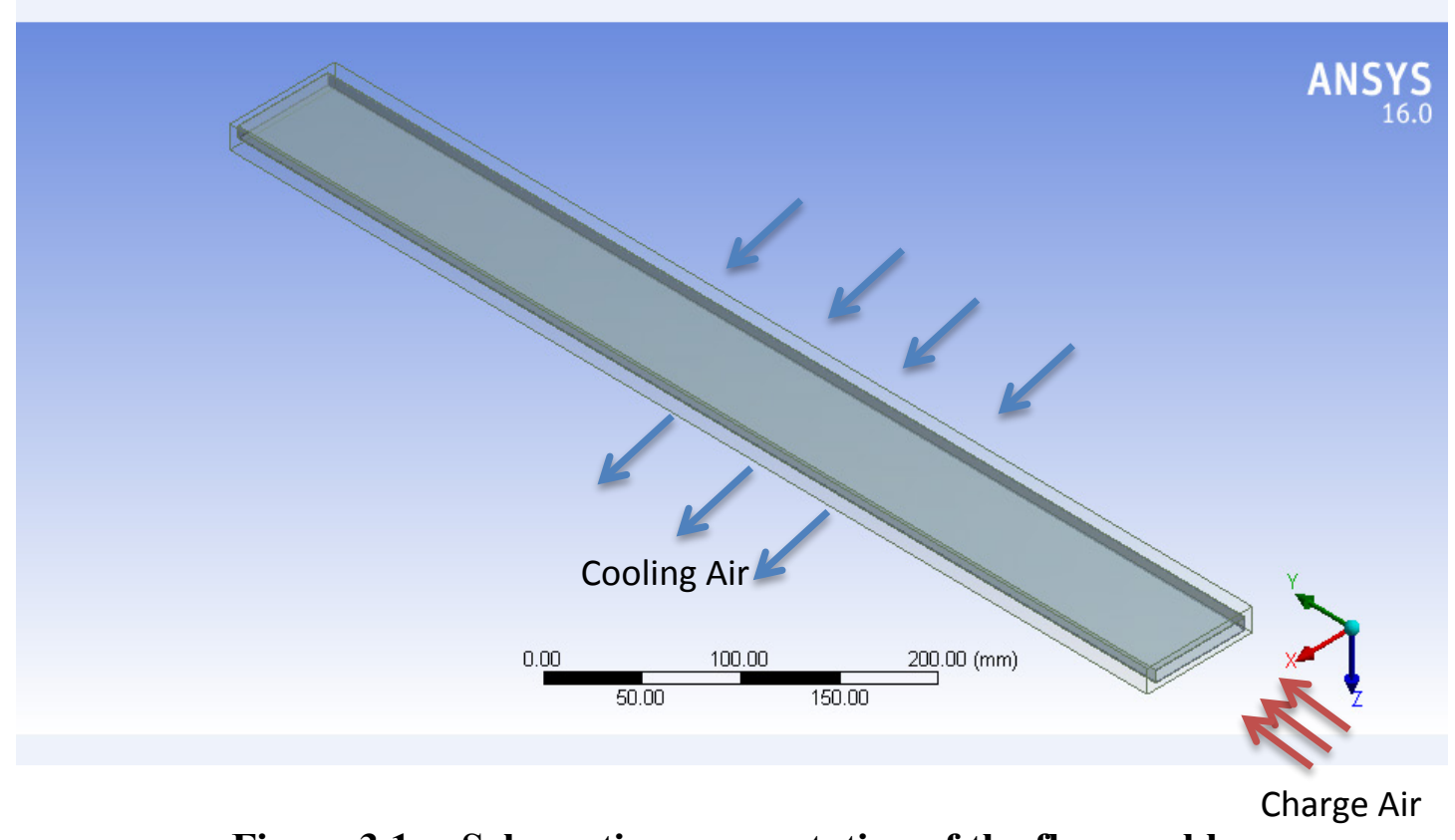

Figure 3.1 - Schematic representation of the flow problem 


\section{Mathematical Formulation}

This three-dimensional, incompressible flow problem is described by the appropriate conservation of mass, conservation of momentum (Navier-Stokes), and conservation of energy equations. The governing equations will be defined, along with the necessary initial and boundary conditions required to solve the velocity profiles, pressure, film temperature, and wall film during operation. Furthermore, the differential equations of motion are expressed in dimensionless form.

Let the following characteristic variables be used for the normalization of the variables in this study:

$$
\begin{aligned}
& \mathrm{H}=\text { Length } \quad \mathrm{U}=\text { velocity } \quad \mathrm{t}=\text { time } \quad p=\text { pressure }=\rho U^{2}, \\
& \mathrm{~T}_{\mathrm{s}}=\text { Surface temperature } \\
& T_{\infty}=\text { Ambient temperature }
\end{aligned}
$$

where $\mathrm{H}$ is the distance between upper and lower surfaces of the flow regime, $\mathrm{U}$ is mean inlet velocity, and $\rho$ is the density of the fluid.

To render the equations dimensionless, the following definitions are assumed:

$$
x^{*}=\frac{x}{H}, \quad y^{*}=\frac{y}{H}, \quad z^{*}=\frac{z}{H} \quad t^{*}=\frac{t}{\left(\frac{H}{U}\right)}, \quad U=\frac{V^{*}}{V}, \quad p^{*}=\frac{p}{\rho U^{2}}, \quad T^{*}=\frac{T-T_{S}}{T_{\infty}-T_{S}}
$$

In the preceding definitions, asterisks indicate the dimensionless parameter.

The hydraulic diameter is defined as $D_{H}=4\left(\frac{\text { Area }}{P}\right) ; \mathrm{P}=$ wetted perimeter. For the case of a narrow rectangle, where the width $\mathrm{b}$ is much larger than the height $\mathrm{H}$, we have:

$$
D_{H} \cong 2 H \text {. }
$$

The internal passage of the charge air flow represents the boundaries for the present solution. 


\section{Definition}

$\vec{x}=x \hat{\imath}+y \hat{\jmath}+z \hat{k}, \quad \vec{V}=u \hat{\imath}+v \hat{\jmath}+w \hat{k}$

where $u(x, y, z, t), v(x, y, z, t)$ and $w(x, y, z, t)$ are the velocity components in the $\mathrm{x}-, \mathrm{y}-$ and $\mathrm{z}-$ directions and $\widehat{\imath}, \widehat{\jmath}$ and $\hat{k}$ are unit vectors in the $\mathrm{x}-, \mathrm{y}-$ and $\mathrm{z}-$ directions, respectively.

$\vec{\nabla}$ is the gradient operator $=\frac{\partial}{\partial x} \hat{\imath}+\frac{\partial}{\partial y} \hat{\jmath}+\frac{\partial}{\partial z} \widehat{k}$ and $\vec{\nabla}^{*}=H \quad \vec{\nabla}$ is the dimensionless gradient operator.

$\nabla^{2}$ is a Laplacian operator $=\frac{\partial^{2}}{\partial x^{2}}+\frac{\partial^{2}}{\partial y^{2}}+\frac{\partial^{2}}{\partial z^{2}}$

$\nabla^{2 *}$ is the dimensionless Laplacian operator $=\boldsymbol{H}^{2} \boldsymbol{\nabla}^{2}$.

\section{Conservation of mass}

$\frac{\partial \rho}{\partial \mathrm{t}}+\vec{\nabla} \cdot(\rho \overrightarrow{\mathrm{V}})=0$

or $\vec{\nabla} \cdot \vec{V}=0 \quad$ when $\rho=$ constant 1

or $\vec{\nabla}^{*} \cdot \vec{V}^{*}=0$ in dimensionless form 2

Conservation of momentum (Navier-Stokes Equations)

$\frac{\partial \vec{V}}{\partial t}+(\vec{V} \cdot \vec{\nabla}) \vec{V}=-\frac{1}{\rho} \vec{\nabla} p_{k}+v \nabla^{2} \vec{V}$

In dimensionless form,

$\frac{\partial \overrightarrow{\mathrm{V}}^{*}}{\partial t^{*}}+\left(\overrightarrow{\mathrm{V}}^{*} \cdot \vec{\nabla}^{*}\right) \overrightarrow{\mathrm{V}}^{*}=-\vec{\nabla}^{*} p_{k}^{*}+\frac{1}{R e} \nabla^{2 *} \overrightarrow{\mathrm{V}}^{*}$

Where $R e=\frac{U H}{v}$ is the Reynolds number, which is the dimensionless parameter that includes fluid properties and the length and velocity scales for the problem. It is the ratio of the inertial forces divided by the viscous forces. 
The kinetic pressure equals $p_{k}$, and can be defined as:

$\mathrm{p}_{\mathrm{k}}=\mathrm{p}+\rho \mathrm{gz}$ where $\mathrm{p}$ is the pressure, and $\rho g \mathrm{~g}$ is the body force

$p_{k}^{*}=p^{*}+\frac{g}{U^{* 2}} z^{*}$ in dimensionless form.

\section{Conservation of energy}

$\rho c \frac{D T}{D t}=k \nabla^{2} T-P \nabla \cdot \nexists \nabla+\not$, where $\Phi$ is the viscous dissipation function that is set to zero since it is negligible. $\nabla \cdot \vec{V}$ is zero due to incompressibility.

$\frac{D T}{D t}=\alpha \nabla^{2} T$

where $\alpha=\frac{k}{\rho c}$ is thermal diffusivity,

$\frac{D T^{*}}{D t^{*}}=\frac{1}{R e} \frac{1}{P r} \nabla^{2 *} T^{*}$ in dimensionless form

where $\operatorname{Re}=\frac{U H}{v}$ is the Reynolds number, and

$\operatorname{Pr}=\frac{c \mu}{k}$ is the Prandtl number.

The initial and boundary conditions required to solve the energy equation for the temperature distribution of the charge air are:

Definitions: $\mathrm{x}$-direction: $\mathrm{w}=$ width, $\mathrm{y}$-direction: $\mathrm{L}=$ length $\mathrm{z}$-direction, $\mathrm{h}=$ height

I.Cs.: $\quad \mathrm{T}_{\mathrm{s}}=21^{\circ} \mathrm{C}$ and $50 \% \mathrm{RH}, \mathrm{T}_{\text {air }}=55^{\circ} \mathrm{C}$ and $30 \% \mathrm{RH}$

$\mathrm{BC1}: \mathrm{k} \frac{\partial \mathrm{T}}{\partial \mathrm{x}} @ \mathrm{x}=\mathrm{W}=\mathrm{h}_{\text {air }}\left(T_{s}-T_{\text {air }}\right)$

BC2: $\mathrm{k} \frac{\partial \mathrm{T}}{\partial \mathrm{x}} @ \mathrm{x}=0=\mathrm{h}_{\text {air }}\left(T_{\text {air }}-T_{s}\right)$

BC3: $\quad \mathrm{T}_{@ \mathrm{y}=0}=55^{\circ} \mathrm{C}$

BC4: $\quad \mathrm{T}_{@ y=L}=24^{\circ} \mathrm{C}$

BC5: $\mathrm{k} \frac{\partial \mathrm{T}}{\partial \mathrm{x}} @ \mathrm{z}=\mathrm{H}=\mathrm{h}_{\mathrm{air}}\left(T_{S}-T_{\text {air }}\right)$

BC6: $\mathrm{k} \frac{\partial \mathrm{T}}{\partial \mathrm{x}} @ \mathrm{gz}=0=\mathrm{h}_{\text {air }}\left(T_{\text {air }}-T_{S}\right)$ 
These boundary conditions are modified by Fluent when the wall metal is included in the conjugate heat transfer model. In such case, the boundary conditions of the cooling air outside the tube will be utilized. These five dimensionless equations, the initial condition, and six boundary conditions are used to solve for the velocity, temperature, and mass fraction of condensate in the tube (Lumsdaine and Voitle 1993; Frank and David 1996; Potter et al. 2011).

The objective of this research is to study the physics of condensate accumulation in the aluminum tube of the $\mathrm{CAC}$ heat exchanger to accurately predict the incident of insipid condensation across the entire line of the tube. The following methodology was used during this research study:

1. Understand the physics of the process and develop the theoretical equations that describe the process.

2. Develop a 3-D computational model of the CAC internal flow with condensate.

3. Conduct laboratory experimentation making use of the Ford Motor Company condensation test rig developed by the Ford research team.

4. Validate the simulation predictions of the 3-D model using measurements from the Ford experimental data.

This research will result in the development of an experimentally validated simulation methodology that can be used when designing heat exchangers for practical applications that encounter moisture in the air stream. 


\section{Experimental setup}

The experimental setup for the $\mathrm{CAC}$ condensation test rig and procedure are summarized in this chapter. The CAC testing rig was designed to simulate conditions that the CAC experiences during vehicle operations in order to understand how condensate forms in the CAC tube. Air flow, representing charge air, of a controlled relative humidity $(\mathrm{RH})$, temperature, pressure, and air velocity rate is passed through a single tube of a CAC. From these known conditions the temperature at fourteen locations along the tube and the total amount of condensate collected were measured.

The test rig was designed and assembled to measure the internal air temperature of the charge air as it was being cooled, as illustrated in Figures 4.1 and 4.2.

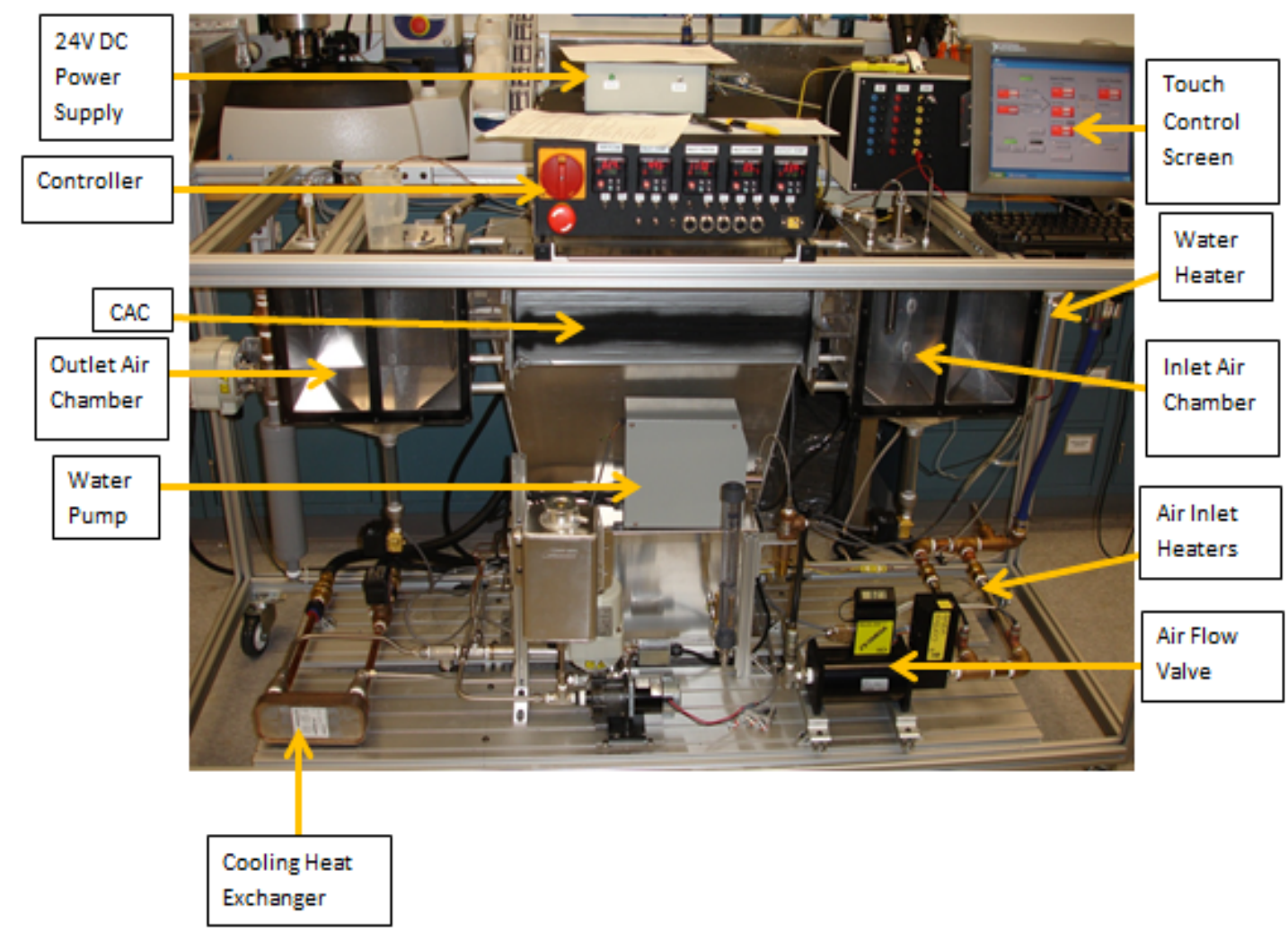

Figure 4.1 - Cooling test rig experimental setup

Reprinted with permission from Ford Motor Company; Internal Report 


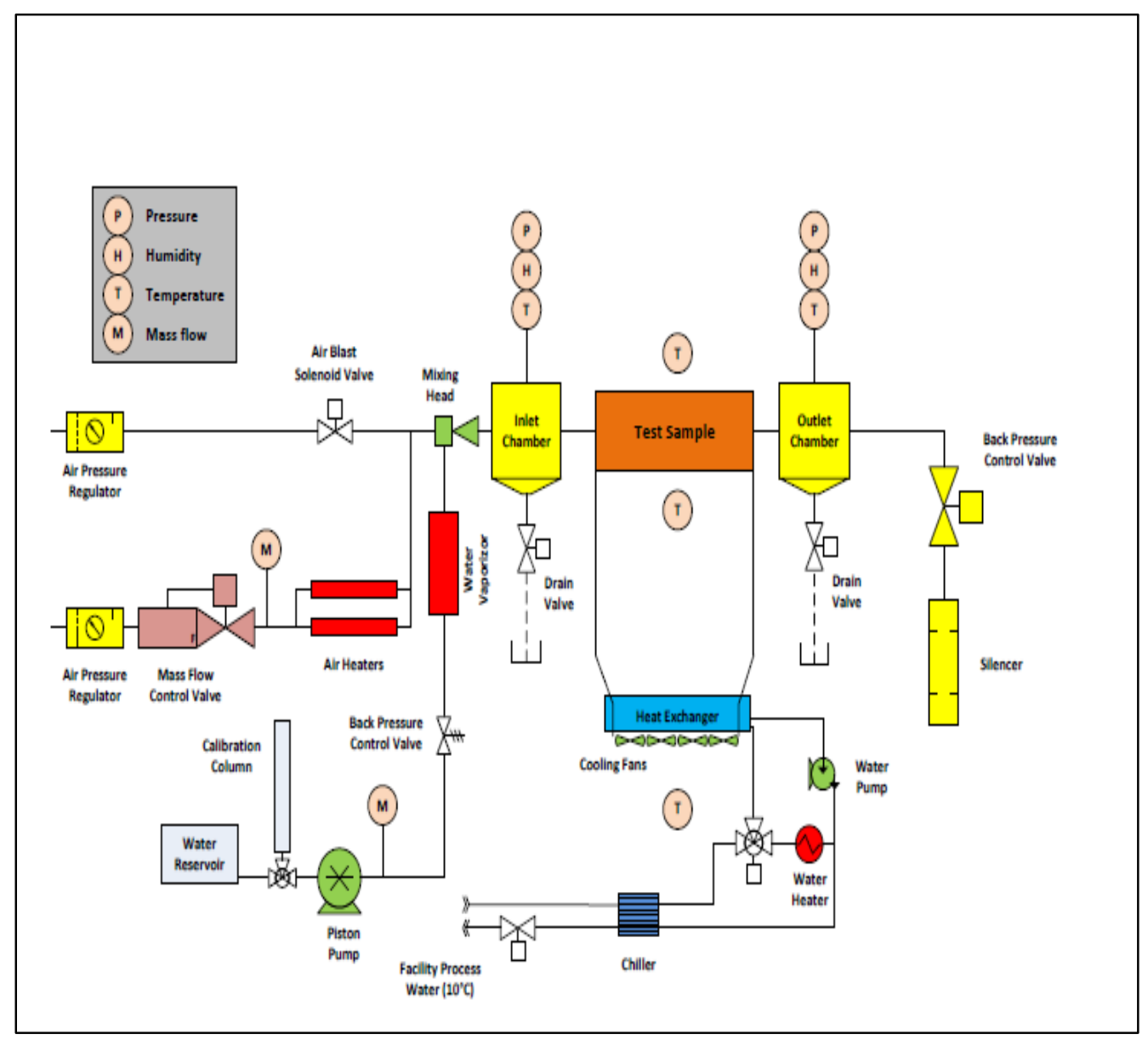

Figure 4.2 - Block diagram of experimental hardware

Reprinted with permission from Ford Motor Company; Internal Report

The CAC test rig was comprised of 100 components, as shown in Table 4.1. 
Table 4.1- Test Rig Build of Material

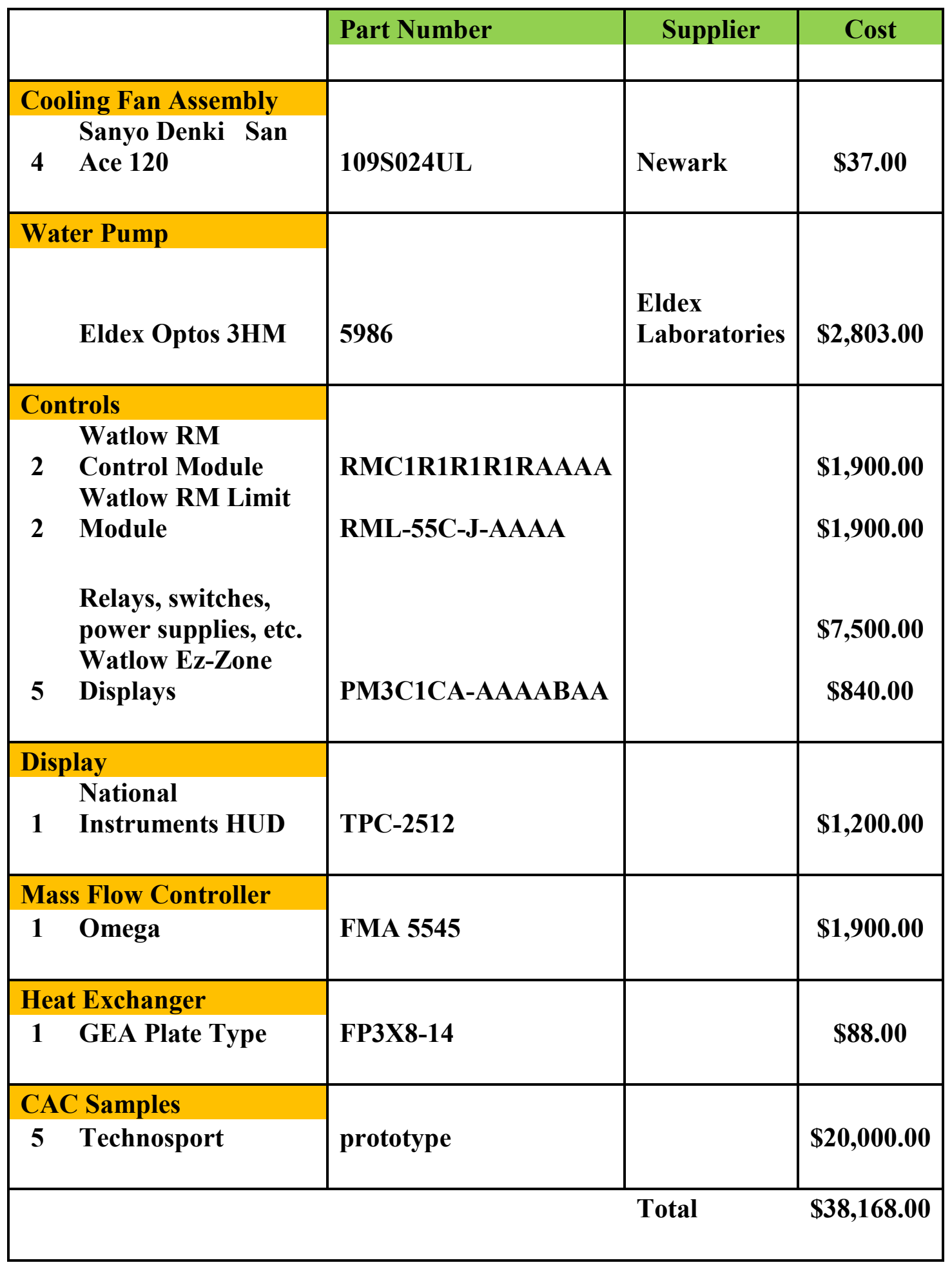


The testing rig's operation limits are defined in Table 4.2. The limits are defined by maximum design temperatures, maximum operational conditions, or lab safety protocol.

Table 4.2: Test Rig Operation Limits

\begin{tabular}{|l|c|}
\hline \multicolumn{1}{|c|}{ Parameter } & $\begin{array}{c}\text { Maximum } \\
\text { Operational Limit }\end{array}$ \\
\hline Inlet Charge Air Temperature $\left({ }^{\circ} \mathrm{C}\right)$ & 80 \\
\hline Pressure $(\mathrm{kPa})$ & 353 \\
\hline Inlet Relative Humidity $(\%)$ & 100 \\
\hline Charge Air Mass Flow Rate $(\mathrm{m} 3 / \mathrm{s})$ & .85 \\
\hline Outlet charge Air Temperature $\left({ }^{\circ} \mathrm{C}\right)$ & 80 \\
\hline
\end{tabular}

The CAC is positioned directly behind the front fascia in the cooling module and in front of the condenser and radiator to extract charge air heat, as shown in Figure 4.3.

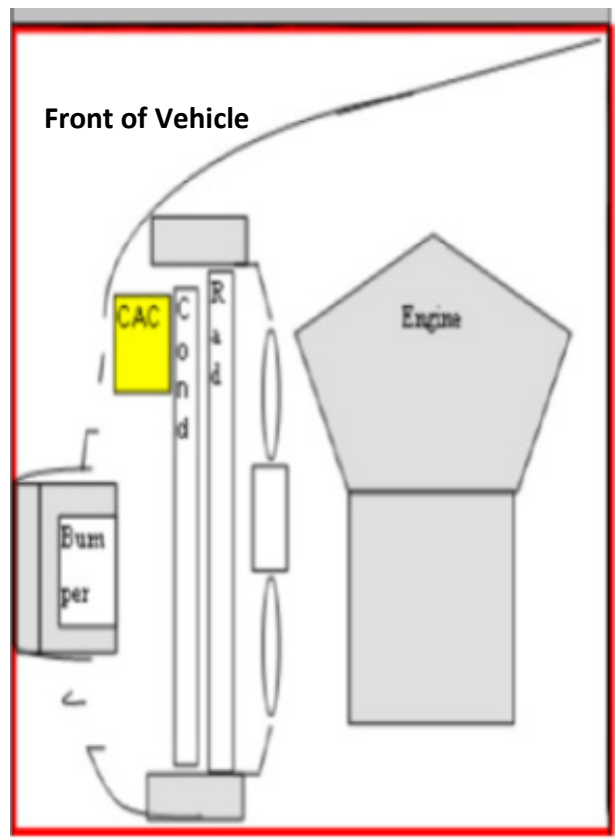

Figure 4.3 - Vehicle Block Diagram of cooling module in vehicle position Reprinted with permission from Ford Motor Company; Internal Report

One CAC tube was instrumented with fourteen 36-gauge thermocouples along the length of the tube, as pictured in Figure 4.4; the thermocouple positions are shown in Figure 4.5 


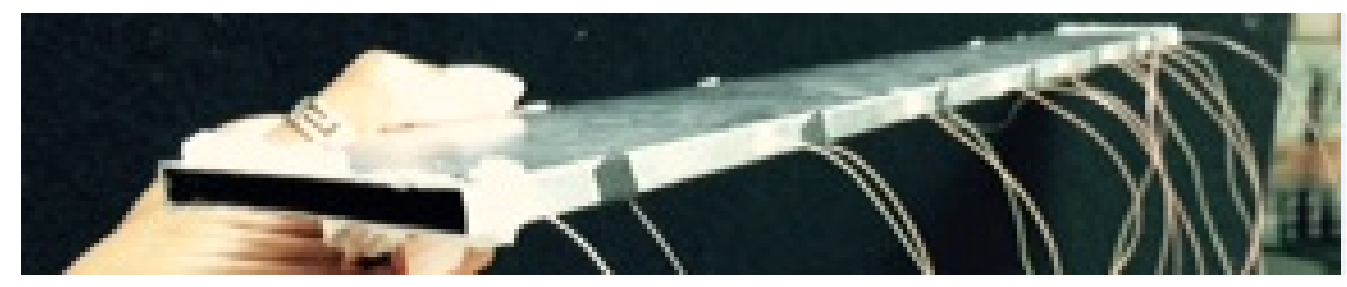

Figure 4.4 - CAC Thermocouple Instrumentation

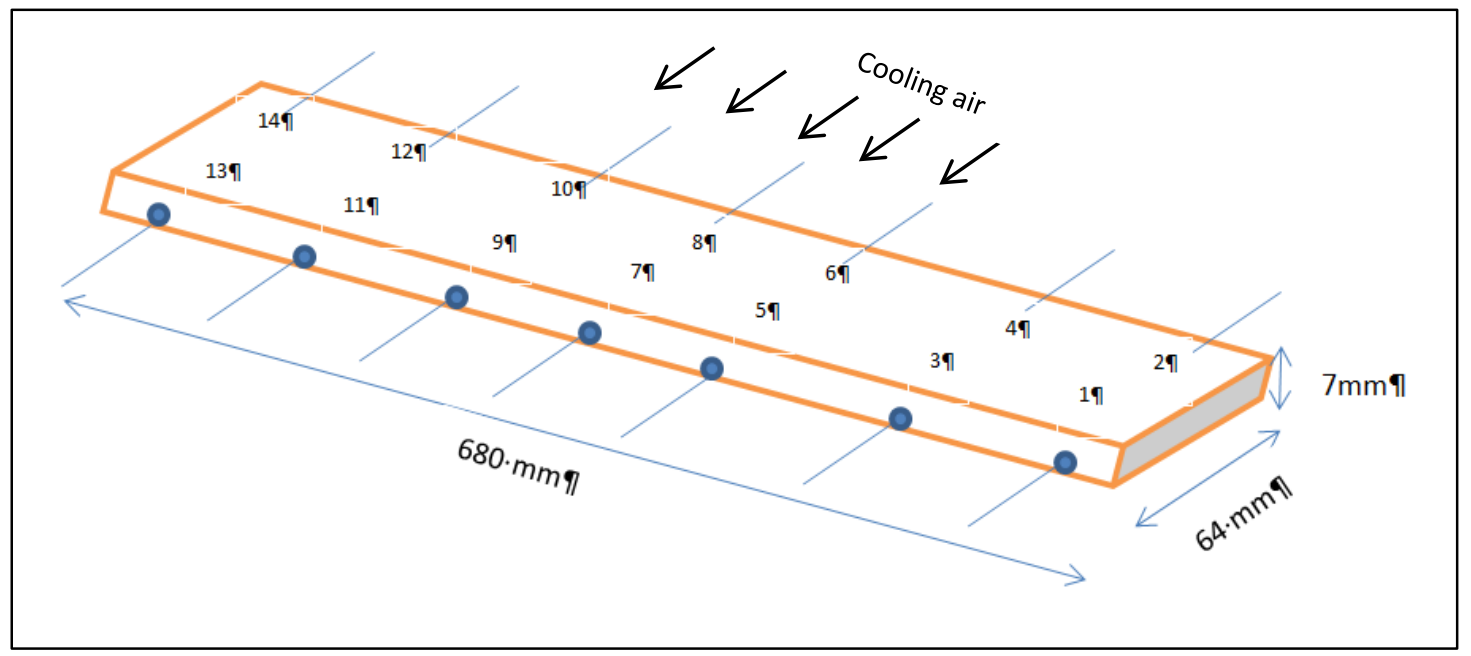

Figure 4.5 - CAC thermocouple locations

The CAC was mounted in a manner that restricted airflow in all tubes except the tube with instrumentation, as pictured in Figure 4.6. The mounted CAC was then attached to the air duct systems that directed cooing air flow in a crossflow pattern, as pictured in Figure 4.7. 


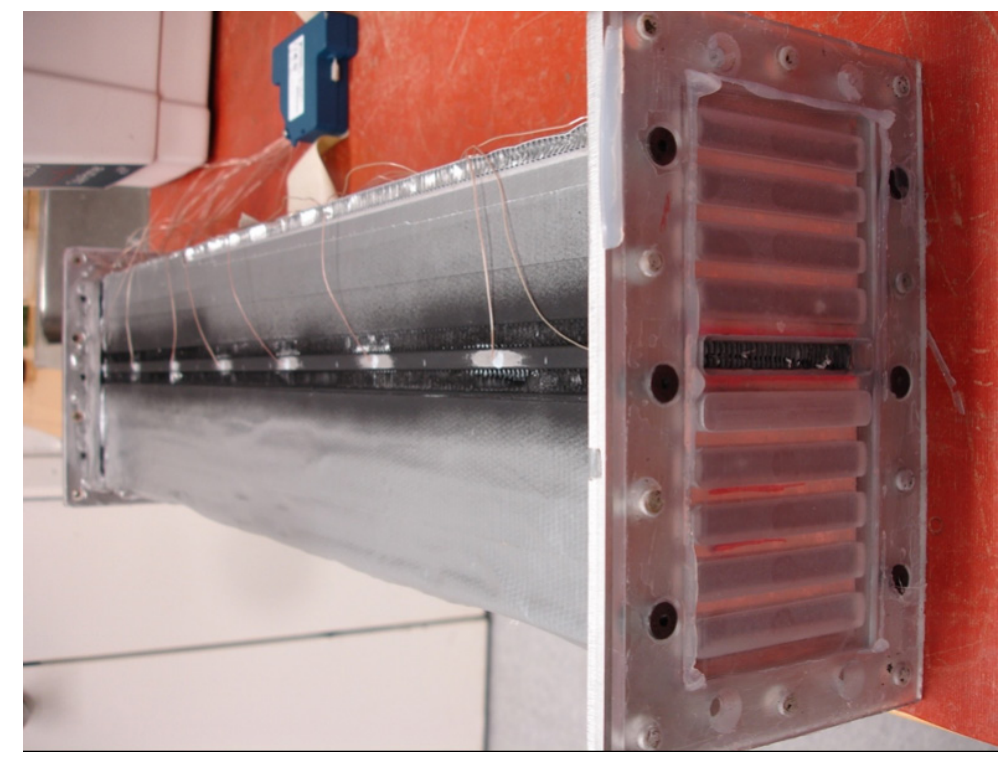

Figure 4.6 - CAC mounted to allow flow through one tube

Reprinted with permission from Ford Motor Company; Internal Report

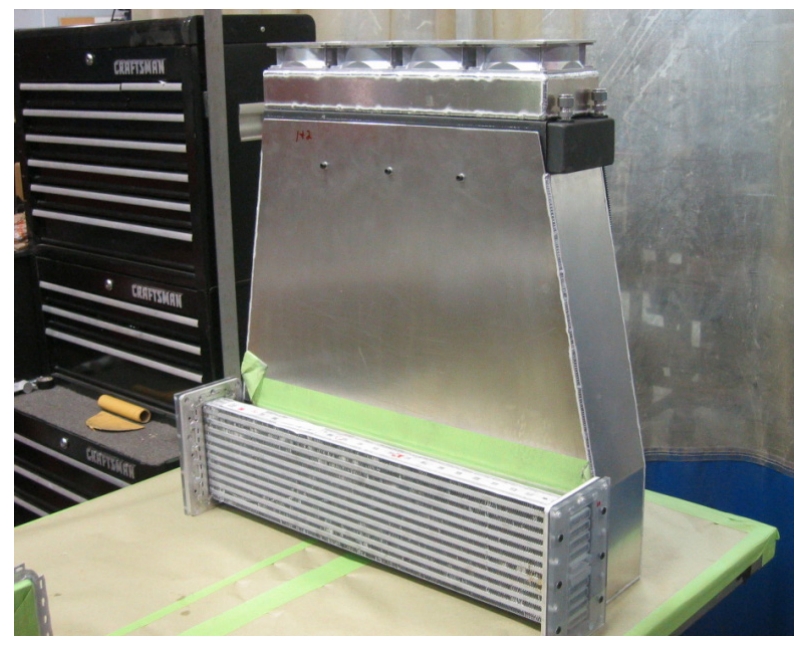

Figure 4.7 - CAC mounted to air duct

Reprinted with permission from Ford Motor Company; Internal Report

Four cooling fans were attached to the top of the air duct and were used to control the mass for rate of the cooling air, as pictured in Figure 4.8. 


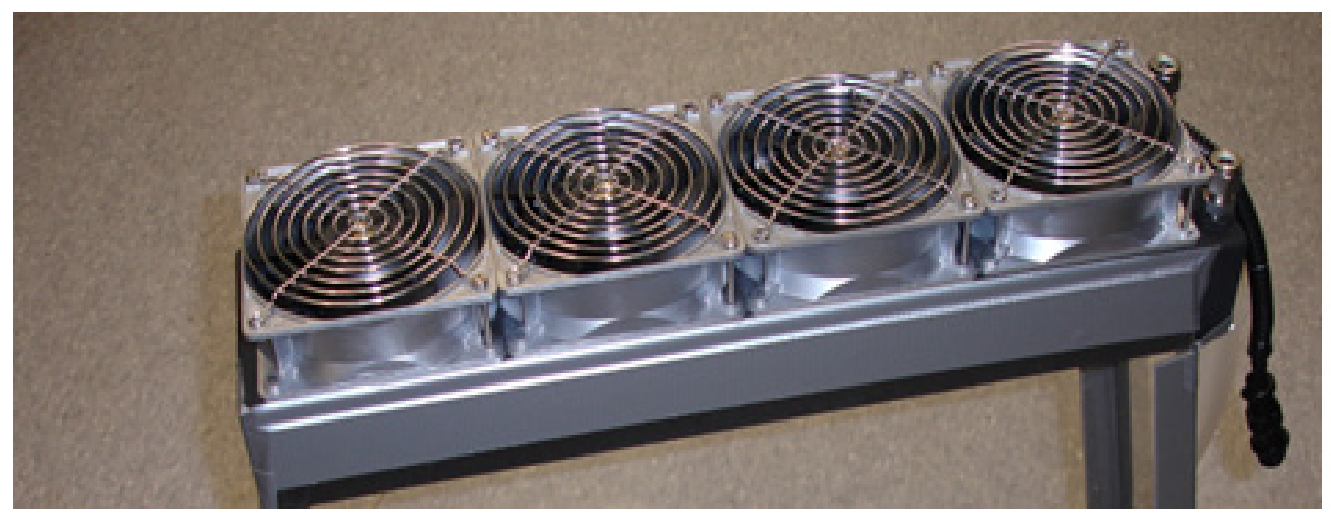

Figure 4.8 - Cooling fans attached to the air duct

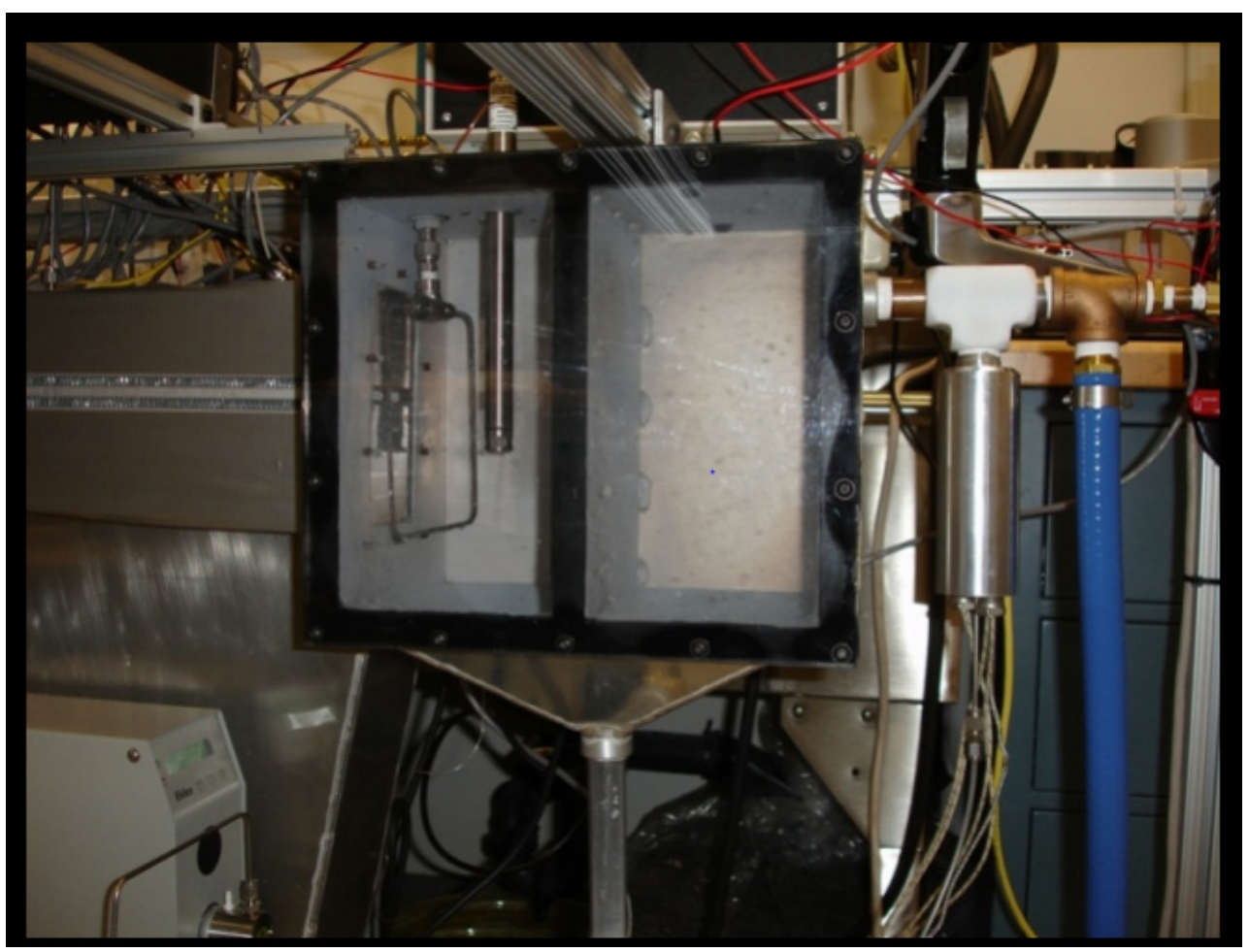

Figure 4.9 - Pressure and velocity instrumentation in air box at charge air let

Figure 4.9 shows the pressure and velocity gauge position inside the air box at the charge air inlet. The remaining components were assembled to replicate the cooling of charge air during vehicle operational modes. Upon completion of the test rig build, the test phase began. 


\section{Test protocol}

The ambient conditions (temperature, pressure, and $\mathrm{RH}$ ) were recorded. The test rig was powered on and the inlet conditions (charge air inlet temperature, pressure, air velocity, and RH) were set. Each test was preceded by a standard baseline. The baseline data was used to determine the consistency of the test data. The cooling rig was run for a period of 60 minutes to achieve steady-state at the baseline condition at a set $\mathrm{RH}$, pressure, temperature, and air velocity. Once the steady-state condition was achieved, the temperature profile was recorded over 60 minutes. After the baseline was established, the appropriate parameter was adjusted and run until it was stabilized (60 minutes) (Wheeler et al. 1996). 


\section{The Computational Scheme}

In this study, in-tube condensation during cooling of charge air is considered, making use of ANSYS ${ }^{\circledR}$ Fluent 15.0, a three-dimensional Computational Fluid Dynamics (CFD) commercial software. The flow field was modeled as incompressible, turbulent flow with conjugate heat transfer. The k-epsilon turbulent model was used with near wall treatment (log law of wall) to resolve turbulence in the small channel. For the pre-processing and after treatment, ANSYS ${ }^{\circledR}$ Geometry Modeler and Meshing utility were used. Postprocessing was done using ANSYS ${ }^{\circledR}$ Workbench report utility.

There were significant advantages of the parallel processing architecture of the Fluent CFD tool, even when dealing with fine grid resolutions. Computational demand for 3-D CFD computation was much larger than what can be managed on a standard desktop, so the Ford high performance computing (HPC) grid with 64 cores per case was used. This reduced the computational time to 12 hours/case instead of an average of 180 hours per case using a personal laptop.

A reasonable approach to simulate this problem by engaging multiple models was taken, which parallels researchers such as Kakimpa (Kakimpa et al. 2010), who used the thinfilm modeling approach to accurately predict and reproduce film thickness with lower computational cost. The researchers modeled the flow as an incompressible Newtonian fluid for which the velocity profiles, film pressure, and temperatures were solved to determine the film flow. In the aforementioned study, the Eulerian thin-film model was successfully paired with the finite volume solution to simulate thin-film over a rotating plate. Al ( $\mathrm{Al}$ et al. 2015) engaged both the Eulerian multiphase and RNG k-epsilon models to investigate flows between a stationary shroud and rotating spiral bevel gear.

In addition to the continuity, momentum and energy equations, the approach followed for this research is listed in Figure 5.1 


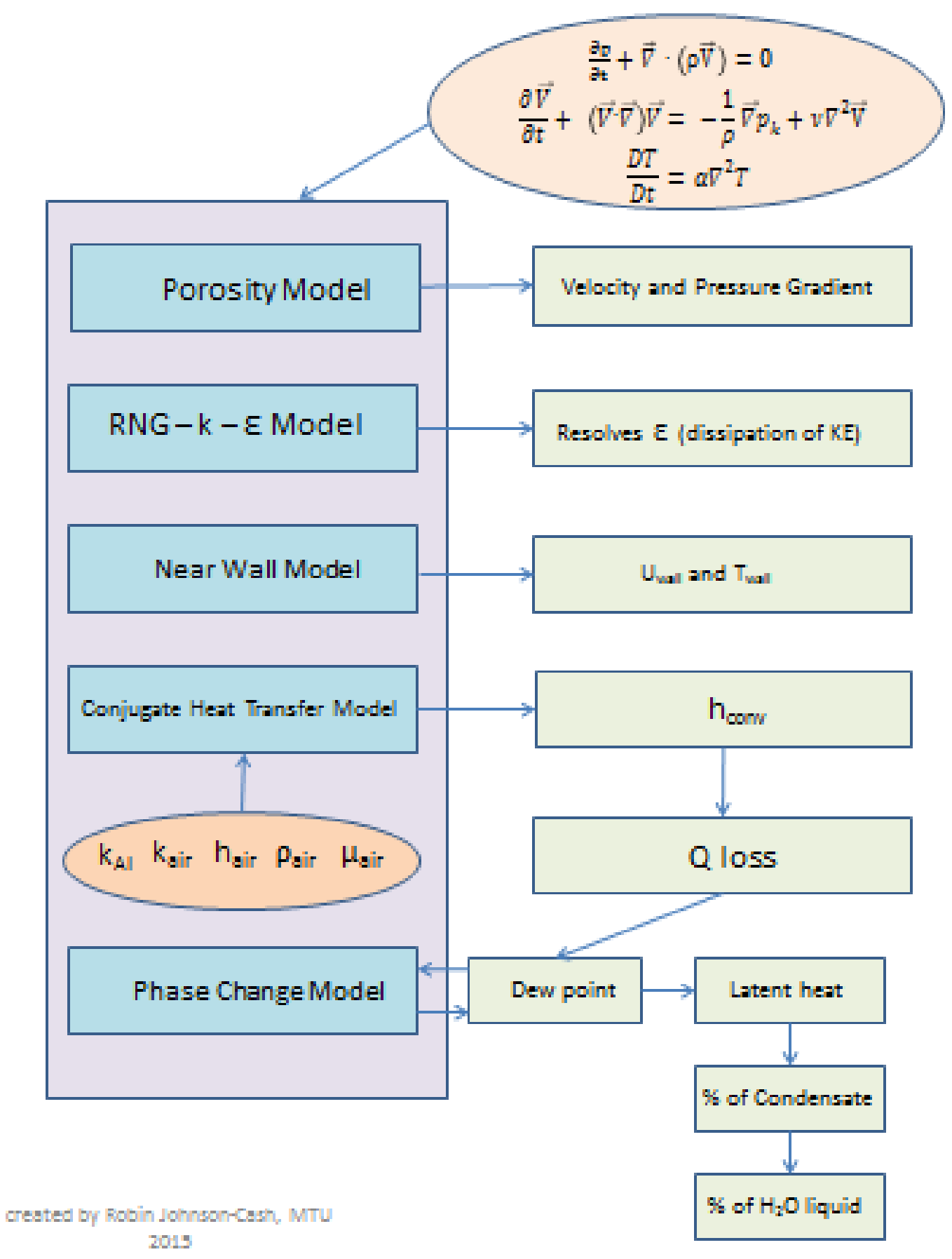

Figure 5.1 - Overview of computational approach 
ANSYS ${ }^{\circledR}$ Fluent includes the necessary models, such as k- $\varepsilon$ turbulent model with near wall treatment, which was crucial for this study. In addition, Fluent can simultaneously use multiple models (conjugate heat transfer and film development due to moisture condensation dominated by the forced convection) and uses all the hardware resources evenly during solving.

Initially, the goal of the CFD study was defined. The objective was two-fold; first, to study the physics of water vapor condensate accumulation in an aluminum tube for different humidity and inlet temperature conditions and secondly, to map the temperature distribution of the fluid in both the $\mathrm{x}$ - and $\mathrm{y}$-directions through the tube. The domain was the singular aluminum tube with pores median to approximate the internal fin structure. The fluid domain was meshed with elevations in the $\mathrm{x}$ - and $\mathrm{y}$-directions.

Additionally, this research sought to accurately predict the amount of water condensate across the length of the tube at any time period of the driving cycle. The Porous and kepsilon RNG model were used to resolve velocity and pressure gradient and dissipation of kinetic energy, respectively. The near wall model (wall film) is used to solve the velocity near the wall. The conjugate heat transfer model is used to include the heat conduction through the wall and the phase change model was used to calculate the mass of the condensate and the thickness of the water film present. The mass of water film and its thickness are two key factors in the design of systems that use compressed air.

CFD simulation results were validated using experimental data. The objective was to develop a new protocol that will aid in CAC tube design that reduces condensate formation during vehicle driving duty cycles.

The CFD simulation model, results, and recommended next steps are included in this chapter. 


\section{Pre-Processing}

\section{$\underline{\text { Geometry }}$}

Initially, the fluid domain (charge air) was created - an extrusion for a singular tube. The aluminum tube with the dimensions $64 \mathrm{~mm}$ wide by $657 \mathrm{~mm}$ long by $7.8 \mathrm{~mm}$ tall of $0.4 \mathrm{~mm}$ thickness was included for this conjugate heat transfer problem. The two bodies were connected to create one domain for consideration. To deal with the variation in the heat flux based on immediate boundary conditions, the model was expanded to include a third domain that represents the cooling air in cross-flow over the aluminum tube, as shown in Figure 5.2. The three domains were connected to create one domain for simulations.

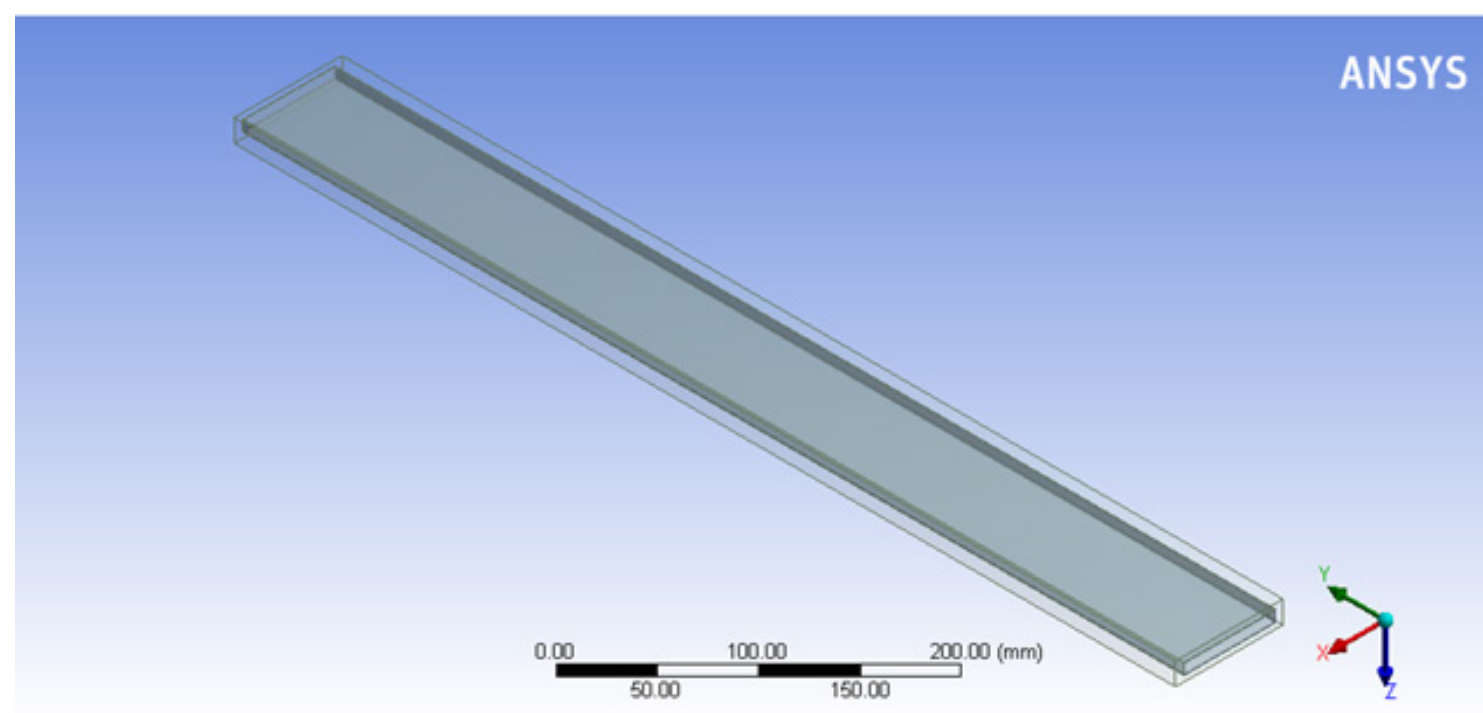

Figure 5.2 - Geometry of 3-dimensional tube with surrounding cooling air region 


\section{Meshing}

Once the geometry was completed, it was determined that the mesh with elevations in the boundary layer, as shown in Figure 5.3, would be used to study the problem. The charge air flows in the positive y-direction and the cooling air flows in the positive x-direction. The solid and fluid domains were discretized using a hexahedral-mesh. A fine mesh was required to ensure wall film solution was obtained. Table 5.1 details the mesh statistics for each case. The solution was based on the fine mesh where a total of 2,040,642 elements were used to discretize the entire domain, including the aluminum tube, charge air (inside the aluminum tube), and external air.

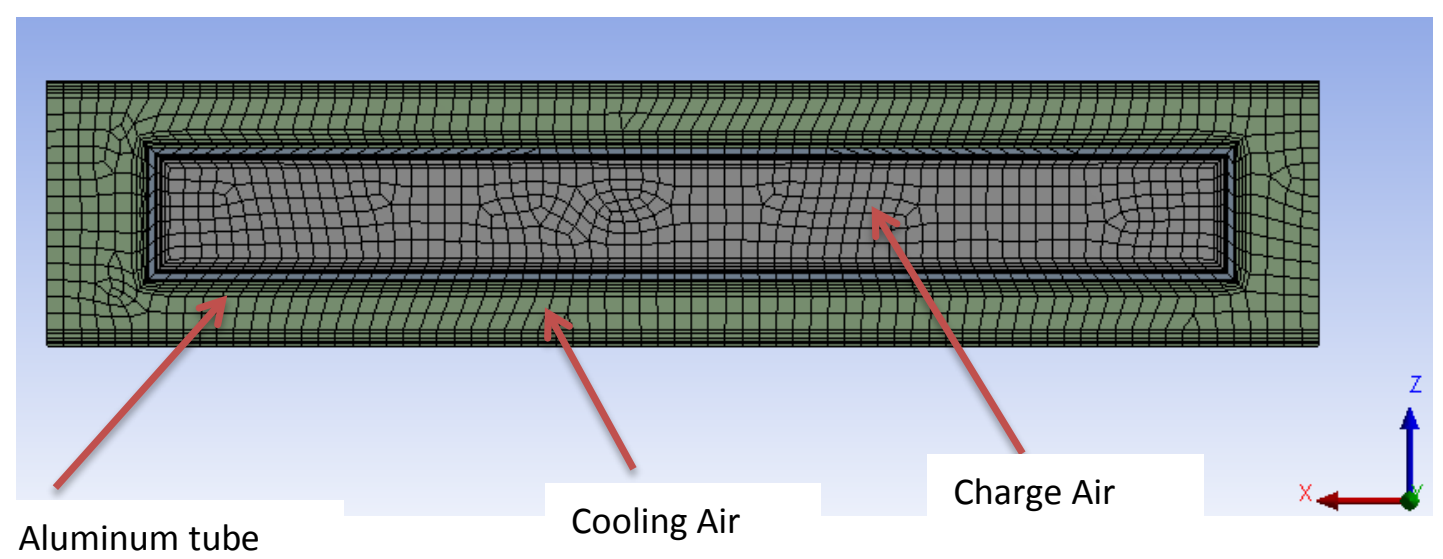

Figure 5.3 - The aluminum tube meshed with the two air flow bodies are connected

Table 5.1: CAC mesh statistics

\begin{tabular}{|l|c|c|c|}
\hline \multicolumn{4}{|c|}{ CAC Mesh Statistics } \\
\hline & $\begin{array}{l}\text { Coarse } \\
\text { Mesh1 }\end{array}$ & Coarse Mesh 2 & Fine Mesh \\
\hline Number of Elements & $\mathbf{9 4 4 , 2 6 7}$ & $1,367,808$ & $\mathbf{2 , 0 4 0 , 6 4 2}$ \\
\hline \multicolumn{1}{|c|}{ Number of Nodes } & 978,267 & $1,414,773$ & $\mathbf{2 , 1 0 6 , 2 5 8}$ \\
\hline \multicolumn{1}{|c|}{ Computation Time } & $2: 31$ & $5: 03$ & $54: 39$ \\
\hline $\begin{array}{l}\text { Maximum Inflation } \\
\text { Layers }\end{array}$ & 5 & 5 & 5 \\
\hline
\end{tabular}


The CFD solver worked better with the hexahedral mesh, so the majority of the mesh was created with hexahedral cells. The boundary layer was measured in micrometers due to the small cross-sectional area of the CAC tube. To partially resolve the boundary layer, a five-layer inflation was added in the mesh with growth rate of 1.2 for each additional layer. (The subsequent layer was 1.2 times the cell height compared to the previous layer.) The maximum cell size was $1 \mathrm{~mm}$ and the minimum face width was $0.0965 \mathrm{~mm}$, with a total of 2,040,642 elements.

\section{$\underline{\text { Boundary Conditions }}$}

The required boundaries conditions were defined to run the solution. The initial temperatures and velocity of the charge air and cooling air were known. However, for the range of charge air velocities, the Reynolds number was calculated to determine if the flow regimen was laminar of turbulent.

\section{Assumptions}

$$
\begin{aligned}
& \mathrm{T}=20^{\circ} \mathrm{C} \text { and } \mathrm{P}=101.325 \mathrm{kPA} ; \rho_{\text {air }}=1.2041 \mathrm{~kg} / \mathrm{m} 3 \text {, and } \nu_{\text {air }}=15.11 \times 10^{-6} \mathrm{~m}^{2} / \mathrm{s} \\
& \operatorname{Re}=\frac{\rho V D}{v}, \text { where } \mathrm{D} \text { (Hydraulic diameter) is } \mathrm{D}_{\mathrm{h}}=\frac{2 a b}{a+b}
\end{aligned}
$$

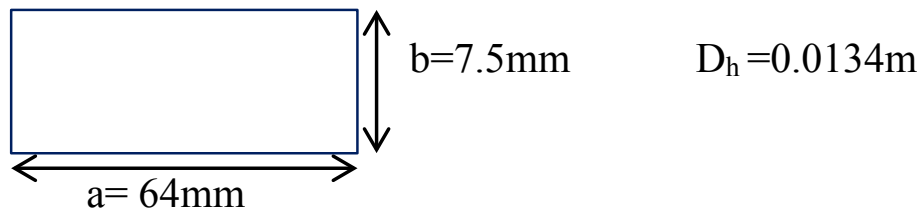

The vehicle driving duty cycle defined the charge air velocity range of $4 \mathrm{~m} / \mathrm{s}$ to $12 \mathrm{~m} / \mathrm{s}$.

$\operatorname{Re}_{\text {low }}=\frac{(4 \mathrm{~m} / \mathrm{s})(0.0134 \mathrm{~m})}{0.00001511 \mathrm{~m} 2 / \mathrm{s}}=3,547.32 \quad \operatorname{Re}_{\mathrm{high}}=\frac{(12 \mathrm{~m} / \mathrm{s})(0.0134 \mathrm{~m})}{0.00001511 \mathrm{~m} 2 / \mathrm{s}}=10,663.06$

Since the full range of the Reynold's number $\operatorname{Re}>2000$, then the flow was turbulent.

The boundary conditions were then considered for a single tube. The charged inlet and outlet air were set. The cooling air temperature varied but was known. Inlet and outlet pressure were set. The velocity of both the charge and cooling air were known. The heat 
transfer coefficient was dependent upon the ambient cooling air temperature and the ambient relative humidity. Table 5.2 details the baseline computation and experimental boundary conditions.

Table 5.2:CAC computational boundary conditions

\begin{tabular}{|l|c|}
\hline \multicolumn{1}{|c|}{ Boundary Condition } & Value \\
\hline Inlet Charge Air Temp & $55^{\circ} \mathrm{C}$ \\
\hline Outlet Charge Air Temp & $24.7^{\circ} \mathrm{C}$ \\
\hline $\begin{array}{l}\text { Inlet Charge Air Relative } \\
\text { Humidity }\end{array}$ & $29 \%$ \\
\hline Ambient Relative Humidity & $50 \%$ \\
\hline Inlet Charge Air Velocity & $10 \mathrm{~m} / \mathrm{s}$ \\
\hline
\end{tabular}

The models used in this simulation included:

\section{Pores Median Model}

It was difficult to create a 3D model of the charged air cooler including fins. Also, if the model were made with fins, it led to the problem of meshing the boundary layer for each fin surface. This added to the computational load and consumed valuable computational time. To model the fins in ANSYS Fluent, passages of the charged air cooler were assumed to be coarsely porous. For this assumption, the distance between two fins was measured and used with the sheet metal thickness to calculate the porosity of the charged air cooler. The porous media model increased the total pressure gradient and provided virtual surface area.

$$
\begin{aligned}
& \Delta p=\frac{1}{2} f \rho_{m} U_{A_{\min }}^{2} \quad \text { pressure drop } \\
& f=\left(K_{c}+1-\sigma^{2}\right)-\left(1-\sigma^{2}-K_{e}\right) \frac{v_{e}}{v_{i}}+2\left(\frac{v_{e}}{v_{i}}-1\right)+f_{c} \frac{A}{A_{c}} \frac{v_{m}}{v_{i}}
\end{aligned}
$$


Definitions of factors are:

$\Delta p=$ streamwise pressure drop

$f=$ streamwise pressure loss coefficient

$\rho_{m}=$ mean primary fluid density

$U_{A_{\min }}=$ primary fluid velocity at the minimum flow area

$\sigma=$ minimum flow to face area ratio

$K_{c}=$ entrance loss coefficient

$K_{e}=$ exit loss coefficient

$A=$ primary fluid-side surface area

$A_{c}=$ minimum cross-sectional flow area

$f_{c}=$ core friction factor

$v_{e}=$ specific volume at the exit

$v_{i}=$ specific volume at the inlet

$\Delta p=$ mean specific volume $\equiv \frac{1}{2}\left(v_{e}+v_{i}\right)$

$K_{c}$ and $K_{e}$ are obtained from experimental data.

$f_{c}=a R e_{\min }^{b}$

$a=$ core friction coefficient

$b=$ core friction exponent

$R e_{\min }=$ Reynolds number for velocity at the minimum flow area

$R e_{\min }=\frac{\rho_{m} U_{A_{\min }} D_{h}}{\mu_{m}}$ 
$\rho_{m}=$ mean primary fluid density

$\mu_{m}=$ mean primary fluid viscosity

$D_{h}=$ hydraulic diameter

$U_{A_{\min }}=$ primary fluid velocity at the minimum flow area

$U_{A_{\text {min }}}=\frac{U}{\sigma}$

For a heat exchanger core, the hydraulic diameter can be defined as

$D_{h}=4 L\left(\frac{A_{c}}{A}\right)$

L represents the flow length of the heat exchanger. If the tubes are normal to the primary fluid flow, then $\mathrm{L}$ is the length in the primary fluid flow direction. $\mathrm{U}$ is the mean fluid velocity and $\sigma$ is the minimum flow-to-face area ratio as described by Kays (Kays and London 1984). The fin geometry pictured in Figure 5.4 was taken from the subject reference guide, which was incorporated in the CAC design by the manufacturer and was used to calculate the porosity factor for simulation.

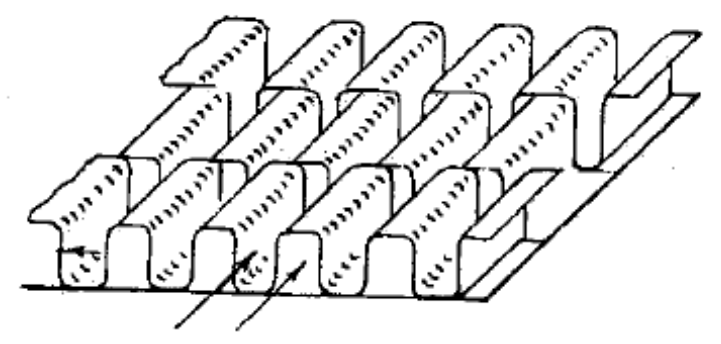

Figure 5.4 - CAC fin cross-area at opening geometry used for porosity calculation

The porosity value for fin geometry was calculated as follows:

$$
\text { Porosity }(P)=\frac{\text { Void Space }}{\text { Total Space }}=\frac{\text { Area cell }=a^{2}}{\text { Area cell }}=.8
$$


The porous media assumption helped to calculate the pressure drop without using extra geometrical features.

\section{Turbulence Model (k-epsilon $\varepsilon$ Re-Normalization Group RNG)}

The CAC was composed of a stack of tubes with a cross-section of $2 \mathrm{~mm} \times 64 \mathrm{~mm}$. Each tube was separated by the same cross-sectional area, which was the passageway for the crossflow cooling air. Both passages for the charged air and the cooling air were also fitted with the fins of wavelength $1.5 \mathrm{~mm}$ across the entire length of the charged air cooler. The objective of the 3-D CFD simulation was to determine the amount of condensate and to identify the timing of the dew point occurrence using transient treatment.

The CAC tube had fins which had a $2.5 \mathrm{~mm}$ x $64 \mathrm{~mm}$ cross-section and had fins inside which were $1.5 \mathrm{~mm}$ apart. Due to the closely spaced structure of the CAC tube, epsilon (dissipation term of the turbulence modelling) was difficult to resolve in the near wall region and could not be used.

The k-epsilon $(\varepsilon)$ RNG model was a good fit because it worked well with the enhanced near wall treatment. RNG k-epsilon model had the extra R-epsilon term in the epsilon equation, which improved the accuracy for rapidly strained flows. In rapidly strained flows, the RNG model yielded a lower turbulent viscosity than the standard - model. RNG theory provided analytical formula for the turbulent Prandtl number, where the standard k-epsilon model uses constant values which make it difficult to resolve turbulent dissipation term near wall.

$$
\begin{aligned}
& \frac{\partial}{\partial t}(\rho k)+\frac{\partial}{\partial x_{i}}\left(\rho k u_{i}\right)=\frac{\partial}{\partial x_{j}}\left(\alpha_{k} \mu_{e f f} \frac{\partial k}{\partial x_{j}}\right)+G_{k}+G_{b}-\rho \varepsilon-Y_{M}+S_{k} \\
& \frac{\partial}{\partial t}(\rho \varepsilon)+\frac{\partial}{\partial x_{i}}\left(\rho \varepsilon u_{i}\right)=\frac{\partial}{\partial x_{j}}\left(\alpha_{\varepsilon} \mu_{e f f} \frac{\partial \varepsilon}{\partial x_{j}}\right)+C_{1 \varepsilon} \frac{\varepsilon}{k}\left(G_{k}+C_{3 \varepsilon} G_{b}\right)-C_{2 \varepsilon} \rho \frac{\varepsilon^{2}}{k}-R_{\varepsilon}+S_{\varepsilon}
\end{aligned}
$$

$G_{k}$ represents the generation of turbulence kinetic energy due to the mean velocity Gradients.

$G_{b}$ is the generation of turbulence kinetic energy due to buoyancy. 
The quantities $\alpha_{k}$ and $\alpha_{\varepsilon}$ are the inverse effective Prandtl numbers for $k$ and $\varepsilon$, respectively. $S_{k}$ and $S_{\varepsilon}$ are user-defined.

$C_{1 \varepsilon}=1.42$

$C_{2 \varepsilon}=1.68$

$R_{\varepsilon}=\frac{C \mu \rho \eta^{3}\left(\frac{1-\eta}{\eta_{0}}\right)}{1+\beta \eta^{3}} \frac{\varepsilon^{2}}{k}$

where $\eta \equiv \frac{S k}{\varepsilon}, \eta_{0}=4.38, \beta=0.012$

RNG theory provides differential formulation for effective viscosity for low Reynolds and is dependent on near wall treatment.

\section{Near wall treatment}

Turbulent flow was significantly affected by the presence of a wall. In addition, the mean velocity field was affected through the no-slip condition that had to be satisfied at the wall. Prandtl postulated that at a high Reynolds number, there is an inner layer close to the wall in which the mean velocity profile is determined by the viscous scales, (Pope 2000).

Currently, Fluent does not handle condensation without a user-defined function (UDF) to resolve diffusion of the wall film. Consequently, the author developed a unique UDF that allowed the case to be solved. Fluent makes use of the near wall law to evaluate the velocity in the region close to the wall. The near wall equation used by ANAYS has the following form:

The law-of-wall for mean velocity yeilds

$U^{*}=\frac{1}{k} \ln \left(E y^{*}\right) \quad$ where

$U^{*}=\frac{U_{p} C_{\mu}^{1 / 4} k_{p}^{1 / 2}}{\tau_{w} / \rho}$ is the dimensionless velocity 
$y^{*}=\frac{\rho c_{\mu}^{1 / 4} k_{p}^{1 / 2} y_{p}}{\mu}$ is the dimensionless distance from the wall

and

$\kappa=$ von Kármán constant $(=0.4187)$

$\mathrm{E}=$ empirical constant $(=9.793)$

$U_{p}=$ mean velocity of the fluid at the wall-adjacent cell centroid.

$k_{p}=$ turbulent kinetic energy at the wall-adjacent cell centroid.

$y_{p}=$ distance from the centroid of the wall-adjacent cell to the wall.

$\mu=$ dynamic viscosity of the fluid.

\section{Conjugate Heat Transfer Model}

In solid regions, the energy transport equation used by ANSYS ${ }^{\circledR}$ Fluent has the following form:

$$
\begin{aligned}
& \frac{\partial}{\partial t}(\rho h)+\nabla \cdot(\vec{v} \rho h)=\nabla \cdot(k \nabla T)+S_{h} \\
& \rho=\text { density } \\
& h=\text { sensible enthalpy, } \int_{T_{-} r e f}^{T} c_{p} d T \\
& k=\text { conductivity } \\
& T=\text { temperature } \\
& S_{h}=\text { volumetric heat source }
\end{aligned}
$$

This research presents a reasonable approach to simulating this problem by using the foundational system of governing equations coupled with multiple models to simulate the 
wall film and temperature distribution across the horizontal tube of the CAC. This approach focuses heavily on the boundary layer close to the wall. Future work on modelling the condensation formation and temperature distributions would include use of the large eddy simulation (LES) model to resolve all boundary layers.

\section{Condensation Model}

The Lee model (Lee 1979) calculated the interfacial heat transfer coefficients and, hence, liquid-vapor mass transfer which is governed by the following vapor transport equations:

$\frac{\partial}{\partial t}\left(\alpha_{v} \rho_{v}\right)+\nabla \cdot\left(\alpha_{v} \rho_{v} \overrightarrow{V_{v}}\right)=\dot{m_{l v}}-\dot{m_{v l}}$

where

$\mathrm{v}=$ vapor phase

$\alpha_{v}=$ vapor volume fraction

$\rho_{v}=$ vapor density

$\overrightarrow{V_{v}}=$ vapor phase velocity

$m_{l v}, m_{v l}=$ the rates of mass transfer due to evaporation and condensation, respectively.

The comparison between the saturation temperature and the actual local temperature is checked using the following equations:

If $T_{l}>T_{\text {sat }}$ (evaporation)

$\dot{m}_{l v}=\operatorname{coeff} \cdot \alpha_{l} \rho_{l} \frac{\left(T_{l}-T_{s a t}\right)}{T_{s a t}}$

If $T_{v}<T_{s a t}$ (condensation)

$\dot{m}_{v l}=\operatorname{coeff} \cdot \alpha_{v} \rho_{v} \frac{\left(T_{s a t}-T_{v}\right)}{T_{s a t}}$ 
If the local temperature is less than saturation temperature, the condensation equation calculates the mass of vapor which is converted into liquid. If the local temperature is greater than the saturation temperature, the evaporation equation calculates the mass of liquid which is converted to vapor. These values are plugged into the vapor transport equation above. 


\section{Experimental Results}

This section describes the primary objectives of this research:

1. Define the test plan of action.

2. Verify that the collected test data were robust and in control.

3. Determine the amount of time required by the experiment to reach steady-state, which required the determination of the time constant $(\tau)$.

4. Define a steady-state range of operation that will be compared to the simulation data.

The test procedure was specifically designed to evaluate the temperature distribution and condensation formation inside a CAC tube at various vehicle representative loads when subjected to variable inlet relative humidity $(\mathrm{RH})$. A test rig was built to isolate a singular tube and send a controlled amount to compressed air at a specified temperature and velocity through the subject tube. The cooling rig pictured in Figure 6.1 was constructed to collect this data. 


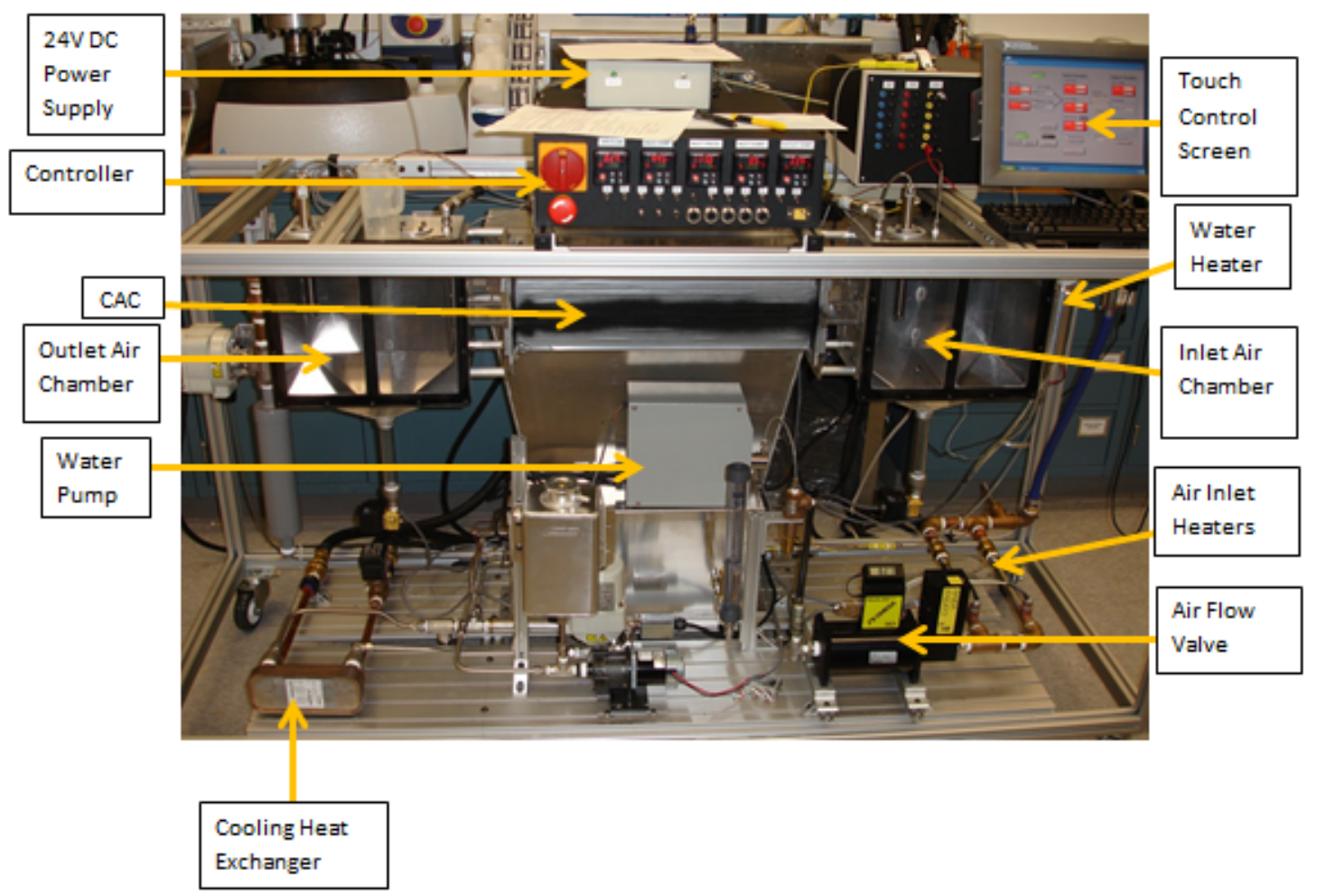

Figure 6.1 - Cooling test rig experimental setup

Reprinted with permission from Ford Motor Company; Internal Report

Velocities $8 \mathrm{~m} / \mathrm{s}, 10 \mathrm{~m} / \mathrm{s}$, and $12 \mathrm{~m} / \mathrm{s}$ were most common in the CAC for vehicle crusing speeds between $55 \mathrm{miles} / \mathrm{hr}$ to $70 \mathrm{miles} / \mathrm{hr}$, where condensate formation led to error states. These cases were investigated for different relative humidities. The outlet temperature of the turbocharger provided constant air temperature at $55^{\circ} \mathrm{C}$; therefore, the $\mathrm{CAC}$ inlet condition was maintained constant at $55^{\circ} \mathrm{C}$ for all cases. In addition, the engine inlet temperature requirement was approximately $25^{\circ} \mathrm{C}$, so the outlet temperature of the CAC tube was maintained at a constant $25^{\circ} \mathrm{C}$. Table 6.1 summarizes the boundary conditions that were run. 
Table 6.1:Test Boundary Conditions

\begin{tabular}{|c|c|}
\hline Boundary Condition & Value \\
\hline Inlet charge air temp & $55^{\circ} \mathrm{C}$ \\
\hline Outlet charge air temp & $24.7^{\circ} \mathrm{C}$ \\
\hline $\begin{array}{l}\text { Inlet charge air relative } \\
\text { humidity }\end{array}$ & $\begin{array}{c}29 \%, 40 \% \\
50 \%\end{array}$ \\
\hline $\begin{array}{l}\text { Ambient relative } \\
\text { humidity }\end{array}$ & $50 \%$ \\
\hline Inlet charge air velocity & $\begin{array}{c}8 \mathrm{~m} / \mathrm{s}, 10 \mathrm{~m} / \mathrm{s}, \\
12 \mathrm{~m} / \mathrm{s}\end{array}$ \\
\hline
\end{tabular}

The test cases listed in Table 6.2 were investigated for different levels of relative humidity.

Table 6.2:Experimental test cases

\begin{tabular}{|c|c|c|c|}
\hline $\begin{array}{c}\text { Velocitycin } \\
\text { m/sec }\end{array}$ & $\begin{array}{c}\text { TempcC } \\
\text { in }{ }^{\circ} \mathrm{C}\end{array}$ & $\begin{array}{c}\text { RHCC } \\
\text { in } \%\end{array}$ & $\begin{array}{c}\text { TempC } \\
\text { out }^{\circ} \mathrm{C}\end{array}$ \\
\hline 10 & 55 & 30 & 25 \\
\hline 10 & 55 & 40 & 25 \\
\hline 10 & 55 & 50 & 25 \\
\hline 12 & 55 & 30 & 25 \\
\hline 12 & 55 & 40 & 25 \\
\hline 12 & 55 & 50 & 25 \\
\hline 8 & 55 & 30 & 25 \\
\hline
\end{tabular}

\section{Procedure}

The ambient lab conditions were recorded and the test rig was powered on. The baseline condition was the initial condition run during testing. The baseline boundary conditions were input and the data acquisition system was activated. The baseline condition was run for 90 minutes to achieve steady-state. This allowed for 60 minutes of recording of steady-state data. The data acquisition system was switched off. A new test condition 
was loaded, new boundary conditions were set, and the data acquisition system was turned on. Ressler (Ressler et al. 2003) indicates that $\tau$ provides a measure of a system's rate of response to input. Furthermore, $\tau$ represents the time required by the experimental system to reach $63.2 \%$ of the steady-state value relative to its initial value. The time constant to steady-state is given by:

$\mathrm{T}(\mathrm{t})=\mathrm{T}_{\mathrm{ss}}+\left(\mathrm{T}_{\mathrm{o}}-\mathrm{T}_{\mathrm{ss}}\right) \mathrm{e}^{-\mathrm{t} / \mathrm{\tau}}$

Where $\mathrm{T}(\mathrm{t})=$ temperature at time $\mathrm{t}$

$$
\begin{aligned}
& \mathrm{TH}_{\text {ss }}=\text { temperature at steady-state } \\
& \mathrm{T}_{\mathrm{o}}=\text { temperature at time initial } \\
& \tau=\text { time constant }
\end{aligned}
$$

Determining the steady-state region of the test was necessary because this data will be correlated to the simulation results. The cooling test rig was comprised of several electronically controlled mechanical components that resulted in a system control system response delay. There was a transient region followed by the steady-state region. The determination of thermal time constant $(\tau)$ was resolved to identify the steady-state region of the experimental test data. A confidence interval was then determined for the normalized mean temperature across the CAC tube to assert a level of control over the experiment. 


\section{Data and Results}

\section{$\underline{\text { Identification of } \tau}$}

The baseline condition of $10 \mathrm{~m} / \mathrm{s}, 30 \% \mathrm{RH}$, and $55^{\circ} \mathrm{C}$ required charge air inlet temperature were used to determine the time constant of the cooling rig. The $\tau$ was based upon the time to achieve steady-state for charge air inlet temperature; $\tau$ equaled 40 minutes. Figure 6.2 illustrates the measured to actual temperature in non-dimensional time, $t / \tau$.

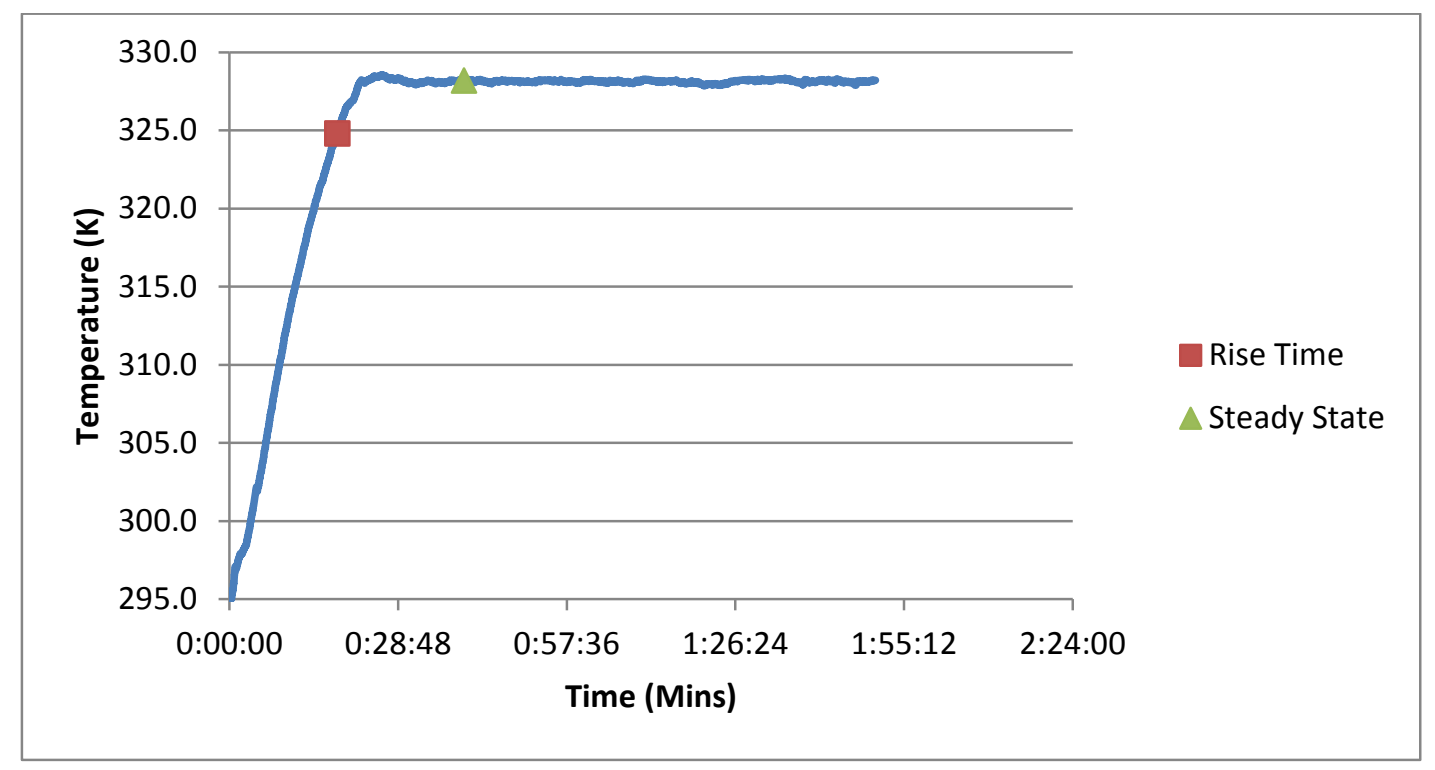

Figure 6.2 - Charge air inlet temperature from start to end of test cycle

Figure 6.3 depicts a normalized plot of the RH (end-point divided by the difference of the max-min values), which illustrates the range in which steady-state was reached. 


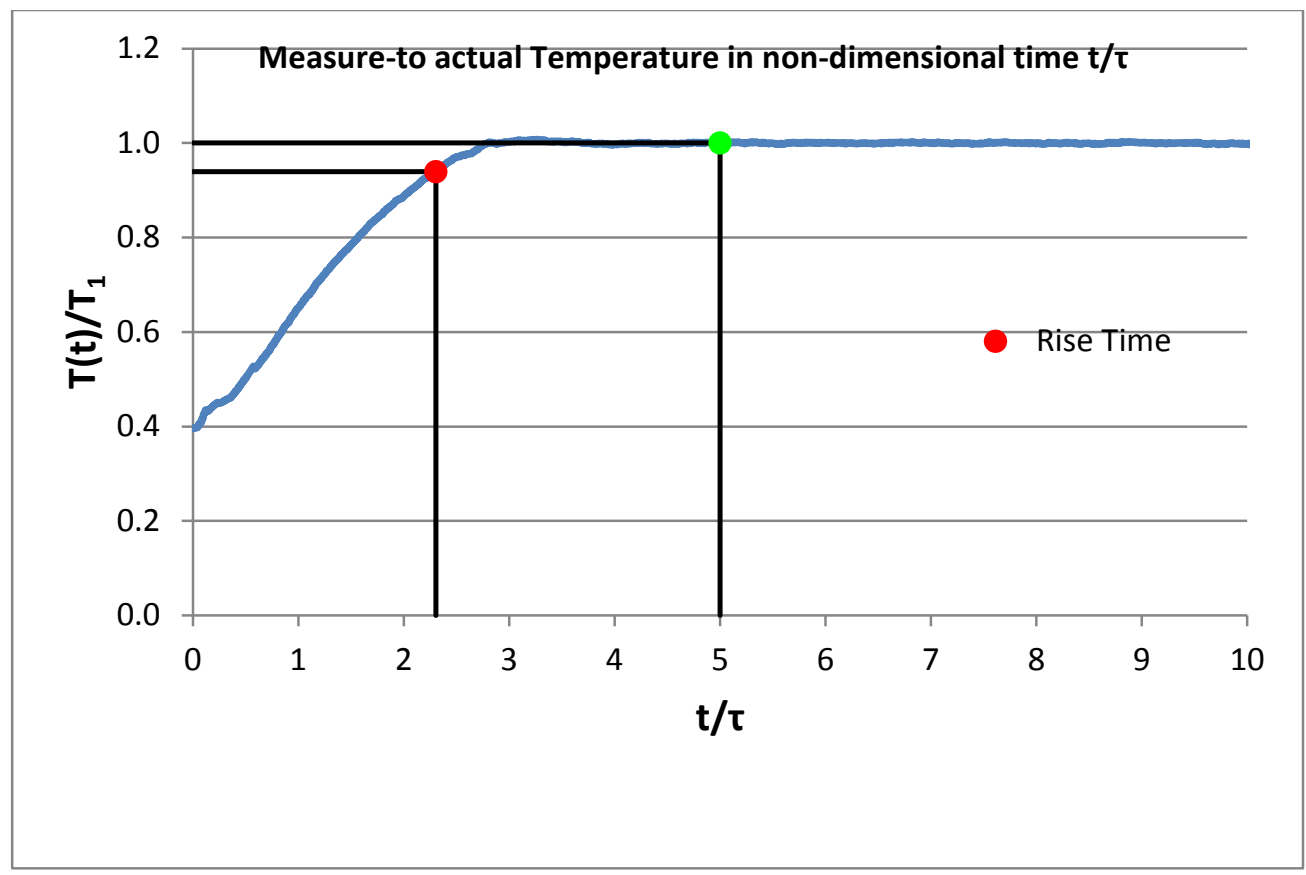

Figure 6.3 - Measure-to actual Temperature in non-dimensional time $t / \tau$

Using Equation 6.1, $\tau$ is calculated to equal 40.03 minutes. The steady-state time interval of 40 to 80 minutes was therefore chosen for simulation correlation.

$e^{-\frac{t}{\tau}}=\ln \frac{T_{t}-T_{S S}}{T_{o}-T_{S S}} \quad \tau=40.03$ minutes.

\section{Validation of Robustness}

Table 6.3 shows the mean temperatures for eight thermocouples placed along the length of the CAC tube for the designated steady-state interval of 40 minutes to 80 minutes. Evaluation of the mean thermocouple data within the identified steady-state region of 40 to 80 minutes fell within 2.5 deviations of the respective mean values, as illustrated in Table 6.3. 
Table 6.3: Mean temperature thermal couples Temperature of specified thermal couples during steady-state region (40 minutes -80 minutes)

\begin{tabular}{|l|l|l|l|}
\hline \multicolumn{1}{|c|}{ TC } & Mean Temp (K) & $\begin{array}{c}\text { Normalized mean Temp } \\
\left(\mathbf{T} \text { mean } / \mathbf{T}_{\text {ambient }}\right.\end{array}$ & \multicolumn{1}{|c|}{$\begin{array}{c}\text { Standard } \\
\text { Deviation }\end{array}$} \\
\hline 2 & 296.7 & 1.00 & 0.0047 \\
\hline 3 & 299.0 & 1.01 & 0.0039 \\
\hline 6 & 298.8 & 1.01 & 0.0055 \\
\hline 7 & 303.9 & 1.03 & 0.0047 \\
\hline 10 & 300.8 & 1.02 & 0.0055 \\
\hline 11 & 306.9 & 1.03 & 0.0061 \\
\hline 12 & 305.8 & 1.03 & 0.0076 \\
\hline 13 & 315.1 & 1.06 & 0.0057 \\
\hline
\end{tabular}

The range of correlation was selected from 40 to 80 minutes (in the identified steadystate region of the test data). Evaluation of the temperature data within the identified steady-state range was successfully demonstrated to correlate with the simulation data with $95 \%$ confidence. A 95\% confidence interval was calculated for the normalized mean temperature for each thermocouple within the identified steady-state range. The mean temperatures for eight thermocouples randomly selected along the length of the CAC tube for the designated steady-state interval are shown in Figures 6.4 through 6.11. 


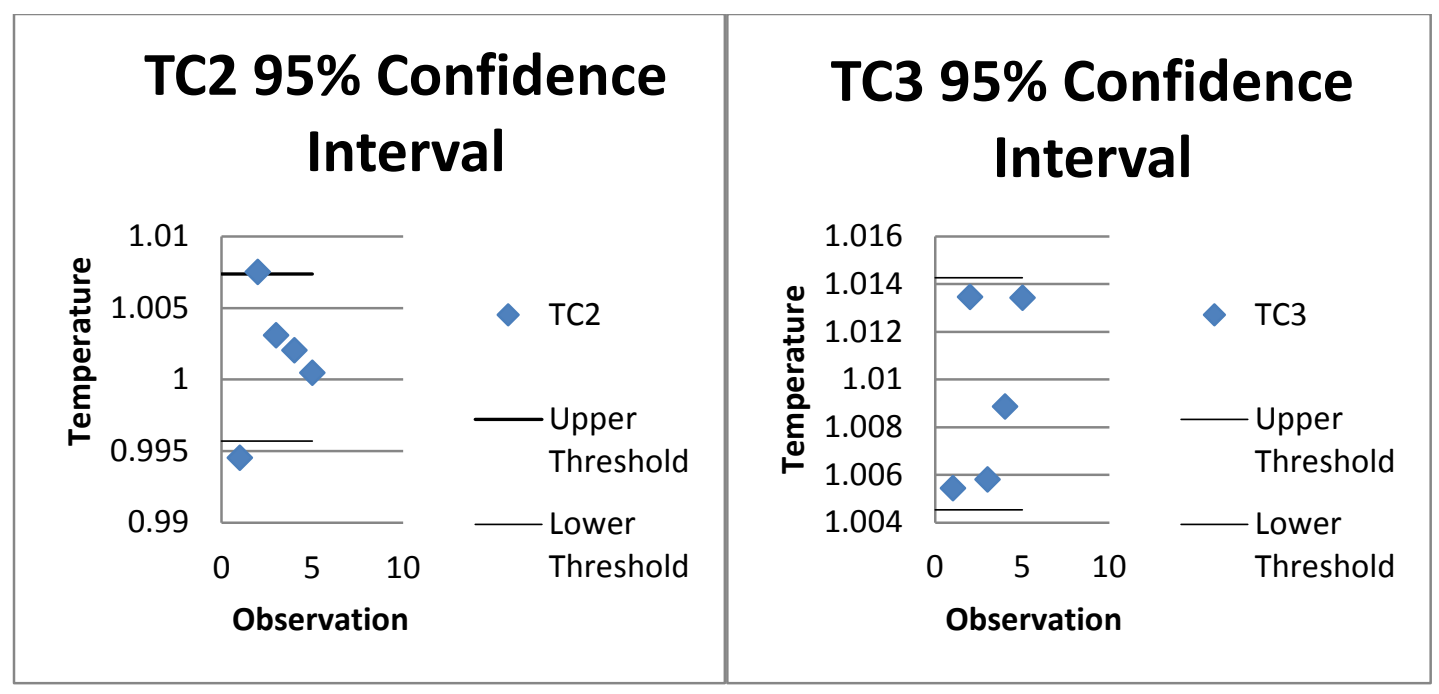

Figure 6.4

95\% confidence interval for TC2
Figure 6.5

95\% confidence interval for TC3

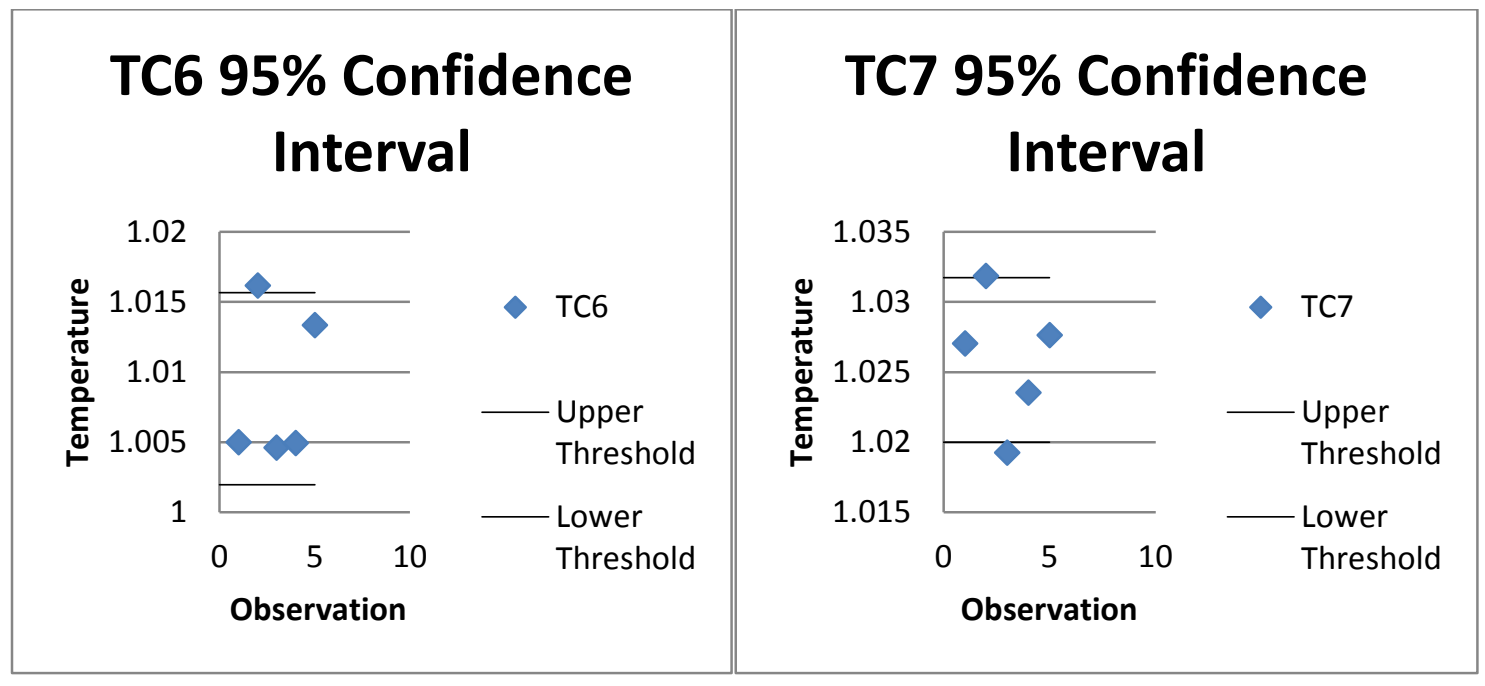

Figure 6.6

95\% confidence interval for TC6
Figure 6.7

95\% confidence interval for TC7 


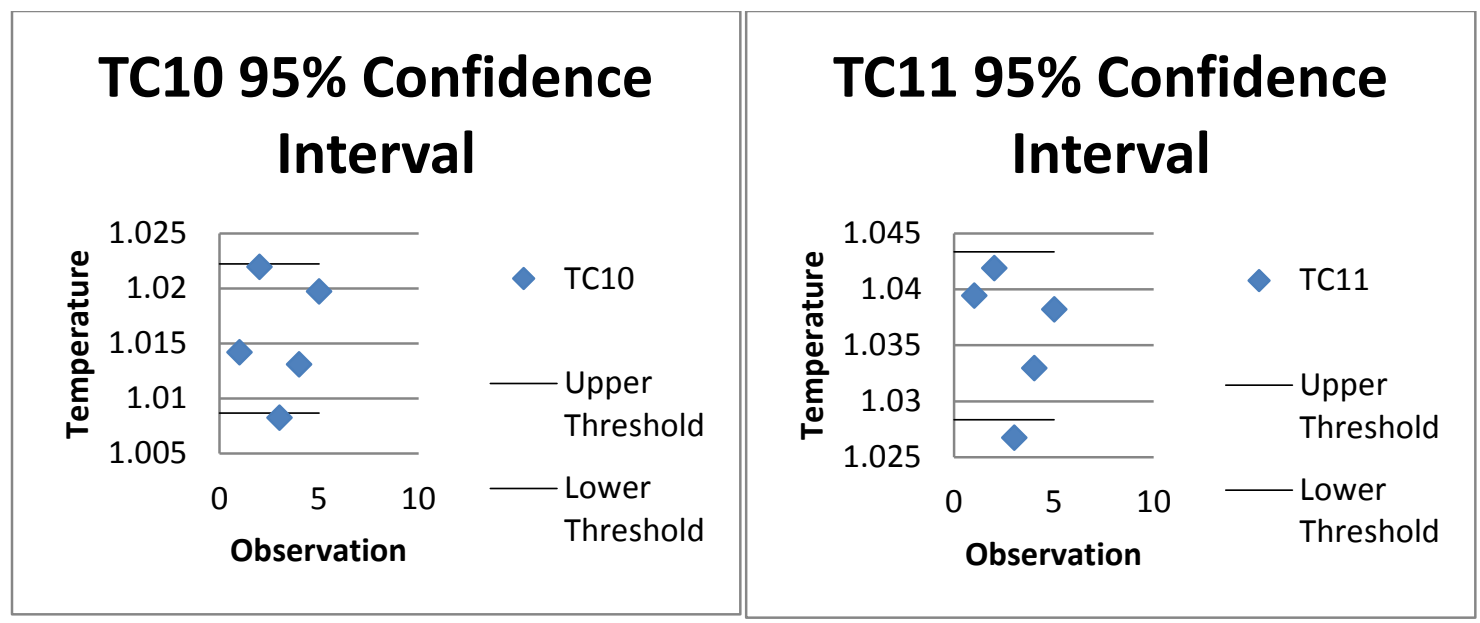

Figure 6.8

95\% confidence interval for TC10
Figure 6.9

95\% confidence interval for TC11

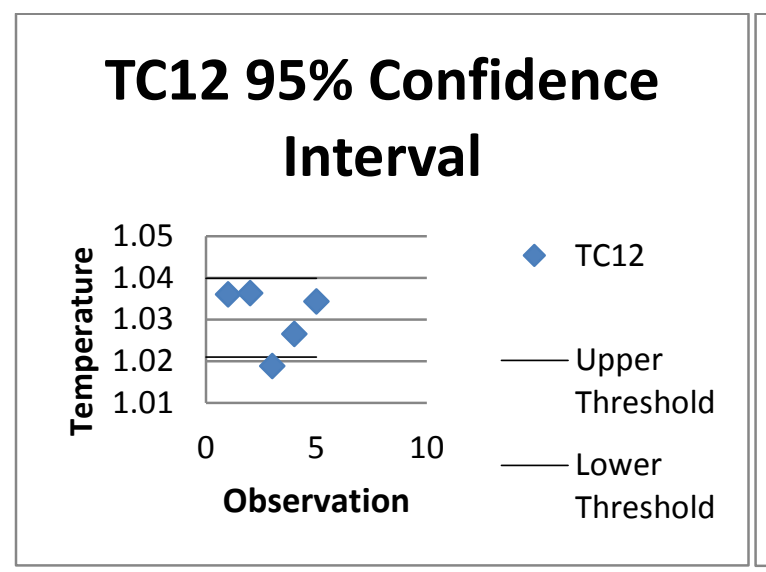

Figure 6.10

$95 \%$ confidence interval for TC12

\section{TC13 95\% Confidence Interval}

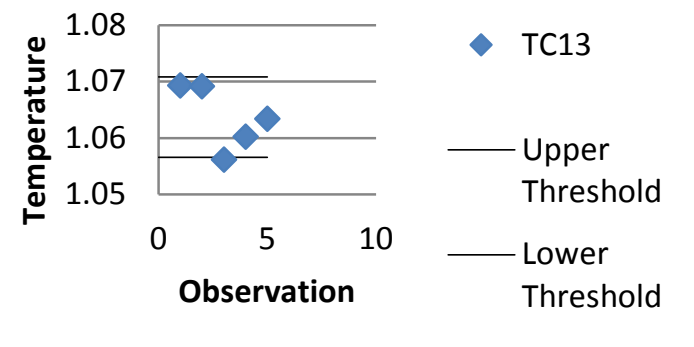

Figure 6.11

95\% confidence interval for TC13

The actual thermocouple profiles demonstrating transient and steady-state regions of data are shown below. The CAC tube was positioned so that the even numbered TCs, which are $2 \mathrm{~mm}$ from the vertical surface of the tube, received first cooling air and were subjected to the effects of forced convection. Figure 6.12 illustrates the temperature profile of the even numbered TCs which have a steady-state temperature range of $301 \mathrm{~K}-295 \mathrm{~K}$. The odd numbered TCs were on the trailing end of the cooling air (62 $\mathrm{mm}$ from the front face) with less direct effects from the cooling air. Therefore, these TCs registered higher 
temperature values. Figure 6.13 illustrates the temperature profile of the odd numbered TCs, which have a steady-state temperature range of $311 \mathrm{~K}-296 \mathrm{~K}$.

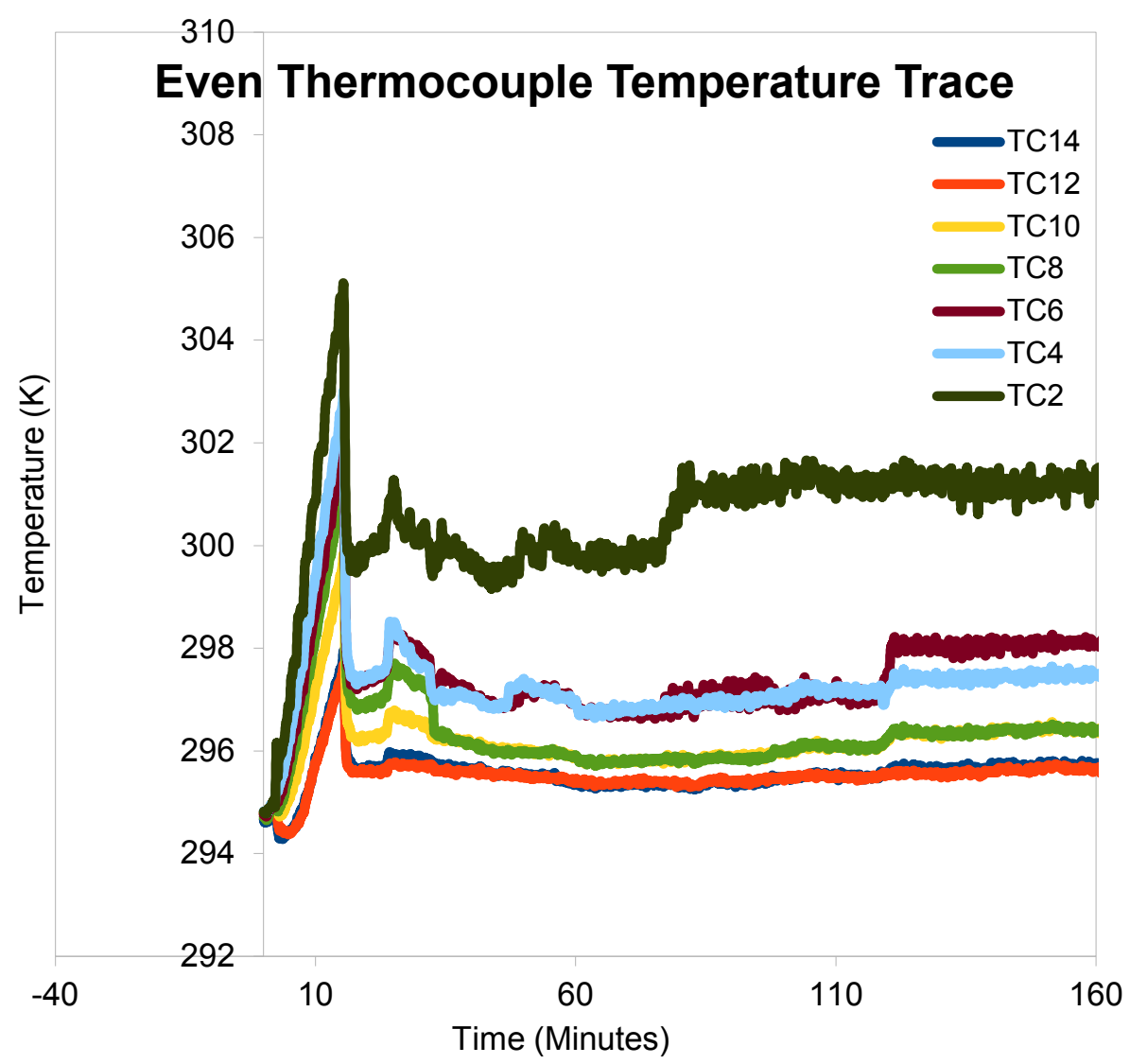

Figure 6.12 - Temperature profile of even TCs 


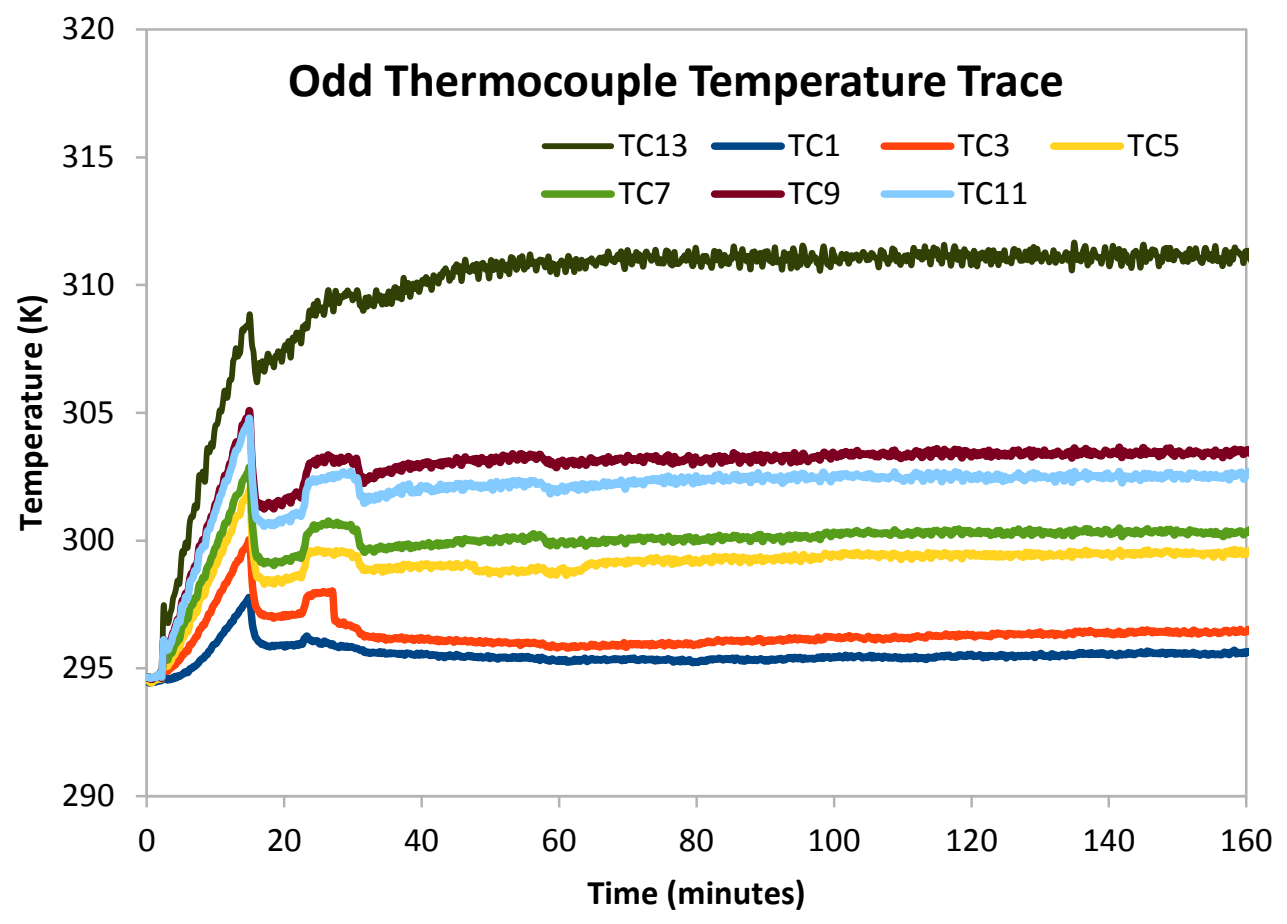

Figure 6.13 - Temperature profile of odd TCs

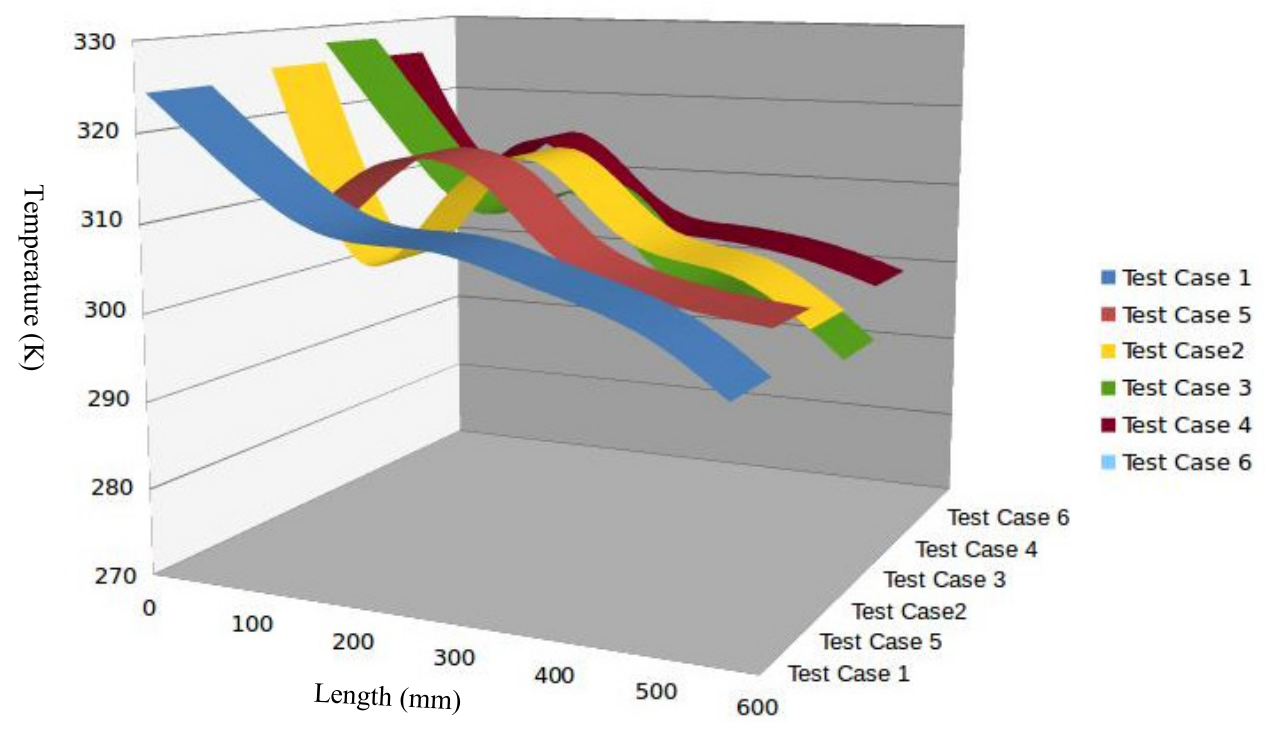

Figure 6.14 - Temperature verse Length of the tube for all cases from the experiment 
Condensation inside the tube occurred for all of the cases, as shown in Figure 6.14. The minimum temperature at which condensation occurred was $305^{\circ} \mathrm{K}$. Once the film formed, the surface heat transfer coefficient dropped suddenly because the film layer also provided thermal resistance.

\section{Conclusion/Opportunities}

The thermal time constant was successfully calculated and the time at which the experiment reached state-state was determined to be 40 minutes. The steady-state time range of 40 to 80 minutes was chosen for correlation. Determining the mean thermocouple temperatures for the steady-state time interval of the experimental data falling within $95 \%$ confidence interval provided assurance that the experiment was consistent. The mean temperatures for the steady-state time interval of 40 to 80 minutes will be used to correlate the simulation data. 


\section{Analysis}

The simulation accurately predicted the temperature profile for all cases. The simulation predicted the amount of condensate formation and presented a flow pattern for all cases with charge air inlet velocity of $12 \mathrm{~m} / \mathrm{s}$, as shown in Table 7.1 .

Table 7.1: Condensate Values from CFD Simulation

\begin{tabular}{|c|c|c|}
\hline Velocity & RH \% & $\begin{array}{l}\text { Condensate } \\
\text { ml/hr. }\end{array}$ \\
\hline 12 & 30 & 19.2 \\
\hline 12 & 40 & 32.05 \\
\hline 12 & 50 & 51.2 \\
\hline
\end{tabular}

The mesh sensitivity study indicated that a coarse mesh would not fully resolve the species concentration within the wall sub layer. Therefore, a finer mesh was created for the simulation correlation. The fine mesh statistics are listed in Table 7.2.

Table 7.2: Fine mesh statistics

\begin{tabular}{|l|l|l|l|}
\hline \multicolumn{4}{|c|}{ CAC Fine Mesh Statistics } \\
\hline $\begin{array}{l}\text { Minimum Face } \\
\text { Size }\end{array}$ & $\begin{array}{l}9.66 \mathrm{e}- \\
002 \mathrm{~mm}\end{array}$ & $\begin{array}{l}\text { Inflation } \\
\text { Growth } \\
\text { Rate }\end{array}$ & 1.2 \\
\hline $\begin{array}{l}\text { Maximum Face } \\
\text { Size }\end{array}$ & $1.0 \mathrm{~mm}$ & $\begin{array}{l}\text { Maximum } \\
\text { Aspect } \\
\text { Ratio }\end{array}$ & 10.652 \\
\hline Transition Ratio & 0.272 & $\begin{array}{l}\text { Number } \\
\text { of Nodes }\end{array}$ & $2,106,258$ \\
\hline $\begin{array}{l}\text { Maximum Inflation } \\
\text { Layers }\end{array}$ & 5 & $\begin{array}{l}\text { Number } \\
\text { of } \\
\text { Elements }\end{array}$ & $2,040,642$ \\
\hline \multicolumn{1}{|c|}{$y^{+}$} & $2-5$ & $\begin{array}{l}\text { Inflation } \\
\text { Layers }\end{array}$ & 5 \\
\hline
\end{tabular}


The fine mesh is shown in Figure 7.1.

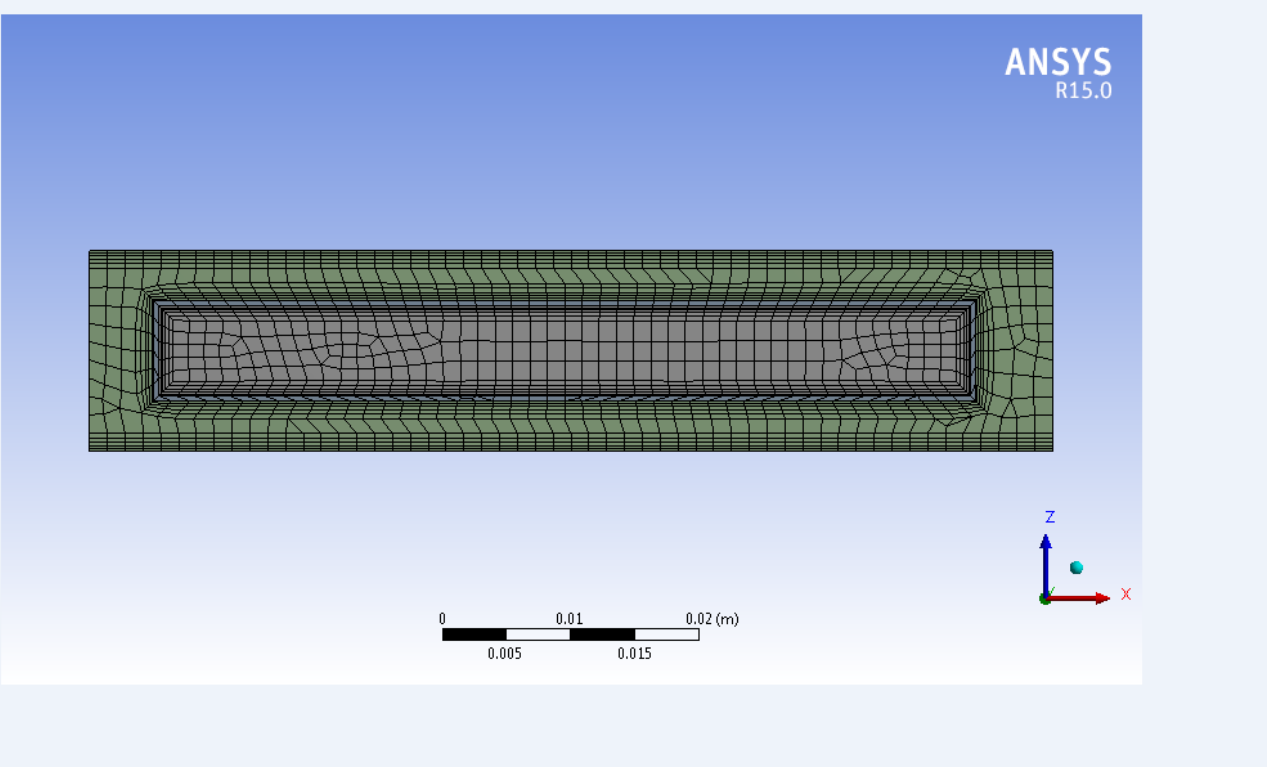

Figure 7.1 - Fine mesh

According to Pope (Pope 2000), to ensure the full boundary layer resolution,

the following condition should be true:

$y^{+}=\frac{y}{l^{*}}$. where $y^{+}$is the measure of boundary layer and

$u_{*}=\sqrt{\frac{\tau_{w}}{\rho}} ; \quad l_{*}=\frac{v}{u_{*}}$

1) Viscous sub-layer $0<y^{+}<5$

2) Buffer sub-layer $5<y^{+}<30$

3) Fully turbulent sub-layer $30<y^{+}<400\left(\frac{y}{\delta}=0.1-0.2\right)$.

The fine mesh was necessary to realize the developed wall film. The cases with a velocity of $12 \mathrm{~m} / \mathrm{s}$ has $\mathrm{y}+$ less than five, as shown in Figure 7.2. Therefore, the viscous sub-layer was resolved and wall film could be determined. 


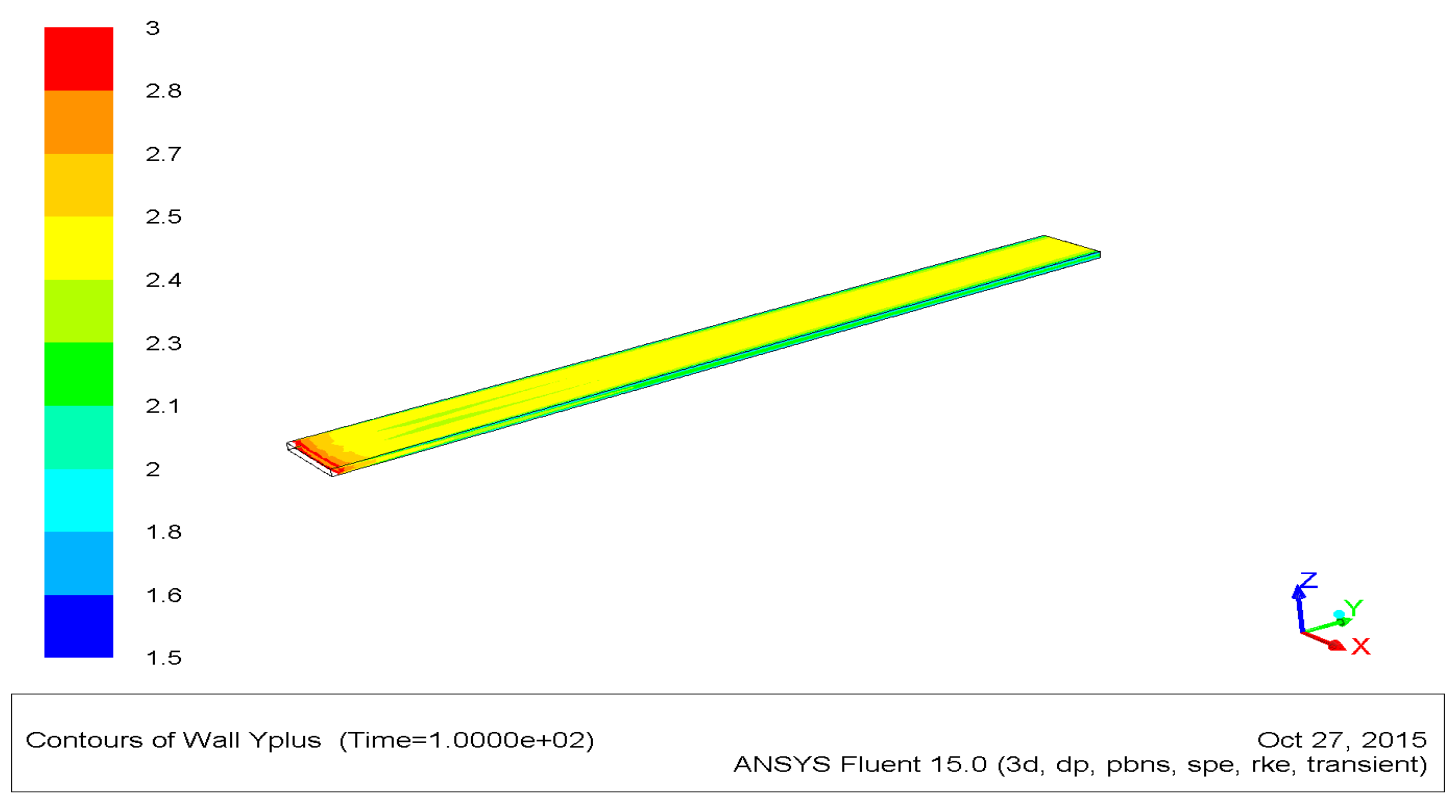

Figure 7.2 $-\mathrm{y}+$ contour for the CAC tube fine mesh

\section{Coarse Mesh}

Eight cases were run with the coarse mesh on the Ford High Performance Computing Gird (HPC), utilizing 64 processors. The experimental mean temperature data were calculated in the time interval of 40 minutes to 80 minutes for the baseline condition of $55^{\circ} \mathrm{C}$ inlet charge air temperature, $30 \% \mathrm{RH}$, and $10 \mathrm{~m} / \mathrm{s}$ charge air velocity and compared to the simulation results, as show in Figure 7.3. Post-processing yielded temperature profiles consistent with the experimental data but did not, however, yield condensate because the mesh did not fully resolve the boundary layer of the flow. 


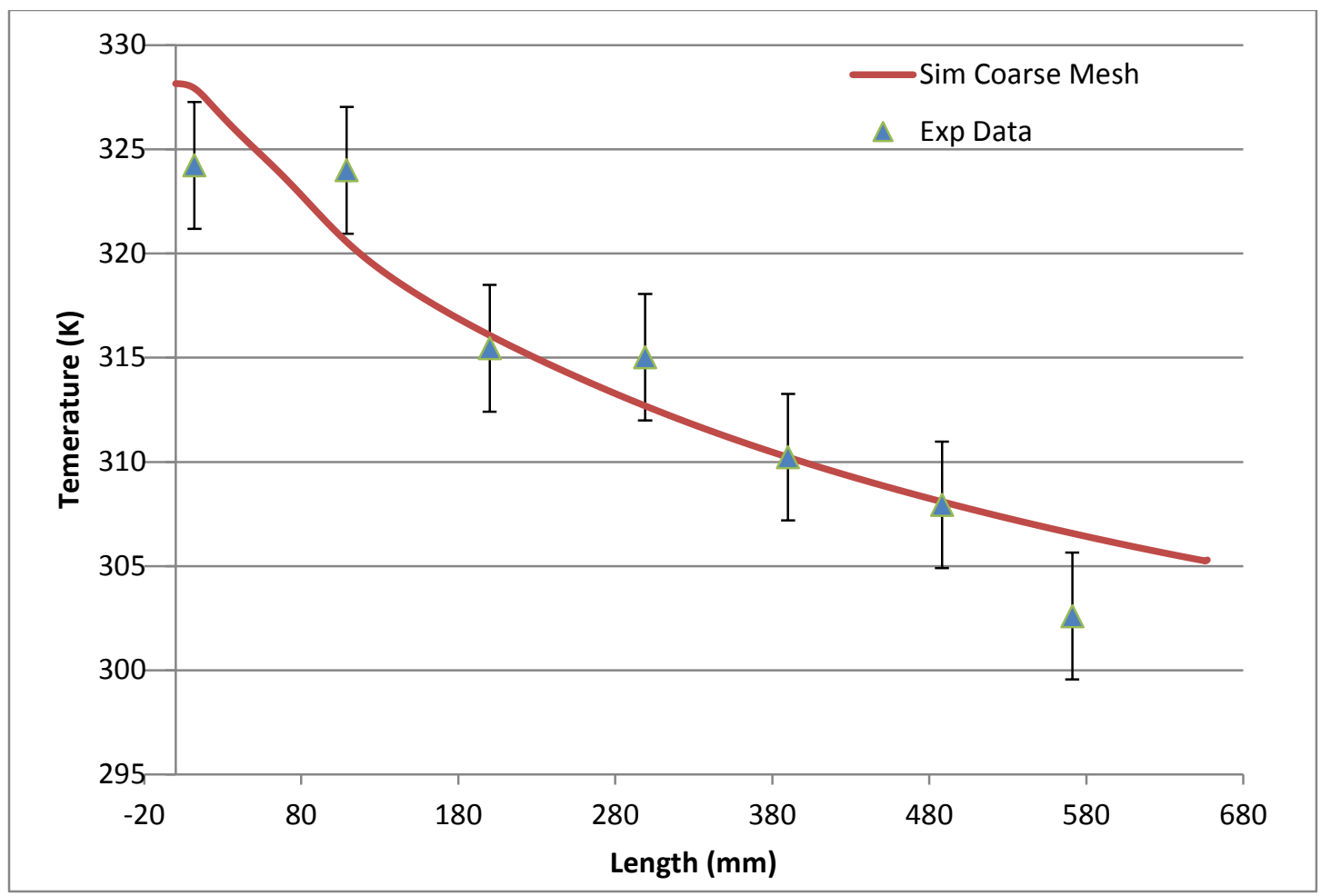

Figure 7.3 - Correlation of experimental to simulation data for coarse mesh $10 \mathrm{~m} / \mathrm{s}$ and RH $30 \%$

The coarse mesh yielded a temperature profile consistent with the experimental data but, due to unresolved boundary layer, the Eulerian wall film model could not predict the film mass. Therefore, a refinement in inflation wall layer was made in terms of $y+$ using ANSYS ${ }^{\circledR}$ Fluent's mesh adaption utility.

\section{Fine Mesh}

The fine mesh simulations were run and the experimental mean temperature data was compared to the steady state turbulence simulation results, as show in Figures 7.4 and 7.5. The error bars indicate the maximum and minimum mean temperatures recorded by the designated thermocouple and demonstrate experimental correlation to the simulation results. The thermocouples at both ends of the tube show slightly lower temperatures $\left(.1^{\circ} \mathrm{C}\right)$ and was outside the experimental data range. The subject thermocouples were in 
close proximity to the air boxes; the air boxes created cooling effects that were not simulated in the CFD model.

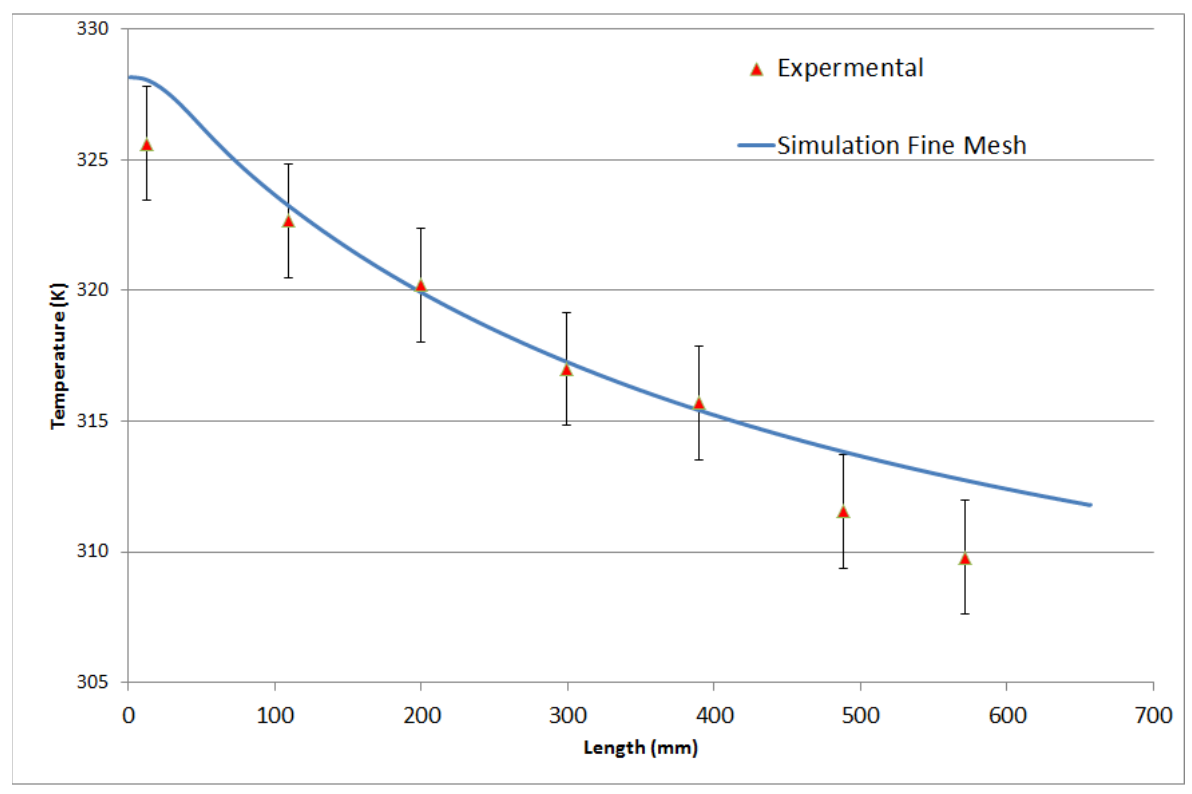

Figure 7.4 - Correlation of experimental to simulation data for $10 \mathrm{~m} / \mathrm{s}$ and $\mathrm{RH} 40 \%$ 
The CAC considered for the research operated at 18,140 Pascal with minimal pressure drop across the tube. Figure 7.5 displays the contour plot of the temperature profile on the inner wall of the $\mathrm{CAC}$ tube for $12 \mathrm{~m} / \mathrm{s}$ and $40 \% \mathrm{RH}$ to range from $306^{\circ} \mathrm{K}$ to $319^{\circ} \mathrm{K}$.

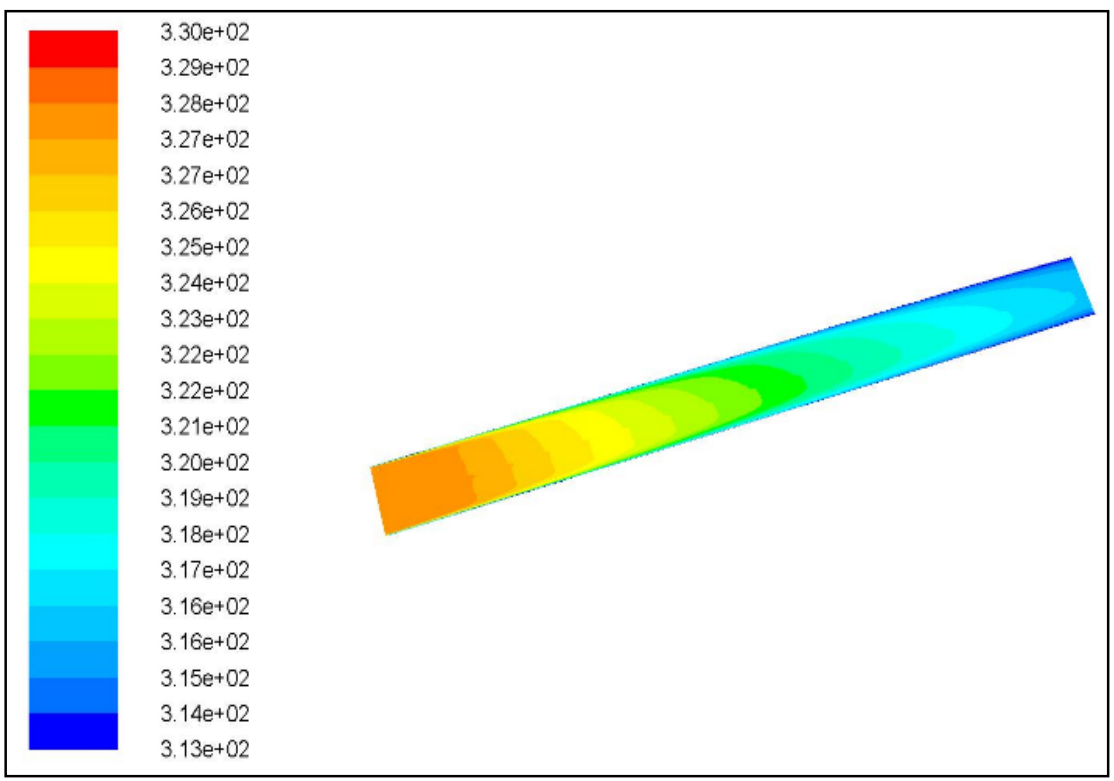

Figure 7.5 - Contour plot of temperature profile on inner wall of CAC tube (K) for $12 \mathrm{~m} / \mathrm{s}$ and $\mathrm{RH} 40 \%$

\section{Condensate Formation}

Figure 7.6 shows the condensation in terms of the inner wall film thickness for the $12 \mathrm{~m} / \mathrm{s}$ and $40 \%$ relative humidity case. After reaching steady-state turbulence, the film of maximum thickness $(25 \mu \mathrm{m})$ develops at the rear face of the tube near the outlet. This indicates that condensate was forming and being reconstituted or pushed and accumulates condensate at the exit end of the tube. This was due to the wall film motion with the air flow and the surface heat transfer coefficient, which changes along the length of the tube. 


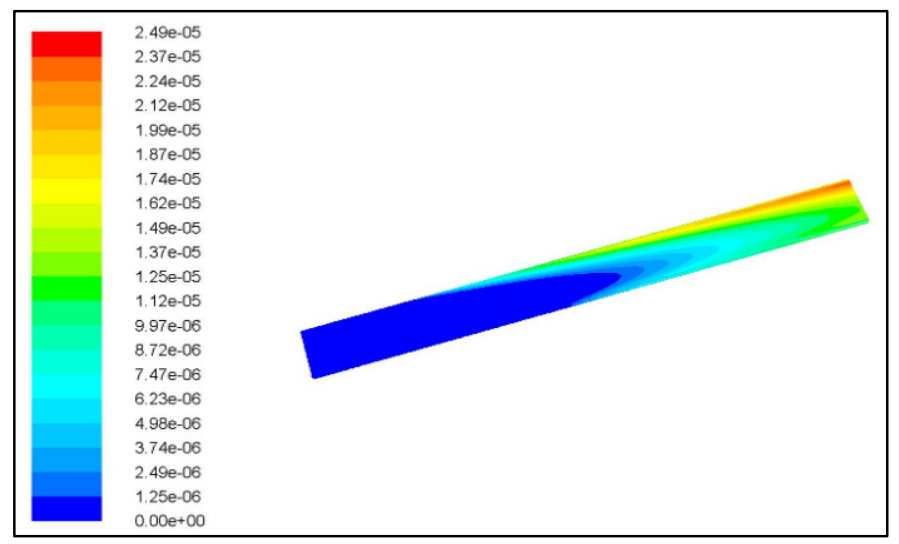

Figure 7.6 - Contour plot of film thickness of the CAC tube inner wall the (m) for $12 \mathrm{~m} / \mathrm{s}$ and $40 \% \mathrm{RH}(\mathrm{m})$

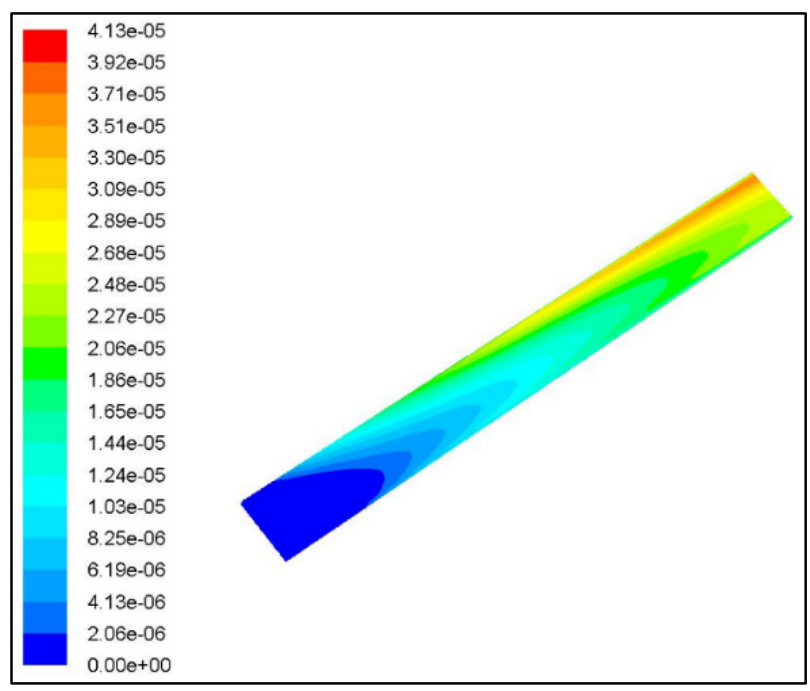

Figure 7.7 - Contour plot of film thickness of the CAC tube inner wall the (m) for $12 \mathrm{~m} / \mathrm{s}$ and $50 \% \mathrm{RH}$

Figure 7.7 shows almost twice the film thickness $(41.3 \mu \mathrm{m})$ due to a $10 \%$ increase in relative humidity. The area covered by the wall film is 1.5 times greater compared to the previous case.

Figure 7.8 illustrates the wall film progression during the 100 seconds of simulation. 


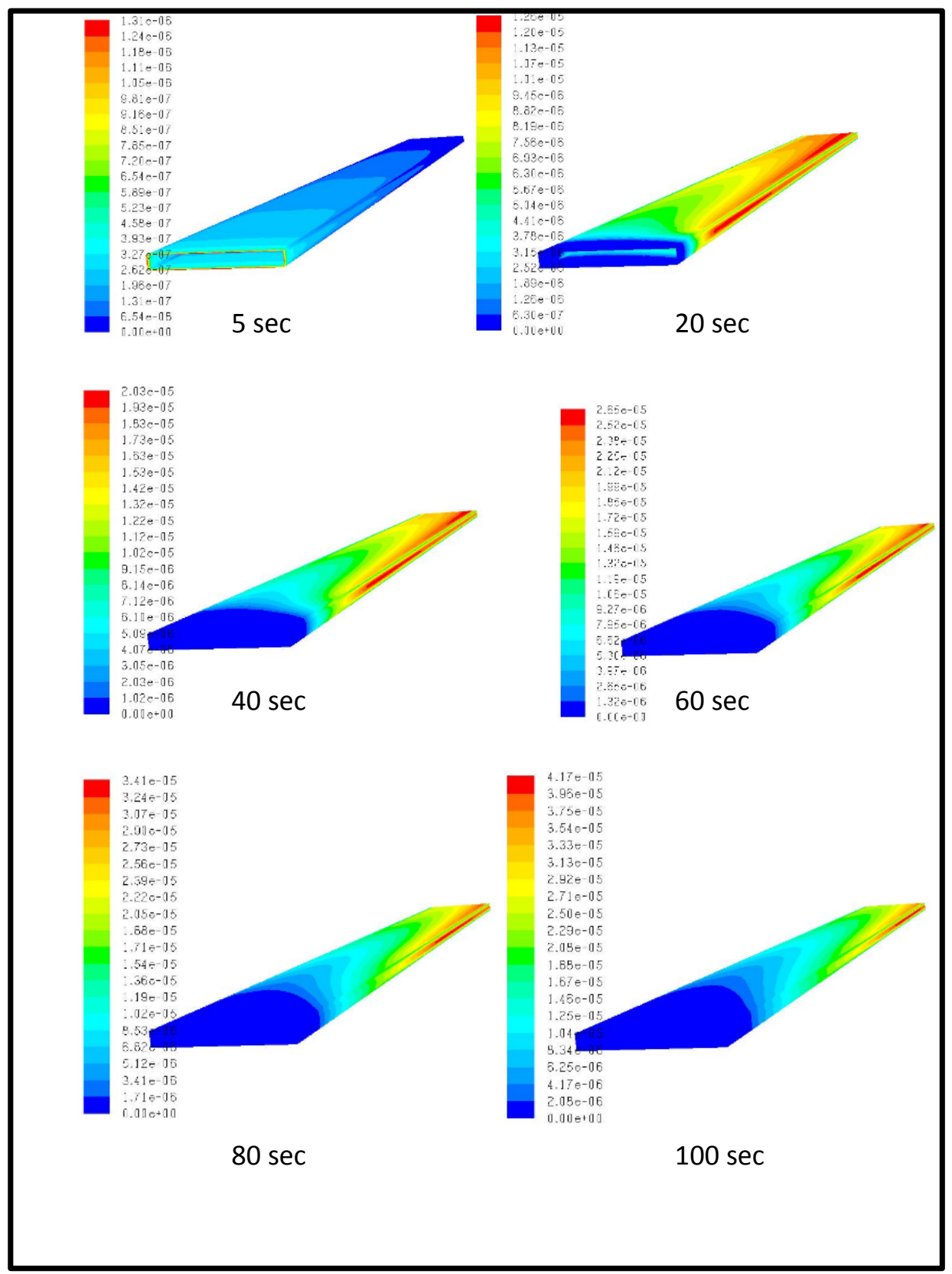

Figure 7.8 - Contour plot of film thickness 100 second inner wall film development of CAC tube $(\mu \mathrm{m})$ for $12 \mathrm{~m} / \mathrm{s}$ and $\mathrm{RH} 40 \%$ 
Experimental data was collected for total mass creation after one hours for the $50 \% \mathrm{RH}$, $12 \mathrm{~m} / \mathrm{s}$ condition. After reaching steady-state turbulence for $50 \% \mathrm{RH}$, the film of maximum thickness, which is $24 \mu \mathrm{m}$, develops at the rear face of the tube near the outlet. By integrating the film mass over the surface area of the tube and time, the total condensation mass is calculated. The values were compared to the amount collected during the laboratory experiment for the same charge air inlet velocity, cooling air mass flow rate and relative humidity of both air streams. The results are shown in Table 7.1.

Table 7.3: Condensation creation for $50 \%$ RH

\begin{tabular}{|c|c|c|}
\hline Velocity(m/s) & $\begin{array}{c}\text { Condensation } \\
(\mathbf{m l} / \mathbf{h r} \text {.) Experiment }\end{array}$ & $\begin{array}{c}\text { Condensation } \\
(\mathbf{m l} / \mathbf{h r} \text {.) Simulation }\end{array}$ \\
\hline 12 & 44 & 51 \\
\hline
\end{tabular}

\section{Heat Transfer}

The surface heat transfer coefficient and heat flux on the inner wall was compared for $12 \mathrm{~m} / \mathrm{s}$ at $40 \% \mathrm{RH}$ to $50 \% \mathrm{RH}$. Condensation occurred when the vapor temperature dropped below its saturation temperature. Condensation also provided resistance to heat transfer between the air and the surface of the inner wall. In this case, when comparing the wall surface along the length of the tube, the heat flux and heat transfer coefficient were greater for $50 \% \mathrm{RH}$ as compared to $40 \% \mathrm{RH}$, as shown in Figures 7.9 and 7.10. The dominate component was the heat transfer across the width of the tube, which varied by approximately $4,000 \mathrm{~W} / \mathrm{m}^{2}$. This was due to the heating of the cooling air that flowed through the $3.5 \mathrm{~mm}$ gap between two tubes. When the cooling air came into contact with the tube (at $\mathrm{x}=0$ ), it suddenly caused a reduction of heat within the tube. At the mid-plane $(x=32 \mathrm{~mm})$, heat flux going out was one- half of its initial value. At the rear edge of the tube $(\mathrm{x}=64 \mathrm{~mm})$, heat flux was approximately equal to that at mid-plane heat flux, though in the opposite direction.

The higher RH caused more condensate and greater film thickness. The moisture acted as a thermal resistor and stored heat. Flow of charge air stripped the wall film away from 
the metal surface, locally increasing the heat transfer (reflected in Figure 7.9 at $y=0.3 \mathrm{~m}$ and $\mathrm{x}=.032 \mathrm{~m}$ ), and condensate re-accumulated to form wall film.

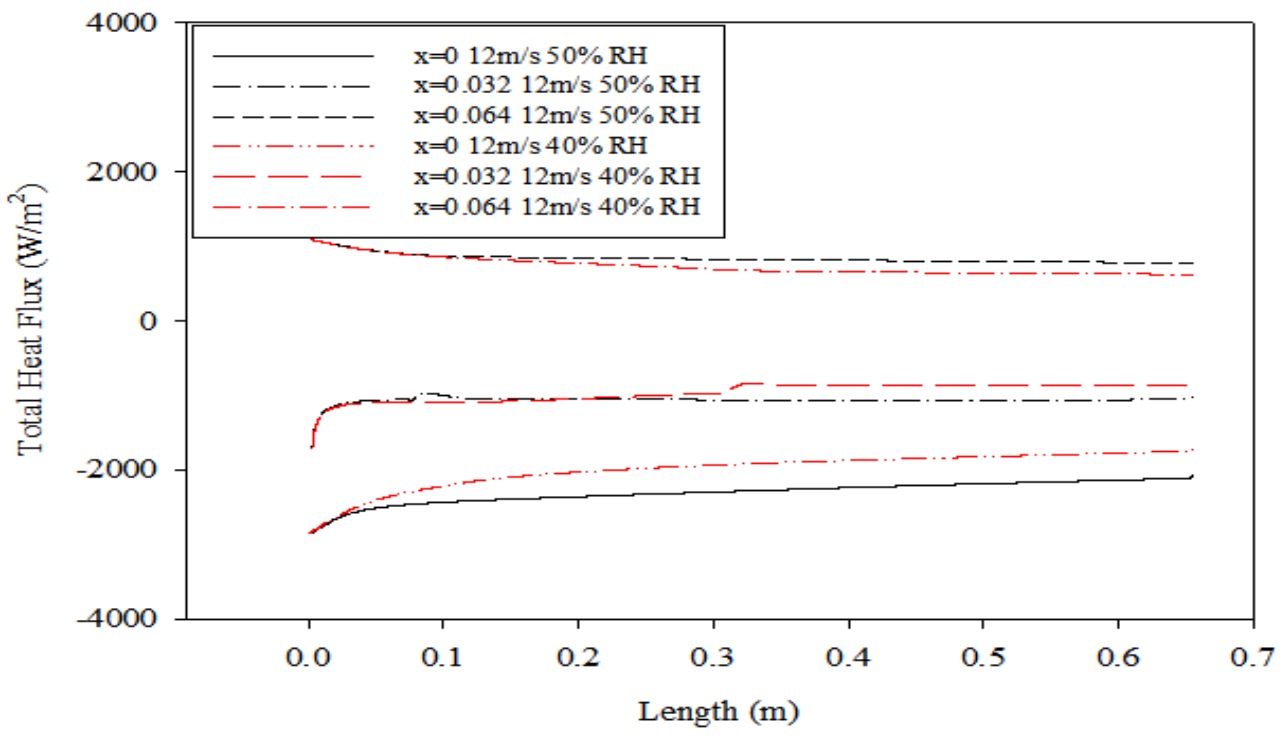

Figure 7.9 - Total surface heat flux $\left(\mathrm{W} / \mathrm{m}^{2}\right)$ for $12 \mathrm{~m} / \mathrm{s}$ comparison of $50 \%$ RH to $40 \%$ RH

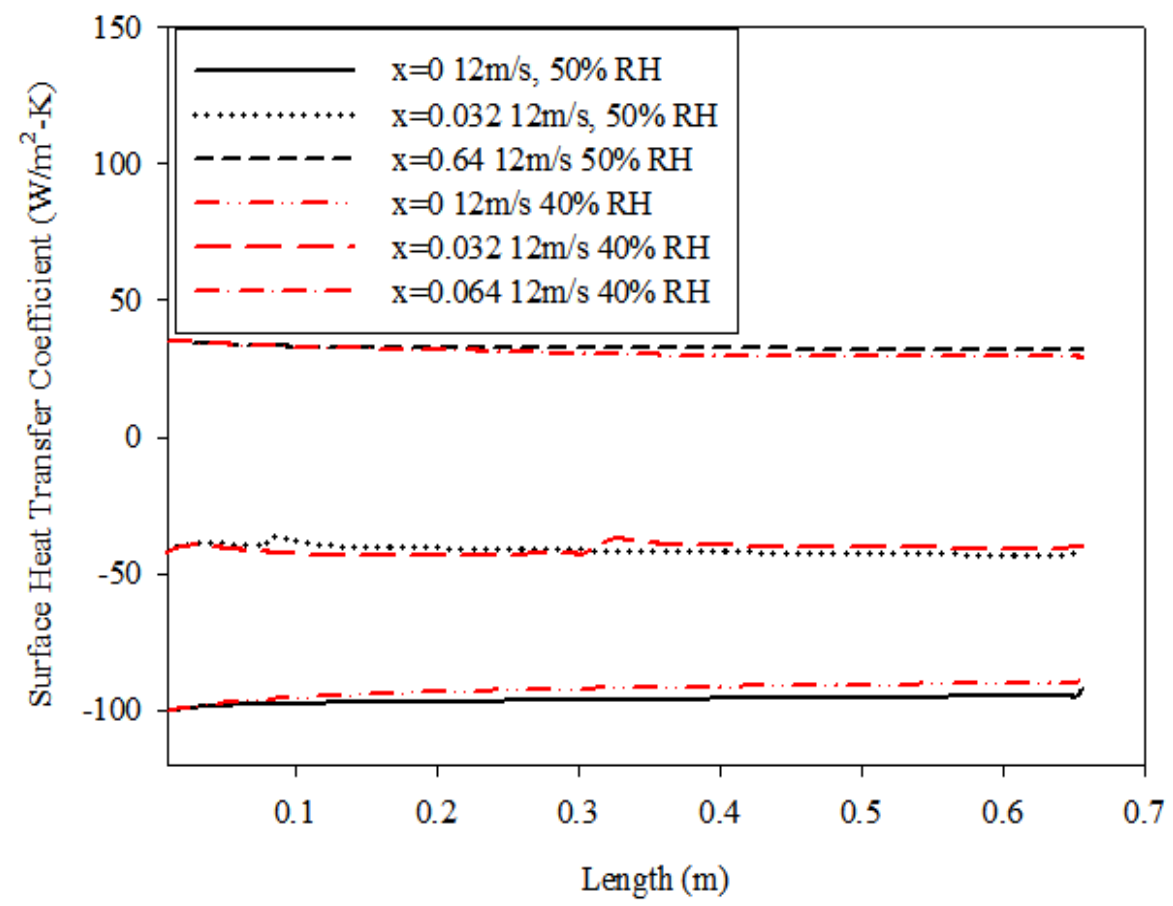

Figure 7.10 - Surface heat hransfer coefficient $\left(\mathrm{W} / \mathrm{m}^{2}-\mathrm{K}\right)$ for $12 \mathrm{~m} / \mathrm{s}$ comparison of $50 \% \mathrm{RH}$ to $40 \% \mathrm{RH}$ 
The wall temperature for $12 \mathrm{~m} / \mathrm{sec}, 50 \% \mathrm{RH}$ is greater than $40 \%$ relative humidity by $3^{\circ} \mathrm{K}$, as shown in Figure 7.11.

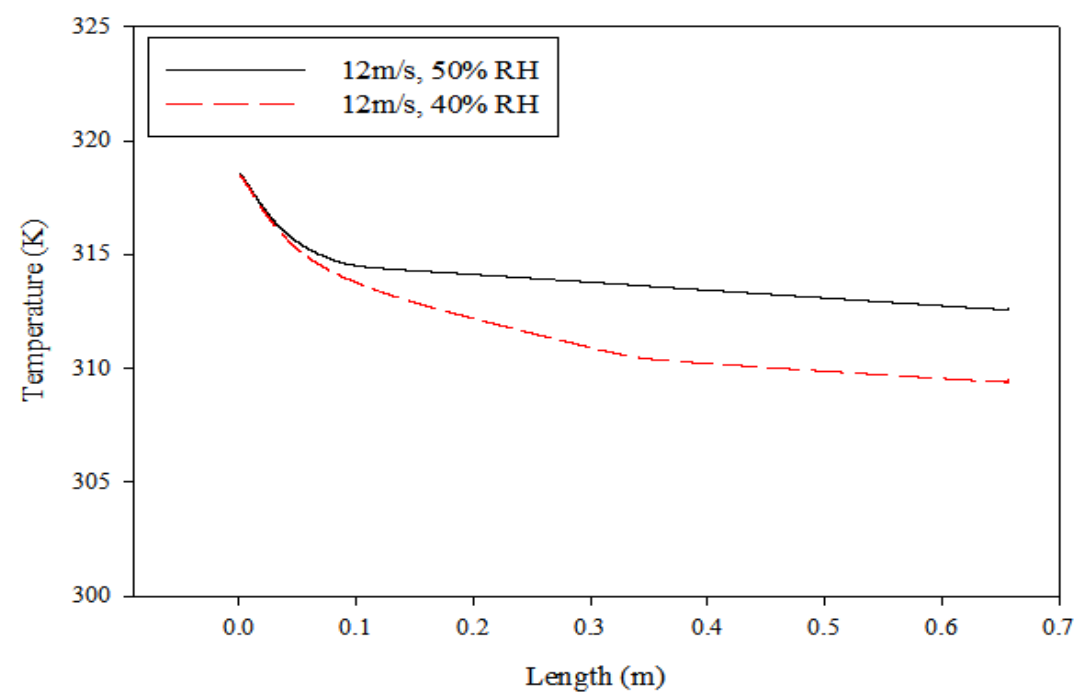

Figure 7.11 - Wall temperature $(\mathrm{K})$ for $12 \mathrm{~m} / \mathrm{s}$ comparison of $40 \%$ RH to $50 \%$ RH

Boosted engines increase the system pressure, which leads to increased dew-point temperatures. According to Tang (Tang 2011), a criterion is defined for condensation based on the typical CAC opening condition of 10,000 Pascal and $20^{\circ} \mathrm{C}$. Saturation temperatures increase as pressure ratios increase. Tang asserted that when the defined operational conditions are met, condensation will occur inside and towards the exit point of the tube and the inlet of the engine intake manifold.

The front side of the CAC tube was exposed to the cooling air first and, therefore, had more heat transfer than any other surface. The minima and maxima for the curves shown in Figure 8 defined the zone for the condensation at that particular velocity. The Eulerian film assumed the temperature of the metal boundary and heat transfer coefficient changed with the temperature of the film.

Wall film acquired the temperature of the wall when it formed, as shown in Figures 7.12 and 7.13. Wall temperature also changed with the motion of the wall film. 


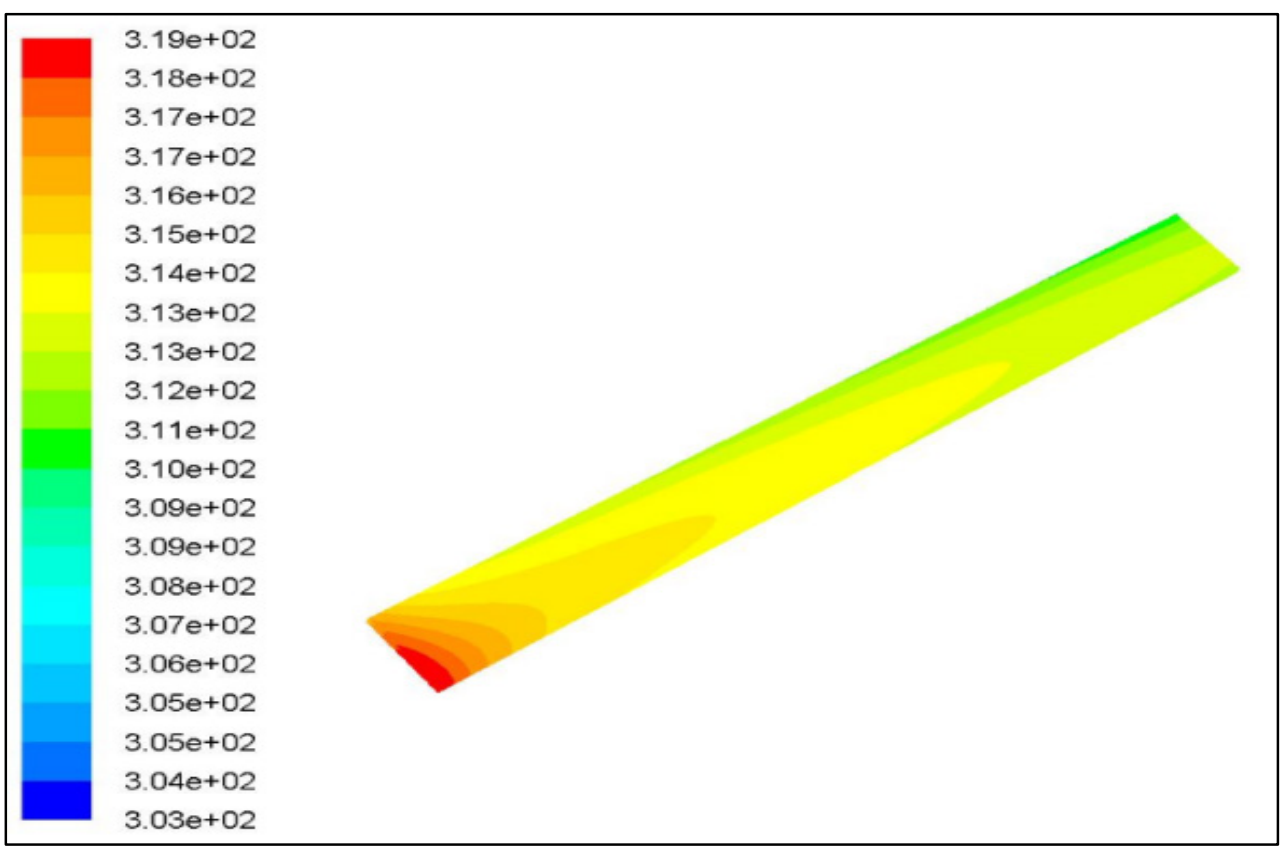

Figure 7.12 - Eulerian film temperature (K) for $12 \mathrm{~m} / \mathrm{s}$ and $50 \%$ RH

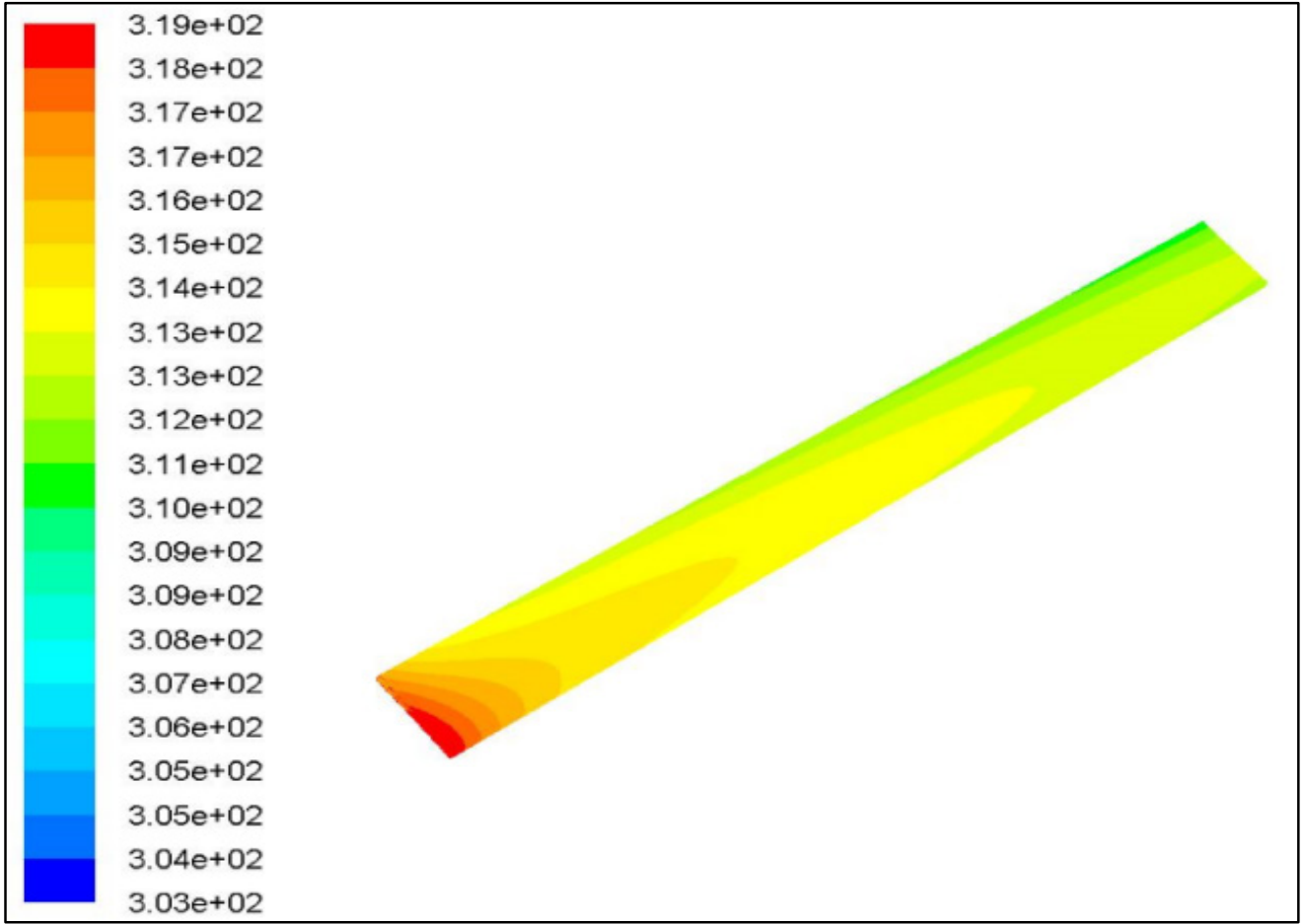

Figure 7.13 - Inner wall temperature (K) for $12 \mathrm{~m} / \mathrm{s}$ and $50 \% \mathrm{RH}$ 
A methodology for the design of CAC that provides maximum thermal performance without generation of a critical mass of condensate is shown in Figure 7.14. The described experimentally validated simulation methodology can be used to evaluate and design CACs that function outside the condensate formation zone during operation modes.

The Methodology is based on:

1) The development of a 3-D computational model of the internal flow for a CAC using ANSYS ${ }^{\circledR}$ Fluent.

2) The simulation was validated by measurements from a Ford Motor Company experimental data which showed correlation.

Upon completion, the model provides a validated simulation methodology for designing heat exchangers for practical applications that encounter moisture in the powertrain air intake air stream. 


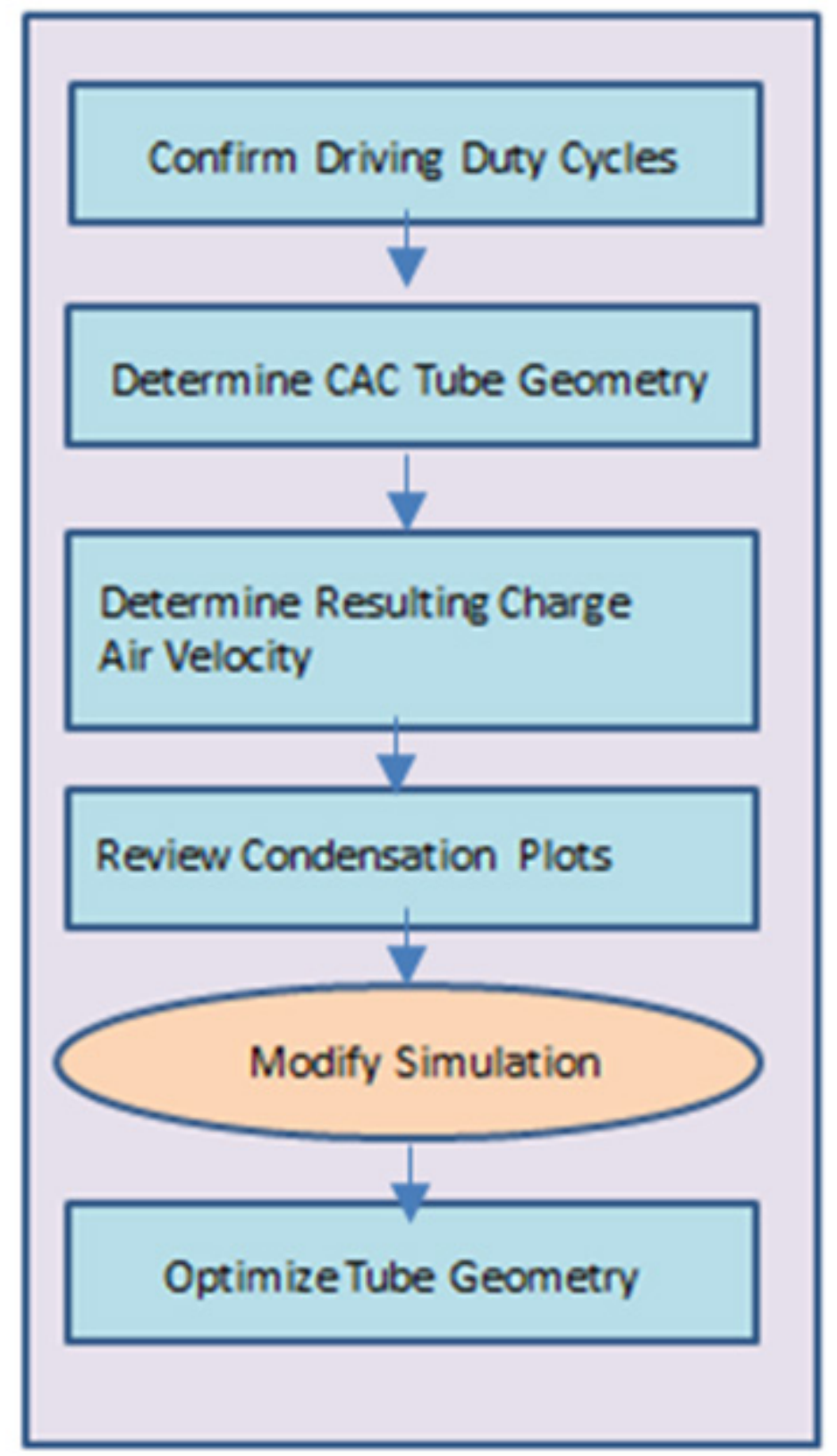

Figure 7.14 - Validated simulation methodology 


\section{Conclusion}

The solution to the problem described in this research is not available in literature. This is a current OEM issue which will persist as long as turbo charged engines continue to be a strategy to achieve fuel economy targets. The creation of the described 3-D multi-phase CFD model that includes a unique UDF that predicts the condensate formations and temperature distribution across the tube is useful in the design of CACs for the following reasons:

1. Experimentation is time intensive and very expensive

2. Effective simulation saves OEMs experimentation time and money.

3. The model provides the engineer with a design tool that saves time and money.

During engine duty cycles, small engines in a big vehicle require more boost. Higher pressure ratio raises the dew point temperature and can create more condensate in a cold CAC tube.

Boosted engines are becoming commonplace in passenger car and light truck applications to achieve fuel economy targets. An unintended error state of charge air coolers is condensation formation. Increasing pressure increases the dew-point temperature, which is aligned with current $\mathrm{CAC}$ operating ranges.

The present research resulted in the following key findings:

1. As the velocity of the inlet charged air was increased, the condensate quantity increased for the same area of the CAC tube wall.

2. Increase in relative humidity was a major factor in the condensation formation along with the velocity of the air.

3. Condensate formation was predominant once steady state was reached in the experiment, as evidenced by the transient simulation. After 100 seconds of the 
steady turbulence in real time, the condensate mass reached the steady formation rate.

4. Wall film formation and evaporation were concurrent processes. Relative humidity, surface heat transfer coefficient, and finned surface area were some of the critical factors that determined the rate of wall film formation and evaporation processes. More investigation is necessary to calculate the relationship between evaporation rate and the condensate formation rate inside the CAC tube.

5. RNG k- $\varepsilon$ turbulence modelling with Eulerian film model provided satisfactory results in terms of the film mass thickness and the movement of the wall film. To obtain realistic values for the film thickness, enhanced wall treatment was most suitable. However, it was an expensive method in terms of computation.

6. $\mathrm{Y}^{+}$in this simulation was in the range of 1-3, which resulted in resolved viscous sub-layer near wall region. This region was the predominant region for the wall film accumulation. The stripping and movement of the wall film was highly mesh-sensitive. In this case, mesh independence was achieved for given boundary conditions.

7. The present research and methodology provide a solution to a practical and escalating problem that has significant functional and financial impact and is not currently available in literature by:

a. Developing a multi-phase CFD model to solve a critical problem by exploring and expanding the usage and capability of the software. It was necessary to write a unique user define function (UDF) to handle the multi-phase flow.

b. Providing a practical and robust methodology to analyze CAC designs.

c. Developing a desktop tool with a user interface where engineers submit a job and obtain results with a rapid turn-around time. 
d. Verifying the Ford CAC test rig and providing confidence in data, providing engineers an experimentally verified methodology to validate CAC designs. 


\section{Future Work}

Experimental errors that are due in large part to the lack of accurate measurements for condensate need to be eliminated.

\section{$\underline{\text { Experimental Opportunities }}$}

1. The boxes at the inlet and the outlet of the experimental rig should be removed from the rig or the boxes need to be included in the simulation, which will require a much larger mesh.

2. Electrifying the tube is a new method to measure the surface temperature. If a very small amount of current is passed through the tube each time a droplet of condensate drops, there is a peak in the current. This allows for accurate location of the condensate formation to correlate the simulation. This could yield comprehensive three-dimensional experimental data.

3. Employ a Particle Image Velocimetry (PIV) method utilizing lasers to determine the velocity. Place a laser into the CAC tube and position a camera to take highspeed pictures to enable velocity vectors and observe development of condensation.

4. Insert a viewing window on the tube where the maximum condensation occurs and take high-speed picture of the condensation, which can be correlated with the simulation data.

\section{$\underline{\text { Simulation Opportunities }}$}

1. Adaptation of $y^{+}-$there is an algorithm that changes half of the mesh and creates different $\mathrm{y}+$ values. Currently, RNG k-epsilon is being used from a $\mathrm{y}+=$ 2.7 and several simulation cases that did not yield condensation. 
2. Complete a parametric study to understand how changes in $y+$ correlate to condensation. Switch from RNG k epsilon model (time averaged), which uses the Eulerian film model. If $y+$ is changed from 5 to 1 , the process by which condensation changes can be evaluated.

3. Use the Large Eddy Simulation (LES) model to solve local data as a function of time and location. If LES is used, any portion of the experimental data can be correlated without having to wait for the experimental data to reach steady-state. 


\section{Reference List}

AbdulNour B. 1998. Numerical Simulation of Vehicle Defoster Flow Field. SAE International Congress and Exposition. Detroit, MI.

AbdulNour B. 1999. CFD Prediction of Automotive Windshield Deforst Pattern. SAE International Congress and Exposition. Detroit, MI.

AbdulNour BS, Foss JF. 1997. Computational and Experimental Predictions of Automotove Winshield Flow. ASME.

Al BC, Simmons K, Morvan HP. Two-Phase Computational Modelling of a Spiral Bevel Gear Using a Eulerian Multiphase Model. ASME Turbo Expo 2015: Turbine Technical Conference and Exposition; 2015: American Society of Mechanical Engineers. p. V05CT15A030V05CT15A030.

Dalkilic AS, Wongwises S. 2009. Intensive literature review of condensation inside smooth and enhanced tubes. International Journal of Heat and Mass Transfer 52(15-16):3409-3426.

Dalkilic AS, Celen A, Awad MM, Wongwises S. 2013. A Critical review on the determination of convective heat transfer coefficient during condensation in smooth and enhanced tubes. Heat Transfer Summer Conference. Minneapolis, MN USA: ASME.

Frank PI, David PD. 1996. Fundamentals of heat and mass transfer.

Garcia JJ. 2012. Exhaust Gas Condensate Corrosion Test on Low Pressure Cooling System of Aluminum Brazed EGR, ACAC and WCAC. 1.

Kakimpa B, Hargreaves DM, Owen JS, Martinez-Vazquez P, Baker CJ, Sterling M, Quinn AD. 2010. CFD modelling of free-flight and auto-rotation of plate type debris. Wind and Structures 13(2):169-189.

Kays WM, London AL. 1984. Compact heat exchangers.

Lee W. 1979. A Pressure Iteration Scheme for Two-Phase Flow Modeling (Technical Paper No. LA-UR-79-975). Los Alamos, New Mexico, USA: Los Alamos National Laboratory.

Lumsdaine E, Voitle J. Contextual problem solving in heat transfer and fluid mechanics. AIChE Symposium Series; 1993: AMERICAN INSTITUTE OF CHEMICAL ENGINEERS. p. 540-540.

Mikhushkin VN, Bogachenko VN. 1992. Design of heat-exchanger/dryers for compressed air allowing for teh condensation of moisture. Chemical and Petroleum Engineering 27(7):5.

Murase T, Wang HS, Rose JW. 2006. Effect of inundation for condensation of steam on smooth and enhanced condenser tubes. International Journal of Heat and Mass Transfer 49(1718):3180-3189.

Pope SB. 2000. Turbulent Flows

Potter M, Wiggert D, Ramadan B. 2011. Mechanics of Fluids SI Version. Cengage Learning.

Ressler K, Brucker K, Nagurka M. 2003. A thermal time-constant experiment. International Journal of Engineering Education 19(4):603-609.

Tandon T, Varma H, Gupta C. 1982. A new flow regimes map for condensation inside horizontal tubes. Journal of Heat Transfer 104(4):763-768.

Tang Y. 2011. The Condensation within a CAC-Thermodynamics Analysis. SAE Technical Paper. No. 0148-7191.

Vyskocil L, Schmid J, Macek J. 2014a. CFD simulation of air-steam flow with condensation. Nuclear Engineering and Design 279:147-157.

Vyskocil L, Schmid J, Macek J. 2014b. <CFD simulation of air-steam flow with condensation.pdf>. Nuclear Engineering and Design:11. 
Wheeler AJ, Ganji AR, Krishnan VV, Thurow BS. 1996. Introduction to engineering experimentation. Prentice Hall New Jersey. 


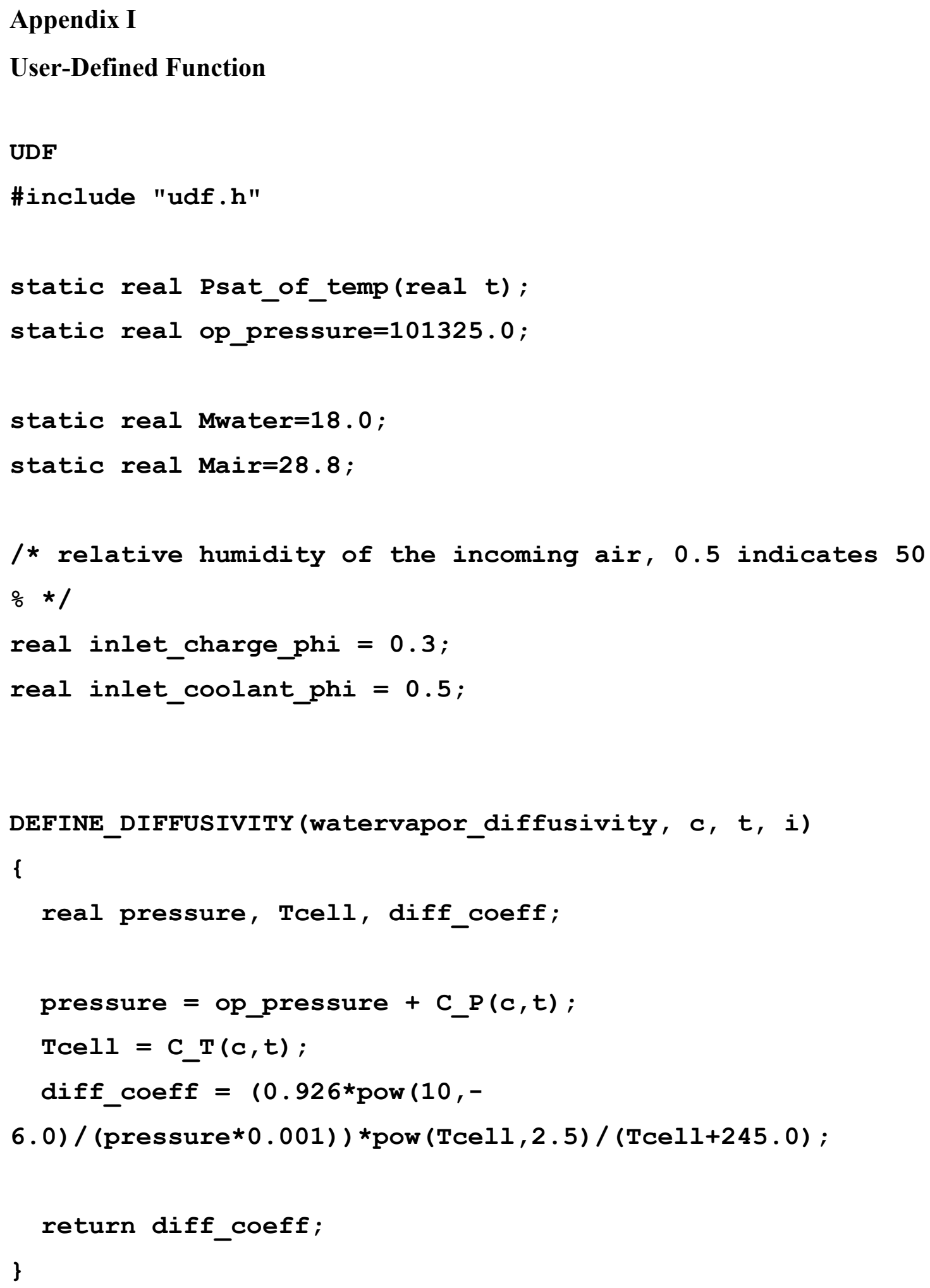


/* The following profile sets the water vapor mass fraction at the inlet based on $T$ and $p * /$

DEFINE_PROFILE (inlet_charge_water_vapor,thread, i)

\{

real Psat, Pwater, Pair, rr, omega, inletrhum;

face_t $f$;

if(!Data_Valid_P()) return;

\#if !RP_HOST

begin_f_loop ( $f$, thread)

\{

Psat = Psat_of_temp $\left(F_{-} T(f\right.$, thread $\left.)\right)$;

inletrhum = inlet_charge_phi;

Pwater $=$ Psat * inletrhum;

/* Corrected Pair - missing F_P ! */

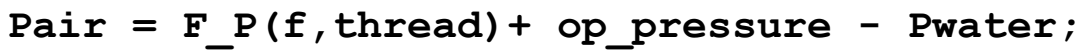

$r r=$ Mwater/Mair;

omega $=r r *$ Pwater/Pair;

F_PROFILE (f, thread, i) = omega/(1.0+omega);

\}

end_f_loop ( $f$, thread);

\#endif

\}

DEFINE_PROFILE (inlet_coolant_water_vapor, thread, i)

\{

real Psat, Pwater, Pair, rr, omega, inletrhum;

face_t $\mathbf{f}$; 
if(!Data_Valid_P()) return;

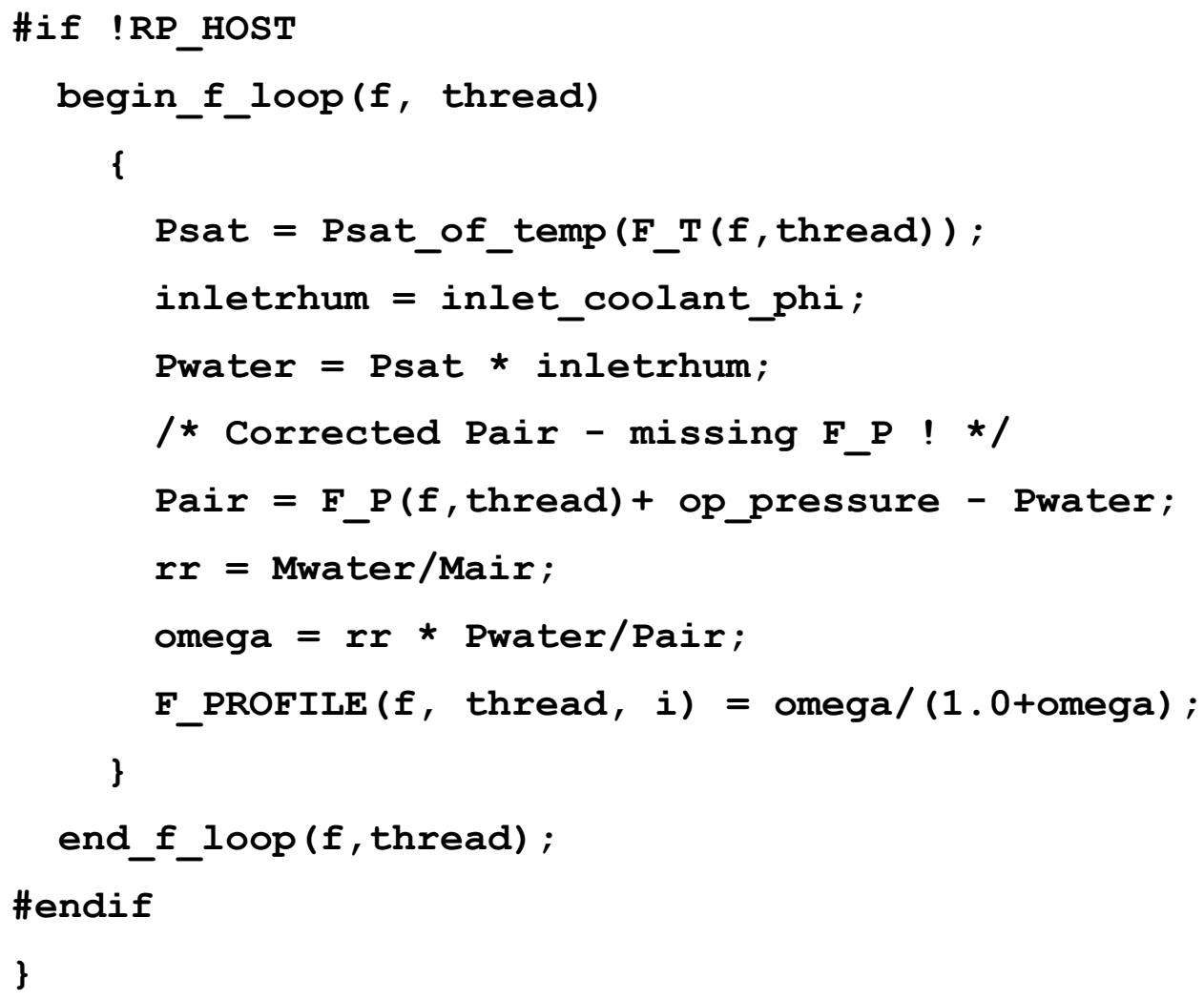




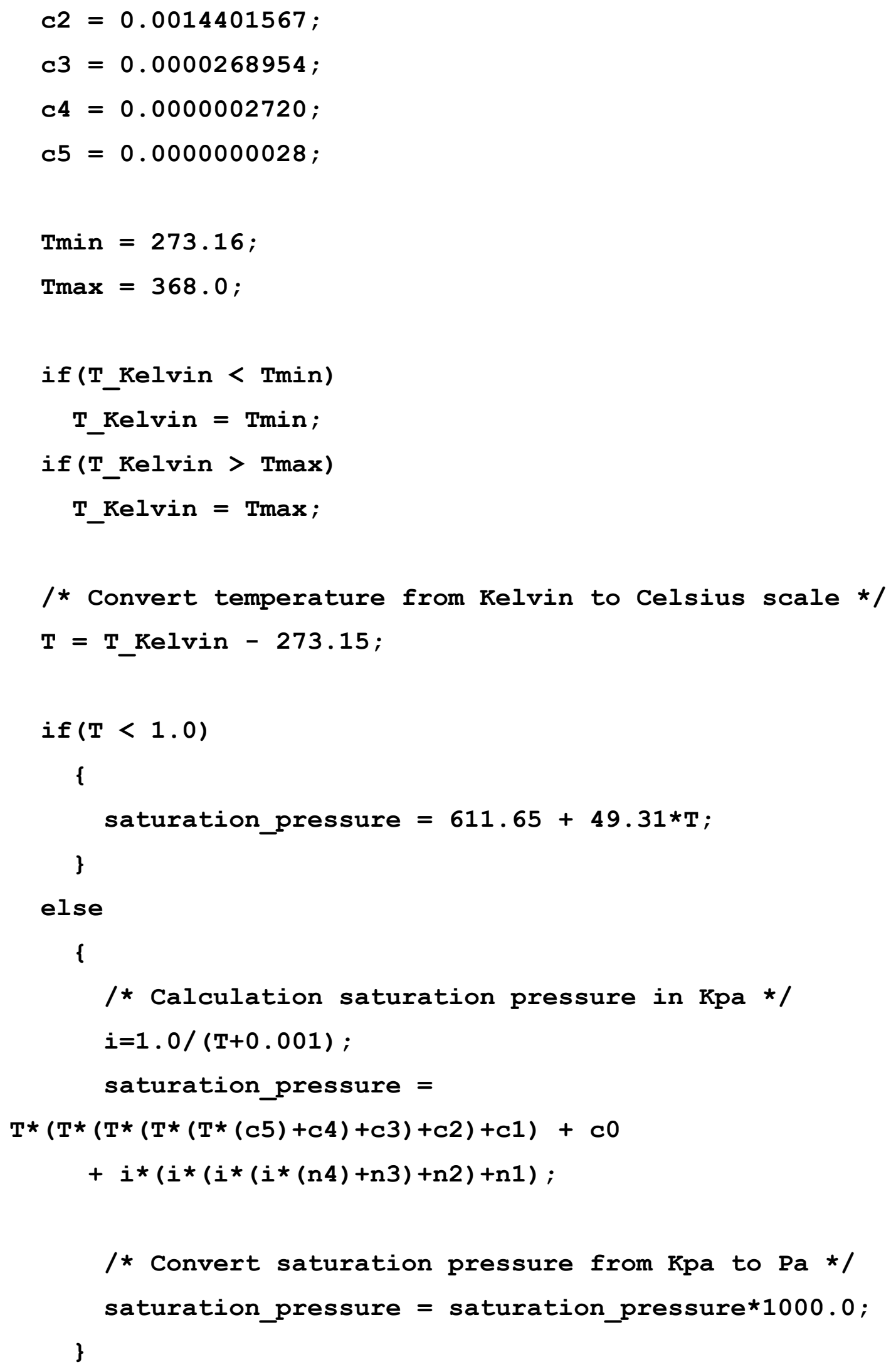


return saturation_pressure;

\}

Appendix II

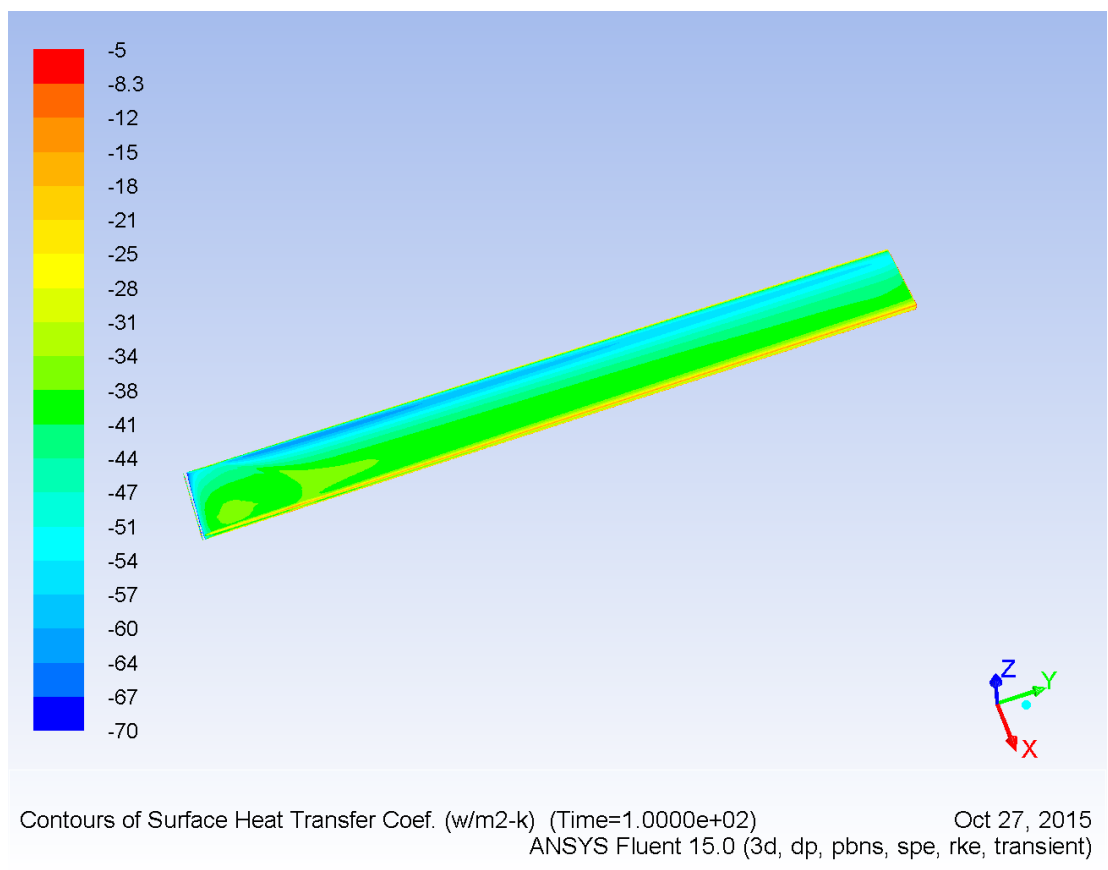

Figure AII.1 - Contours of Surface Heat Transfer Coefficient

At $x=0$, surface HT coefficient is maximum (negative suggests outward direction of heat flow). 


\section{Appendix III}

This letter provides permission to use figure 2.1.

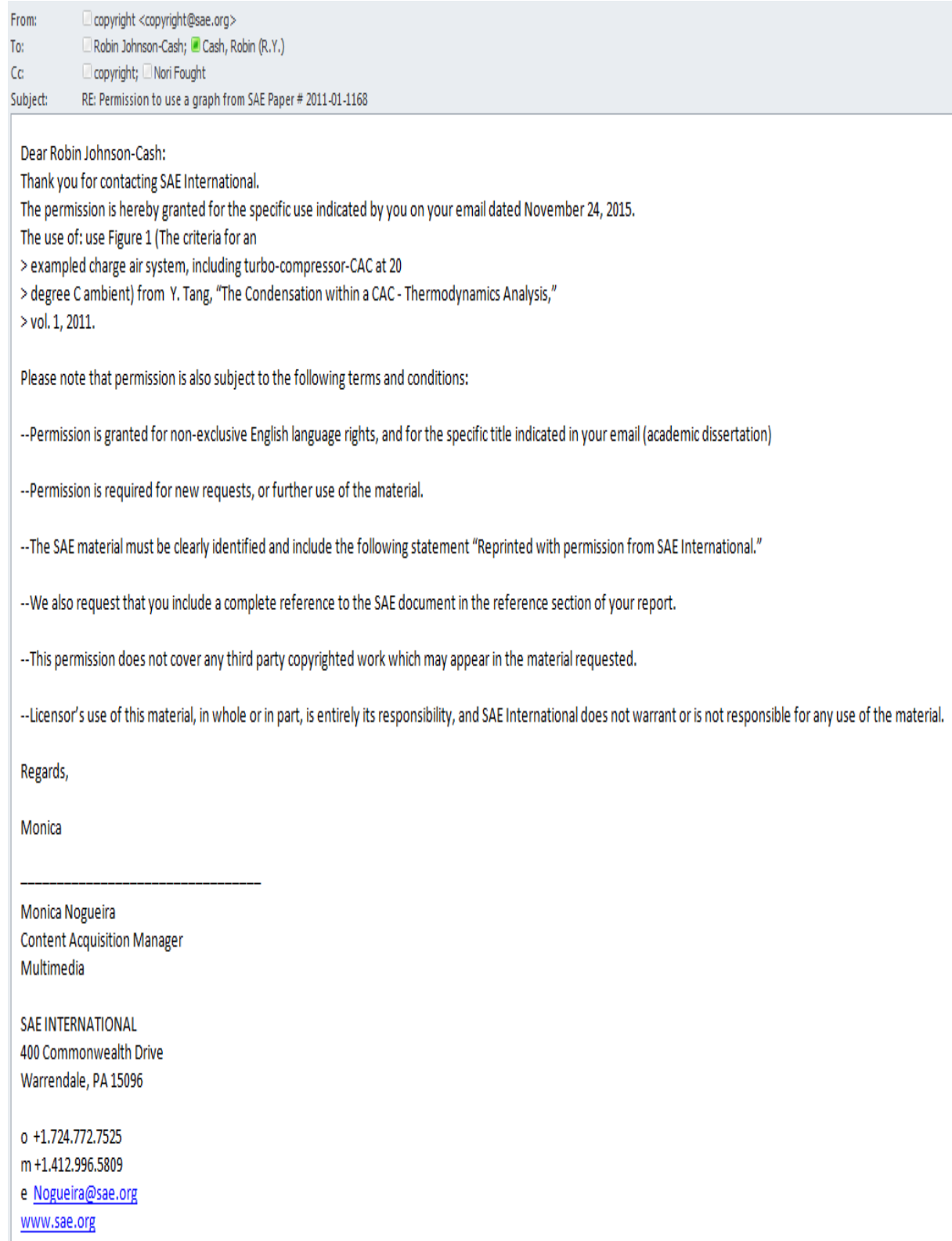




\section{Appendix IV}

This letter provides permission to use figures 1.2,1.3, 1.4, 4.1, 4.2, 4.3, 4.6, 4.7 and 6.1.

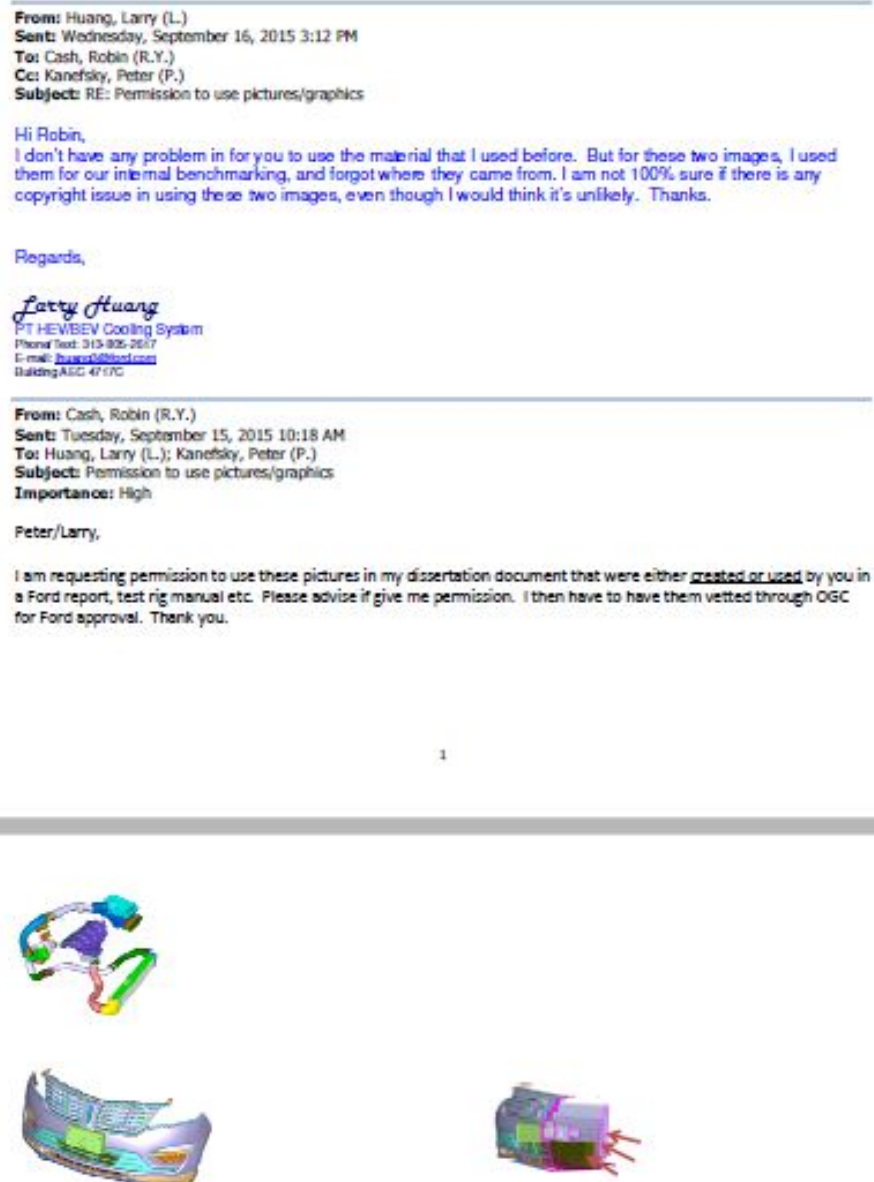




\section{Appendix V}

This letter provides permission to use figures $1.2,1.3,1.4,4.1,4.2,4.3,4.6,4.7$ and 6.1 .

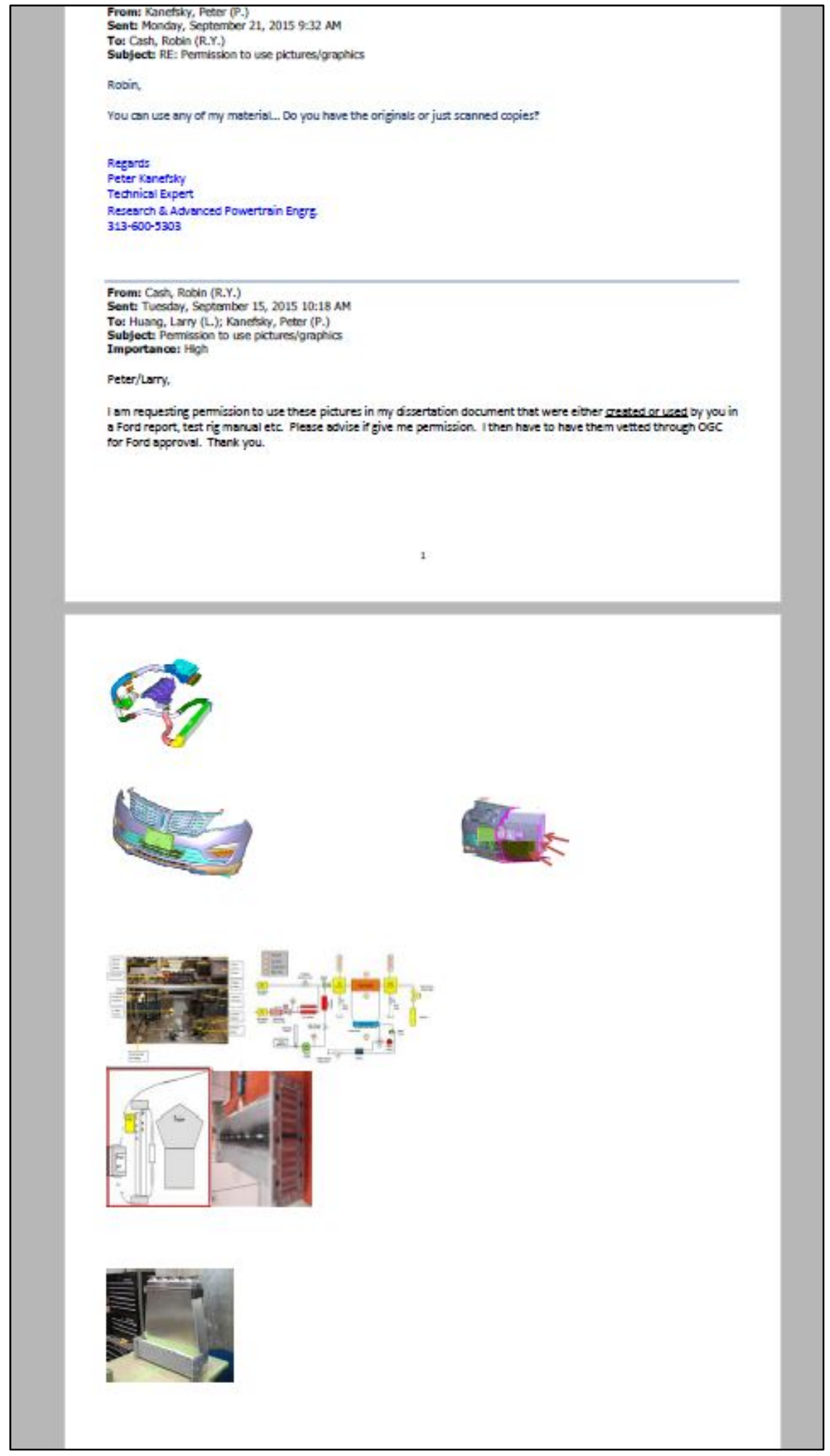




\section{Appendix VI}

This letter provides permission to use figure 1.1. 


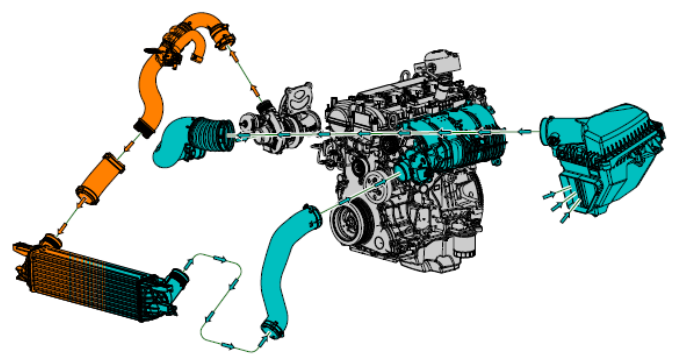

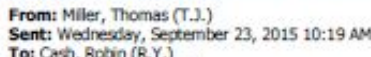

To: Cash, Robin (R.Y.)

Ce: McLenon, Nan (AM.)
Subject: RE: Pertission to use llutration

Robin,

You're welcome to use it. Alan might be able to get you o nicer copy.

Regardz,

Thomas L. Miliet

Ford Motor Co.

$\frac{\text { Tmiller6istord.com }}{313945-9652}$

From: Cosh, Robin (R.Y.)

Sent: Wednesdoy, Septemiber 23, 2015 10:19 AM

To: Mdiencon, Aan (A.M.)

Subject PU: Pomiscion to use llustration

Thanks Tom.

Alsn, please advise if I moy use this cutaway in the manner described below.

From: Miler, Thomas (T.J.)

Sent: Wednesday, September 23, 2015 10:17 AM

To: Cash, Robin (R.Y.)

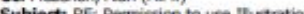

Hi Robin,

Alsn McLenon in our section should be able to help you out with cutswsy drawings:

Regards,

Thomos 1 . Miller

Ford Motor Co.

Imiller6efford.com

313 849-9662

From: Cosh, Robin (R.Y.)

Sent: Wednesdoy, September 23, 2015 9:20 AM

To: Miller, Thomas (T.J.)

to use flustration

Importance: High

Tom

I am working on my PhD dissertstion (With an agreement with Ford snd Michigan Tech) and I need to use some picture

for purposes of talking demongtrating the issue (CAC condensation). Did someone from your team creste the engine

portion of the picture: if so, may I use it in my dissertation? I would cover up the name of the engine 